University of Nebraska - Lincoln

DigitalCommons@University of Nebraska - Lincoln

The Nebraska Educator: A Student-Led Journal Department of Teaching, Learning and Teacher

Education

$10-6-2021$

The Nebraska Educator, Volume 6, Issue 1 (2021)

Follow this and additional works at: https://digitalcommons.unl.edu/nebeducator

Part of the Teacher Education and Professional Development Commons

This Article is brought to you for free and open access by the Department of Teaching, Learning and Teacher Education at DigitalCommons@University of Nebraska - Lincoln. It has been accepted for inclusion in The Nebraska Educator: A Student-Led Journal by an authorized administrator of DigitalCommons@University of Nebraska - Lincoln. 


\title{
The Nebraska Educator
}

\author{
Volume 6, Issue 1 \\ 2021 \\ Published by the College of Education and Human Sciences \\ University of Nebraska-Lincoln \\ Editor-in-Chief \\ Amy Barry \\ Senior Editors \\ Justin Andersson \\ Taylor Hamblin \\ Associate Editors \\ Heidi Jo Bartlett \\ Donger Liu \\ Elizabeth Svoboda \\ Danika Lang \\ Olivia Kennedy \\ Ipsita Mitra \\ ISSN 2375-6853 \\ doi: 10.32873/unl.dc.ne020 \\ The Nebraska Educator \\ nebeducator@unl.edu \\ College of Education and Human Sciences \\ University of Nebraska-Lincoln \\ Lincoln, Nebraska 68588-0355 \\ https://cehs.unl.edu/cehs/student-organizations/nebraska-educator/ \\ http://digitalcommons.unl.edu/nebeducator/

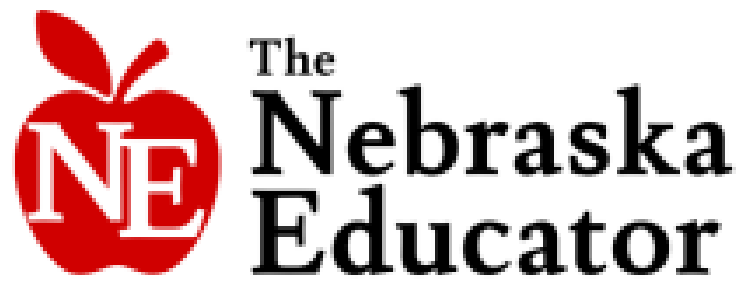

(C) 2021 University of Nebraska-Lincoln 
THE NEBRASKA EDUCATOR, VOLUME 6

\section{Contents}

$5 \quad$ Again Awake: A White Researcher's Iterative Positioning for Entering Black Spaces ${ }^{1}$ Eileen Boswell, Teaching, Learning, and Teacher Education

42 Exploration of Lived Experiences of Science Teachers of English Language Learners: A Transcendental Phenomenological Study

Uma Ganesan, Teaching, Learning, and Teacher Education

80 Confronting the Past, Challenging the Future: Linguistic Hegemony and Neoliberalism in TESOL

Crystal Bock Thiessen, Teaching, Learning, and Teacher Education

92 The Effects of Self-Regulated Strategy Development on Students with

Emotional/Behavioral Disorders: A Literature Review

Danika Lang, Special Education and Communication Disorders

109 Assessments and Accommodations for English Language Learners: A Literature Review Heidi Jo Bartlett, Teaching, Learning, and Teacher Education

128 Triangulating Research in Decolonizing and Race-Based Educational Theories ${ }^{2}$

Beth Dotan, Teaching, Learning, and Teacher Education

153 Multiracial Individuals and Educational Testing ${ }^{3}$

Karen Alexander, Educational Psychology

191 Diversifying the Classroom: Masculinity and Intersectionality in (Teacher) Education: A Review of the Literature ${ }^{4}$

Scott V. Gealy, Teaching, Learning, and Teacher Education

\footnotetext{
1 Winner of the 2021 Award for Exemplary Student Work

2 Runner Up for the 2021 Award for Exemplary Student Work

${ }^{3}$ Runner Up for the 2021 Award for Exemplary Student Work

${ }^{4}$ Runner Up for the 2021 Award for Exemplary Student Work
} 


\section{Letter From The Editor}

The act of writing is inseparable from the act of reflecting. As I reflect on the last year, I have realized the sheer magnitude of collaboration, cohesion, and work that have transpired to make Volume VI possible. The editorial board, my compatriots, who have worked together tirelessly on setting things in motion behind the scenes. Our external reviewers, who have put hours of their time into providing robust feedback for our authors to ensure the quality of our publication. And of course, our authors, whose exceptional academic content is the reason for the existence and continued success of The Nebraska Educator journal.

In addition to continuing to grow in scholarly quality, I am pleased to announce that Volume VI of The Nebraska Educator marks a growth of quantity. This is issue one of three - two additional issues of this volume will be published over the next year, a Nebraska Educator first! Not only is this a special edition because it is the flagship issue of Volume VI, but also because it is comprised of manuscripts that artfully and scholarly center around his year's chosen theme of diversity, equity, and inclusion.

I would like to take a moment to spotlight the very first paper at the top of this issue, "Again Awake: A White Researcher's Iterative Positioning for Entering Black Spaces” by Eileen Boswell. This paper is the winner of the inaugural Nebraska Educator Journal Award for Exemplary Student Work, and its stunning discussion about decentering whiteness is sharp, intimate, and crafted with care. I would like to thank the College of Education and Human Sciences and Dr. Sherri Jones for making this award possible. Also, thank you to faculty members Dr. Stephanie Bondi, Dr. Carrie Clark, Dr. Michael Hebert, Dr. Jenelle Reeves, and Dr. Rachel Schachter for participating in the exemplary student work award review process.

Another new initiative for Volume VI is the inclusion of a new type of manuscript: book reviews. Since our editorial board wanted to use the real estate in this issue to present the original student work that most closely aligned with our diversity, equity, and inclusion theme, you will discover book reviews in Volume VI issues two and three. We look forward to releasing more content and becoming a constant voice of research and source of student ideas over the coming year; a voice to parallel the timeframe of your own studies and educational experiences.

I encourage you to reflect as you read the following selections. I can only hope that that act of reflection will influence and inspire you to write, allowing the circle of academic thought to continue unbroken. May your sense of wonder always manifest into writing and action.

With Love,

Amy Barry

Editor-in-Chief, 2021 
The editors of The Nebraska Educator would like to express our sincere gratitude to the following individuals who lent their time and talents to serve as external reviewers for this volume. The Nebraska Educator would not be possible without your tireless efforts.

Kathie Sweet

Alexa Yunes

Matt Brooks

Consuelo Gallardo

Crystal Uminski

Om Joshi

Grace Kelly

Veronika Cummings

Cassandra Schroeder

Analay Perez

Mike Schiwart

Trenton Haltom

Hamza Rfssa

Amy Sokoll

Leonardo Brandolini Kujman

Chris Labenz

Grant (Roger) Scribner

Erin Hamel

Alessia Barbici-Wagner

Crystal Thiessen

Samantha Smith

Viyon Dansu

Fitsum Adebe

Neha Chaudhary

Junrong $\mathrm{Lu}$

Uma Ganesan

Maria Del Rosario

Jody-Ann Coore

Eileen Boswell

Scott Gealy

Brittany Bearss

Elizabeth Hasseler

Sarah Barker

James E. Baker 


\title{
Again Awake: A White Researcher's Iterative Positioning for Entering Black Spaces
}

\author{
Eileen Boswell \\ Department of Teaching, Learning, and Teacher Education \\ University of Nebraska-Lincoln
}

\begin{abstract}
In this blend of critical annotation and personal reflection, the author narratively frames a selection of works comprising a contextualized reading list for White researchers confronting and positioning their whiteness for the first time. Built around 21 influential texts, this personalized collection of what to read and possible directions for contemplation reflects one educator's awakening to the crucial situating of White research in Black spaces. The texts include academic journal articles, magazine pieces, and book chapters covering topical and methodological considerations, in addition to monographs and popular press books. The narrative and annotation are interwoven, creating a mini literature review that is grounded in the author's iterative forays into research with Black students as her own awareness of race as a power construct (Kendi, 2019) and of her whiteness are continually challenged and developed through classroom, community, and campus experiences. This iterative process is necessary and natural, but requires a zigging and zagging of racial consciousness for which semester-length course models and individual books do not automatically provide adequate guidance. The intended audience for this paper is any graduate student or professional researcher who is taking on not only the steep climb of antiracist activism out in the world, but also the internal, sincere, and cyclical self-education that comes with authentic racial awakening.
\end{abstract}

Keywords: researcher positionality and reflexivity, critical race theory, critical Black

studies, critical whiteness studies, racial capitalism

\section{Author Note}

Thank you to Zac Casey, Amanda Morales, and the staff and reviewers of this journal for supporting this work throughout multiple reformulations. 


\section{THE NEBRASKA EDUCATOR, VOLUME 6}

In every story, every secret told, you are not the first to wake up - to learn your lines before you have the part.

-Carl Newman, Unguided 


\section{THE NEBRASKA EDUCATOR, VOLUME 6}

About fifteen years ago, at a late spring potluck dinner in my apartment complex, a friend of a friend of mine named Helen announced she was taking a class through her church about race. I didn't know Helen well; mostly we were joined through mutual friends and saw each other at their home only occasionally. But Helen had announced in an around-the-room say-onething-about-yourself ice-breaker that she was taking this race class. That was 2006. I've lost track of Helen, and of our mutual friends for that matter, but still it sticks with me that Helen, who is light-skinned, shared this with a group of almost-strangers who stared awkwardly at their paper plates as she made this disclosure.

Fast forward to 2015 when $\mathrm{I}^{5}$ was taking an improv class at the Omaha Community Playhouse. In one exercise, the instructions were to line up single file, then quickly answer a 'deep' question from the improv player in front of you in line, and then immediately turn around and ask a new deep question to the person behind you. I can't remember what the person in front of me asked, but after I answered and swung around, I said to the player behind me, "What are you afraid of?" I asked this enthusiastically, in keeping with the improv instructor's directives. Recalling this incident today, I distinctly remember that the person behind me replied nonchalantly, "White people." At that moment I had what I now know to call a flash of fragility, although I was far from knowing this term at the time.

Touchstone moments such as these, as well as the physical objects that accompany themthe tattered prompt cards at improv, the soggy paper plates at the potluck—stand as signifiers of my racial ignorance and of its slow disassembly. Along the way, these moments are punctuated by the texts I was reading as I gradually came face to face with my own racial socialization, both privately and in interactions for which I had varying levels of preparation (or grace). This paper

\footnotetext{
${ }^{5}$ First person is used throughout, where appropriate, in keeping with the emphasis on reflexivity and positionality.
} 


\section{THE NEBRASKA EDUCATOR, VOLUME 6}

reconfigures a critical annotation I wrote when I was beginning to confront my White socialization as a person, educator, and researcher. The principal aim of this collection is to articulate my understanding of race as a social power construct (Kendi, 2019). I further aim to summarize the key resources that have begun to weave together into my understanding of the modern-day manifestations of the U. S. history of racial capitalism. I begin with a set of annotations that informs my positionality as a White researcher working with Black students as participants in my dissertation project. Then I cover texts concerning the origins of racial categorization in the United States, followed by contemporary critical race studies. I close with seminal works of Black and African studies. All 21 texts annotated herein appear as a list in Appendix A.

\section{Conceptual Framework}

I am an 'educated' person by many metrics. Nevertheless, I was 41 and in a doctoral program before I deeply and directly confronted issues of race-in my upbringing, in my chosen field, and in myself. So it is that when asked to craft a critical annotation on race for a class project, I chose to write about my "White awakening" — a rude one at that — and how it shapes my work as a teacher educator, education researcher, citizen, and human. Doing race work is a constant collision of what I know and what I don't know, personally and professionally. I would also describe my White racial awakening this way. In the sections that follow, I imagine this process as a series of four 90-degree turns, or "reflective pivots" that lead me through a full circle of critical contemplation. As depicted in Figure 1 below, I use four lenses to approach my White awakening; each of these lenses corresponds to one of the four turns or pivots, and each pivot corresponds a cluster of texts on a particular topic that has been indispensable to my continued racial awakening. 
THE NEBRASKA EDUCATOR, VOLUME 6

\section{Figure 1.}

Conceptual Framework: Four Lens/Reflective Pivots

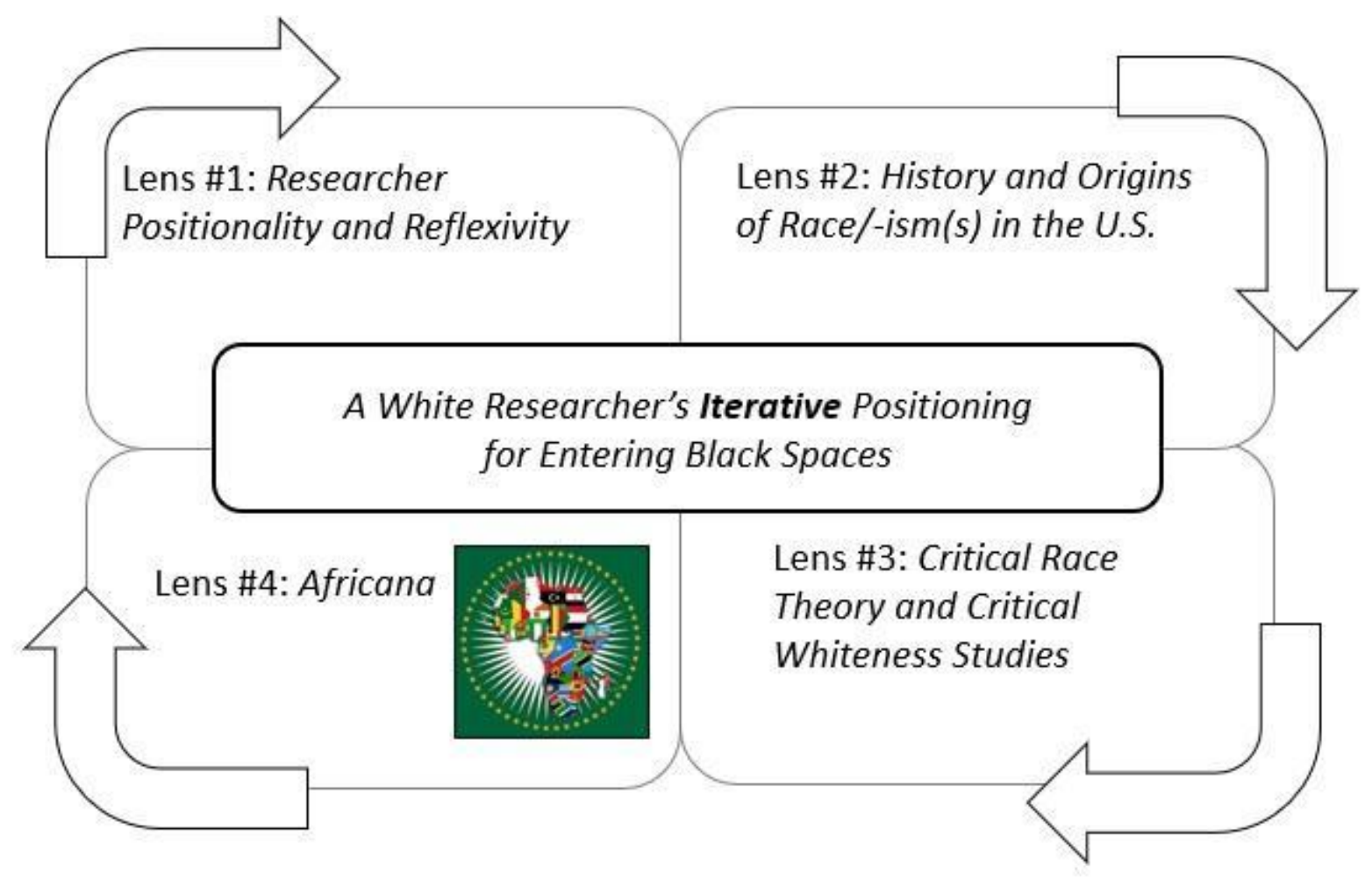

The four lenses or text clusters that guide my continued racial awakening are: (1) qualitative research methodology that specifically attends to researcher positionality and reflexivity; (2) works explaining the origins of race and racism in the United States; (3) critical race theory and other criticalities; and (4) works of Africana, including those that teach about Afro-centric curricula. Following a brief anecdote - as this is an annotation wrapped in a narrative, or perhaps the other way round - the paper describes the most important readings that have helped me understand racial socialization and my own social location, the critical studies that provide me with specific nomenclature and tenets to continue studying race critically, as 
THE NEBRASKA EDUCATOR, VOLUME 6

well as practical applications of these theoretical frameworks to research, pedagogy, and my ongoing personal and professional work.

\section{The Incident of the Fine-Toothed Comb}

I once heard that the secret to writing a compelling screenplay is that viewers must feel they have entered the middle of the story, not the beginning. This is the middle of my story. I'm standing in my classroom trying to build rapport and orient my undergraduate students at the beginning of the semester. The orientation part asks them to complete a syllabus quiz, which in turn asks them to "go through the syllabus with a fine-toothed comb." Without skipping a beat, I add, "I'll supply the comb" with what I think is wry wit as I circulate throughout the room handing out plastic combs I bought at CVS on my way to campus. (I had a self-congratulatory chuckle thinking of this joke while in transit.) After depositing three or four of these cheap plastic objects on each team's table, it suddenly dawns on me that the comb I am brandishing is a White person's comb. This is just one of the spontaneous awakenings I have had to my whiteness and how it figures into my behavior in a room where students of color are also present. In the sections that follow I will revisit the idea that a physical object, such as the comb, can stand as an artifact of racial awakening, and I am grateful for these tactile reminders of my White racial socialization.

"Wisdom often arrives as a warning" said poet Ocean Vuong (Tippett, 2020), and this incident was a warning to me that I need to WAKE UP if I plan to continue educating myself and others. As I position myself, reposition myself, and acknowledge my whiteness in different spaces, I sometimes feel, as Newman (2007) wrote, that I am 'learning my lines before I have the part.' I experience this acute dimension of antiracism as though I were an impostor-a racist masquerading as an antiracist. There have been times in this process when I did not know what 


\section{THE NEBRASKA EDUCATOR, VOLUME 6}

to say, but there have also been times when I had the words but didn't quite feel that I 'had the part' of speaking as an antiracist. These ideas of knowing and not knowing what to say, and having and not having a role to play are iteratively part of positioning myself in all my teaching and research, which, of course, entails live human interactions with other people-encounters for which we must genuinely prepare and for which we are never totally prepared either.

The textual experiences that hew this process are as important as the non-text experiences, such as the fine-toothed comb incident, because a racial reckoning can never be only an academic exercise. My commitment to this dual process — awakening through quotidian moments alongside the heavy lifting of academic study—is informed by work on intertextuality. Readers can think of the works in this annotation as being, in Sarroub's (2005) words, "forms of discourse that were manifested in different contexts and that bridge, subvert, and recreate" (p. 60). Sarroub draws on Gee's $(2004,2015)$ work in discourse analysis, as well as Erving Goffman's (1959) work, and stresses how these theorists teach us that "the presentation of self and identity [are] relational activities whose textual performance is mediated by the space that participants occupy" (Sarroub, 2005, p. 60). Therefore, as I annotate below the works that have facilitated my iterative awakenings, I challenge the reader to imagine an everyday object (perhaps a piece of cotton clothing, which calls to mind the enslavement of Africans on U.S. cotton plantations) or an encounter that brings each text to life in the course of our collective antiracist work. This can be a disturbing activity—and necessarily so — as it disrupts complacency and unearned comfort with whiteness and how it has been constructed through the othering of communities of color. As Lensmire (2017) has written, “as white people, we used people of color to figure out who we were. We used, and continue to use, people of color to 
THE NEBRASKA EDUCATOR, VOLUME 6

create ourselves as white Americans" (p. 7). In the following section I explore how this has operated in my own presentation of self and identity.

\section{Pivot 1: Know Thyself}

\section{Positioning Myself in this Paper and Beyond}

I identify as privileged, Euro-American and in middle age, reared and socialized as "White" in a Catholic, middle-class household in the midwestern region of the United States. Anti-Latinx racism, subtle and overt, was common in my childhood community. My exposure to, and socialization around, Black individuals was different and more complex. I had regular contact with African Americans but not in contexts where we would ever be friends or put into meaningful dialogue with each other. Moreover, Black Americans who had moved to the United States from African countries or from Haiti (I knew both in my small town) were characterized differently from those born in this country: I began to understand that people labeled as 'immigrants' or 'refugees' were treated differently from those visiting short-term, with prestige placed on all things 'international.' I had met a number of people born in Africa before I traveled there myself ${ }^{6}$ and chose to engage in research projects alongside African-born students and families who have immigrated to the United States.

I was socialized to help, but not to understand or learn from, individuals and groups portrayed as other in relation to my birth family, congregation, and the predominantly White community that contained and constrained all of my social, academic, and religious education. As I am now in direct engagement with students of color, it is paramount that I continually reposition myself, using the lenses and reflective pivots described herein, in order to mitigate bias and build trustworthiness with my participants. But for all of us, standing in a classroom or

\footnotetext{
${ }^{6}$ I lived in Senegal and Guinea, West Africa, from 1998 to 2001 as a teaching volunteer for a U.S.-government sponsored service program.
} 
THE NEBRASKA EDUCATOR, VOLUME 6

research space with any students of color requires an acknowledgment of how we are all raced, classed, gendered, as well as how we are alternately othered or cast as main players in the dominant narrative. Some of the methodological literature guiding qualitative researchers aids in this process.

\section{Positionality and Reflexivity in Qualitative Methodology}

Reflexivity is the process of "researching the self, researching the self in relation to others, engaged reflection and representation, and shifting from the self to system" (Milner, 2007, p. 388). It involves seeking "heightened awareness of the self in the process of knowledge creation, a clarification of how one's beliefs have been socially constructed" (Grbich, 2013, p. 113). Positionality, or "positioning" oneself, is about power; it requires "thinking about the ways in which our social positions influence not only our interactions in the field but also what we see and hear" (Reyes, 2017, p. 212) as well as "the realization that who we are as people interplays with how we conduct research" (Ardoin \& martinez, 2019, p. 6). Positionality extends to the researcher-participant dynamic as well—one that is all too often "characterized by the 'powerful' researcher and the 'meek' respondent" (Hoong Sin, 2007, p. 478). Qualitative research reports often include an author positionality statement; sample positionality statements appear above (mine) and are linked in footnote 2 of Appendix B.

Although they may be lacking from quantitative research, positionality and reflexivity form a "qualitative imperative" (Boswell, 2021) in naturalistic inquiry. Often when this imperative is undertaken in qualitative research, the author(s) of a study might consider the "usual suspects" of race, class, and gender-all of which could be crucial elements of positionality. But depending on the focus of the study, additional elements to consider could include the researcher's age, ability, immigration or citizenship status, military/veteran status, 


\section{THE NEBRASKA EDUCATOR, VOLUME 6}

caste, religion, educations, experience, and housing/mobility or incarceration status. Education researchers new to reflexivity and positionality can glean helpful details about how to approach these topics by studying Roni Berger's work. Berger (2015) is a grief researcher who deeply considers the implications of one's insider/outsider status in the field, writing that, "The degree of researcher's personal familiarity with the experience of participants potentially impacts all phases of the research process, including recruitment of participants, collecting data via interviews and/or observations, analyzing and making meaning of the data, and drawing conclusions" (Berger, 2015, p. 229, sic). Importantly, one's position in relation to the research can be additive and not just subtractive, in that it can confer additional dimensions of insight and empathy.

Tying these frameworks back to my own research, I acknowledge that my research with Black students will not be free of bias, but its biases can be managed by taking all of the above into account. My own beliefs and biases motivate, shape, and limit my research. Given this handicap, I have chosen Richard Milner's (2007) work on race, culture, and positionality to lead myself through considering how my research approach can be meaningfully and sensitively improved by committing to a rigorous de-centering of my power as a White person. Being mindful of this downshift aids in preventing the known dangers of patriarchal approaches to education research including framing a study on students of color with race-blind, color-blind, or culture-blind assumptions (Milner, 2007, p. 392). I am, inescapably, a White researcher inserting myself in Black communities for research purposes, and increased reflection will not alter this reality. I will perpetually need to subordinate myself in relation to my research participants and thus, keeping Milner's prescriptions and proscriptions top of mind. 
THE NEBRASKA EDUCATOR, VOLUME 6

\section{Reflecting On, and Positioning, Our Institutions}

Personal reflexivity can be augmented by considering institutional positionality, or the ways in which one's institutional histories and affiliations direct one's research. Leigh Patel's (2016) Decolonizing Educational Research ought to be required reading for graduate students earning advanced degrees in education at any institution voicing a commitment to antiracism, social justice, or dismantling White supremacy as embodied in institutions of higher learning. To begin, Patel establishes what is meant by settler colonial "logics" and how they are enacted in higher education, and especially in education research. Deficit perspectives in education, Patel argues, are enacted by "a seemingly endless stream of interventions for 'at-risk' populations" (p. 26). In this way, "[E]ducational research is complicit in a system that normalizes the achievement and wealth of some while pathologizing and marginalizing others" (p. 21). In the second chapter, Patel builds from these premises to critique "the academy's closed circuitry of publication" (p. 44), pointing out ideological flaws with formulaic approaches to dissertation research that confer all-knowing status to the researcher at the expense of authenticity with participants. "The role of the researcher as detector and implicit fixer or resolver of pathologies" they write, "also subtly imbues the researcher with an almost omniscient-like ability to know" (p. 41). They call on education researchers to be more intentional and explicit about how scholarly work is situated in and affected by material conditions and ideologies (p. 66) as well as to recognize how specialization silos give us permission to ignore, and thus perpetuate, settler colonial logics in the academy.

Patel asserts that "research is relational" (p. 48) and demonstrates how education research reifies colonial and imperial systems of power and dominance, underscoring that, "Logics of coloniality are problematically enlivened through educational research" and that "[e]ducational 
THE NEBRASKA EDUCATOR, VOLUME 6

research is a text, and as such, is never neutral but instead imbricated with potential and unruliness to motivate, disincentivize, and render invisible various realities" (Patel, 2015, pp. 12-13). Part of viewing the university as an institution as susceptible to - and guilty ofinstitutional racism as any government agency or corporation is understanding how the different levels of racism in our society interlock. To this point, Scheurich and Young (1997) delineate distinct levels of racism from individual to civilizational. Their construct of epistemological racism, for example, exists at the civilizational level (p. 4). Epistemological racism is a structured and entrenched form of racism whereby some ways of knowing are legitimated at the expense of others. This leads to the domination of academic publishing by work exhibiting predominantly White, masculinist, Eurocentric ideologies.

Monopolies of thought, as described in theories of epistemological racism, are further delineated by Kubota (2020), who alerts us that even an author's name can dissuade publishers from choosing to advance a manuscript if the name is indicative of a particular race, gender, or other identity. Kubota emphasizes that, "the perceived legitimacy of knowledge is linked to the location of knowledge production" (p. 721). Their call to action includes denouncing the system that has resulted in near worship of European and North American (the "Global North") knowledge systems, which reproduce themselves in academic publishing without a sustained disruption of the systems that legitimate and publish only certain knowledges. This disruption relies upon courageous scholars of color and their White colleagues to bring attention to oppressive research and publishing practices akin to what Kubota highlights. Calling out institutional racism ultimately leads us to ask how we got here. 
THE NEBRASKA EDUCATOR, VOLUME 6

\section{Pivot 2: Origins of Racial Categorization}

In the opening to A Pedagogy of Anticapitalist Antiracism: Whiteness, Neoliberalism, and Resistance in Education, Zac Casey (2016) writes, "I am not here, in the United States as a white man, by chance or accident. People killed other people so that I could live here" (p. 7). When I first read this, it called to mind another physical object that serves as a touchstone of my racial awakening - a felt Halloween costume (hand-sewn by my mother) I had worn in my youth, one that remade my appearance into that of a Native woman. We would have unthinkingly called this an 'Indian' costume with zero awareness of what this act of costuming meant or harkened to. I remember the fringe at the bottom and the feathers on top: a sensory experience devoid of any understanding of Native peoples or why it was considered socially acceptable for me to walk the streets dressed as one of them on this one day of the year. Native dress was a contrastive 'costume' with my regular clothes and school uniform because I was 'White'...even if this truth was never uttered aloud.

\section{How Did I Become White?}

The Halloween costume as a bodily experience, coupled with text experiences as I began to read poetry, are obvolute in my racial socialization. I, along with other U.S.-born people, first encountered Ralph Waldo Emerson as a poet and essayist, and an oft-quoted wordsmith who delivered inspirational adages. Indeed, I probably had more than a few bookmarks, calendars and coffee cups with Emerson quotes on them. Over the past two years, though, Nell Irvin Painter's (2010) The History of White People has had me questioning what it meant for me to use a bookmark or coffee cup bearing a celebrated quote from an early U.S. citizen who is roundly revered in many literary and political circles, but who has now come to be seen as a 'founding father' of White supremacist notions. I selected Painter's book for this collection because 


\section{THE NEBRASKA EDUCATOR, VOLUME 6}

learning more about who has been written into and out of history scrambles my ideas of who is an 'American hero.' Thomas Jefferson, for example, Emerson, and others, come under scrutiny in Painter's book for their contributions to White racial ideals in the early United States. Painter devotes an entire chapter to Emerson and his work on what later came to be known as English traits.

Painter's book is particularly important to me in reinterpreting my upbringing as the grandchild of Hungarian, Polish, and Irish immigrants to the United States. Traces of Painter's argument are evidenced in stereotypes I overheard while growing up. One whole chapter of Painter's book details comparisons made between Black Africans/African Americans/West Indians and the Irish, who were collectively essentialized in cartoons and pervasive jokes as backward, dirty, impure, and incapable of governing themselves (pp. 132-150). Studying this aspect of history and the story of How the Irish Became White, I was horrified to learn of efforts to dissuade Irish immigrants from joining the Abolitionist movement in the first half of the nineteenth century (Ignatiev, 2009, pp. 20-26).

The primary role of Painter's text in my racial awakening is that it details the historical power dynamics whereby arbitrary genetic differences were repackaged by the ruling class as desirable qualities, despite the fact that they are largely cosmetic differences outside human control. Painter's book shows convincingly that differences can be manipulated to dehumanize,

to divide, and to conquer. The more arbitrary and involuntary the difference, the more a powerful ruling majority can exploit it for their personal gain. This kernel of an idea-that difference started out as arbitrary but was refashioned into something thought to be permanent and meaningful—sits at the base of my understanding of race and racialization. 
THE NEBRASKA EDUCATOR, VOLUME 6

\section{American Slavery and Racial Capitalism ${ }^{7}$}

There is an anecdote that appears in Isabel Wilkerson's (2020) Caste in which someone approaches Wilkerson after a lecture and says, "There are no Black people in Africa” (p. 52). This sentence is used to upend the way many people came to think about race. Africans, as it were, became 'Black' once enslaved, just as the Irish became White once enlisted in bigotry against Black Americans. Coates (2015) has expressed this sentiment by saying that, "race is the child of racism, not the father" (p. 7). It was, in other words, colonial power structures that imbued color differences with social significance and not something inherent in the differences themselves. Processing this reversal of what I had long (mis)understood about my social studies education in high school, I progressed from Nell Painter's work to scholarship on racial capitalism that revealed to me the economic motivations and pervasive greed that led to the system of racial capitalism that persists in the United States today.

Racial capitalism is the hierarchical categorization of human beings for economic purposes - an historical fact that was instrumental in the creation of the early United States of America, prior to independence. The specific histories of racial categorization and racial socialization must inform the analysis of any legacic colonization experiences. Indeed, Ribeiro (2011) emphasizes that a focus on capitalism, the driver of slavery and thence anti-Black racism in this country, must be "the primordial focus of analysis" (p. 290) in any approach to studying post-, neo-, or other colonialisms. Thus, the conceptual underpinnings of racial capitalism begin with the theory that capitalist-centered greed and self-interest led to slavery in the early United States as a means of using exploited African labor to work on land seized through the genocide and exploitation of Indigenous American peoples of many tribal affiliations and heritages.

\footnotetext{
${ }^{7}$ Additional information about racial capitalism appears in the Critical Black Studies section.
} 


\section{THE NEBRASKA EDUCATOR, VOLUME 6}

The provenance of the term racial capitalism is a White, Marxist publication from an economic group in London (Legassick \& Hemson, 1976) during anti-apartheid movements that mobilized activists in the United Kingdom, the United States, and across the globe in support of South African liberation leaders. While the term and its use were contested within and across various anti-apartheid movements, the circulation of the term reached a critical mass and in 1979 Neville Alexander — a leader of the black consciousness movement in South Africa—introduced the term into the rhetoric of South African liberation struggles. Four years later, Alexander had fully adopted a theory of racial capitalism as espoused in his 1983 national forum committee speech on the fitness of a theory of racial capitalism to oppose 'non-racialism' (i.e., colorblind) ideologies. Johnson $(2009,2013,2018)$ and Baptist (2016) extend this history to show that, although slavery pre-dated the colonization of what is now the United States, the use of enslaved labor to facilitate economic advance on a massive scale is a uniquely American invention.

Exposing the horrors of history points to the ways in which economics and racial dynamics are inextricably entwined in the United States. Additional research has focused on the role of racial capitalism and slavery in building some of today's most prestigious institutions of higher learning (Wilder, 2014). To begin to unravel these dynamics, Golash-Boza (2016) explains the historical construction of race and its ties to multiple forms of subjugation, stating that, "Europeans and their descendants have used the idea of race to rationalize exploitation, slavery, colonialism, and genocide" (p. 4). The colonizers' ideologies of social superiority created a race-based system of hierarchy that relegated African people to the lowest rungs of society. 
THE NEBRASKA EDUCATOR, VOLUME 6

\section{What is Race?}

Golash-Boza's (2016) Race \& Racisms: A Critical Approach provides an unambiguous historical record of how race has been socially constructed and used as a justification for sociopolitical systems including apartheid, slavery, and other forms of torture. Its introductory chapter sits in sharp relief to the 1980s schooling I encountered with regard to Christopher Columbus and the 'discovery' of America. Connecting historical conceptions of race to present day conditions in the United States, Golash-Boza's work, as well as Omi and Winant's (2014) Racial Formations in the United States refute biological or scientific bases of race and argue instead that race is a political invention to preserve the self-interest of those in power. After establishing the facts in this regard, and contextualizing them against the United States' troubled history of race-based policies, Omi and Winant forge a new definition of race: "an unstable and 'decentered' complex of social meanings constantly being transformed by political struggle” (p. 7). It is with this definition that I pivot to scholarly pieces that structure my developing knowledge of race-based theories and epistemologies.

\section{Pivot 3: Critical Race Studies}

\section{Critical Race Theory}

I had difficulty at first understanding the widespread effects of White dominance in education and industry. For me, keeping in mind the image of a "flesh-colored" Crayon or BandAid was one way to examine how commonplace the idea of whiteness as default or whiteness as 'normal' pervaded my adolescence. These objects are the visual framing that I use to guide my study of systemic racism and White supremacy, as outlined below. 
THE NEBRASKA EDUCATOR, VOLUME 6

\section{Key Tenets}

Before celebrating key texts in critical race theory (CRT), I first briefly explain seven key tenets of CRT that guide my work:

1. Racism is ordinary (Delgado \& Stefancic, 2017, p.8); one need not create any conditions to find it because it is embedded into U.S. social dynamics. In other words, "The system isn't broken; it was built this way."

2. Whiteness is a form of 'property' or capital that confers upon its members certain unearned advantages.

3. So-called 'colorblindness' or race-neutral policies and practices do not liberate communities of color and in fact will inevitably sustain advantages for the dominant race (i.e., White individuals) who already enjoy these unearned advantages.

4. Whiteness and White people must be de-centered in discussions of race because claiming a White person's views on the matter are' objective', 'neutral', or 'normative' erases the centrality of other people's authoritative knowledge about their own experiences of oppression. The knowledge and experiences of Black, Indigenous, and people of color must be centered in the study of racial dynamics - a principle sometimes called the centrality of experiential knowledge (Pérez Huber, 2009).

5. Intersectionality (Crenshaw, 1990, 1997, 2017; Hill Collins \& Bilge, 2020) is the notion that overlapping identities create unique circumstances of oppression that cannot be fully understood (or remedied in the law) by an additive view of multiple identities, such as being a person of color living with a disability.

6. Interest convergence (Bell Jr, 1980), whereby the interests of those in power occasionally converge with the advancement of communities of color, is commonplace. White people 
THE NEBRASKA EDUCATOR, VOLUME 6

confer such advancements in due time that our own interests converge. There is also a companion principle of interest divergence.

7. Material aims refers to the fact that communities of color and Indigenous populations have endured material losses perpetrated in the pursuit of establishing and maintaining racial hierarchies. There is thus a concurrent principle of pursuing material changes and palpable gains for those who have been oppressed.

\section{Key Resources}

While there are far too many resources on writ large to include herein, a few stand out as forming the foundation to which I return often in order to re-explain CRT to myself and to find simplified ways to explain it to others. Published more than twenty years apart, Ladson-Billings and Tate's (1995) call for a critical race theory of education and Delgado and Stefancic's (2017) more recent primer on the same topic give any student a concise set of talking points and rationale for CRT and its application to the field of education. Noteworthy is Ladson-Billings and Tate's argument that racial inequities in education are not surprising and in fact they are a "logical and predictable result" (p. 47) of not attending to the racialized dimensions of our society and our public institutions. The authors recommend that one must not assume a bland, inconsequential "unity of difference" but rather that race must be the central concern of renewed curriculum efforts (Ladson-Billings \& Tate, 1995, p. 62). This brings us to critical pedagogy and the first of several scholars whose work highlights the subjugation embedded in normative (i.e., White, Euro-American, masculinist) curricula.

\section{Critical Pedagogy}

Critical pedagogy interrogates not only how we teach but what concepts we take for granted. In their chapter on Dissonance, Taylor and Reynolds (2019) recount their experiences as 


\section{THE NEBRASKA EDUCATOR, VOLUME 6}

two participants on a service-learning trip focused on school improvement in Ecuador. Their thesis is that such trips, designed as they are to enlighten college students to the plight of those "less fortunate," are themselves created around White, masculinist, Eurocentric epistemologies. Using a Black feminist framework, they go on to point out the limitations of the "foundational conceptualizations of dissonance" and then propose their "critical conceptualizations of dissonance" (Taylor \& Reynolds, 2019, pp. 98-100). The differences between the two models begin with the premise that women and people of color have experienced doubt more often than not as the target of White, masculinist bias, skepticism, and speculation; therefore, relying on a 1950s definition of dissonance steeped in an individual's otherwise blissfully ignorant view of the world is misapplied if used in educational contexts where learners of color are present.

Even as a pedagogically useful concept, cognitive dissonance and its associated educational theories the authors argue, "stemmed from positions of unexamined privilege and thus are often inaccurate given that they do not account for students' lived experiences amid societal systems of privilege and oppression" (Taylor \& Reynolds, 2019, p. 94). Their redefinition of dissonance upends the foundational conceptualizations by incorporating lies into the bedrock experience of students of color - thereby clarifying that the racial discrimination experienced by minority members of a service-learning group can be so oppressive as to impede learning. Thus, they help us see that not all dissonance is productive and that if oppressive dissonance cannot be resolved it then has to be met with support and solidarity (Taylor \& Reynolds, 2019, p. 100) if learning is to occur.

Taylor and Reynolds's redefinition is an unequivocal challenge to a very popular concept. In articulating this challenge, they confront the status quo and broaden our fundamental concepts to better represent students and citizens through their deft application of pluralist and 
THE NEBRASKA EDUCATOR, VOLUME 6

critical frameworks. Another disruption of the status quo comes from Picower (2009) who grounds a theory of the "tools of Whiteness" pre-service teachers exhibit when confronted with racial inequalities in education. Emotional, ideological, and performative ways of deflecting and rationalizing White privilege, as well as reverse (i.e., White) victimization comprise these tools. Disabling these tools cannot exclusively be handled by centering concepts of privilege (Lensmire et al., 2013; Leonardo, 2004); it requires large-scale efforts to diversify teachers and curriculum, collaborate with awakened and awakening White educators, as well as meaningfully involving community stakeholders outside of the academy.

Within the academy there is also work to be done. Jupp, Berry, Morales, and Mason (2018) caution teacher educators to not only develop critical and decolonizing education sciences but to utilize them to respond to the ubiquitous demands of (White) institutional practices in teacher education through clear historical contextualization of the tools of critical pedagogy. In so doing, they argue, critical pedagogy can "spurn previous education science's Eurocentric, whitened, and universal aspirations" (Jupp, Berry, Morales, \& Mason, 2018, p. 306).

\section{Critical Whiteness Studies}

Jupp (2020) traces the history of critical White studies (CWS), a term used interchangeably with critical whiteness studies (p. 1). CWS is crucial in teacher education and education research because it rightly labels whiteness as hegemonic normativity; condemns uncritical notions of White identity and nation building; and incorporates CRT's principles of whiteness as property, unwarranted White privilege, and racism made manifest through falsely neutral notions of colorblindness or race-evasion (Jupp, 2020 p. 4).

In my current research I use a CWS lens to craft appropriate positioning and humility for my dissertation examining the racialized campus experiences of Black, African students at 
THE NEBRASKA EDUCATOR, VOLUME 6

predominantly White institutions. Given that I taught in some of the same postcolonial African countries whence come these students (and consequently believed, erroneously, that I understood something about race), I draw on CWS to humble myself to the legacy of White domination of Black communities. Toward this aim, Ribeiro (2011) suggests that "what is needed is a postimperial imagination, critique, and programme" (p. 295). I therefore focus on inverting the 'America-first' motives that drove me_as a U.S.-government sponsored volunteer boasting diplomatic protections and having sworn an oath to the U.S. Constitution - to West Africa in order to teach people there particular competencies their government and my own had determined to be important life skills. Twenty years later, I am now painfully and painstakingly reassessing the impact of my presence as a 'teacher' in the village that hosted me, alongside the propagandist narrative that I was serving people who needed something for me. Whereas I am loath to claim that my dissertation work constitutes a reversal of those actions, the project is an inversion of the colonizing drive that sent me to West Africa. It is thusly that I pivot at this juncture from critical White studies to critical Black studies, and to adjacent works of Africana.

\section{Pivot 4: Africana and Critical Black Studies}

The reflective pivot to Africana is necessary in order for me to contemplate what it meant for me to be White in West Africa and what it now means for me to be White in Nebraska, and how these racialized experiences interrelate. Doing so requires that I supplement my previous travel and service experiences with academic and historic texts pertaining to the transatlantic slave trade and the resulting African diaspora in North America.

\section{Back to Africa}

To tie the historical status of African Americans to the continent of Africa and the panAfrican movements for Black liberation, one can look to Marcus Garvey. Garvey led the 
THE NEBRASKA EDUCATOR, VOLUME 6

Universal Negro Improvement Association (UNIA), sometimes referred to as the "Back to Africa" movement, owing to its call for an "autonomous, black-led nation" on the African continent (Garvey, 1920, p. 1). The UNIA creed enumerating the rights of African American veterans of World War I and their disillusioned Black compatriots was entitled the Declaration of the Rights of the Negro Peoples of the World and has special significance for me as I seek to integrate my knowledge of and experiences in Africa (and with Africans) with my experience as a White U.S. American among African Americans.

Garvey astutely echoes the Declaration of Independence in noting that "all men are created equal" ( $\S$ II.1) despite the discriminatory treatment of war-weary returning Black soldiers at the time. Labor, taxation, terminology, and torture are among the issues addressed in Garvey's Declaration. This is an essential piece for students to contemplate historical systems of power, and race-based rights for Black individuals, and then to question this and grieve the realization that some American citizens have race-based rights conferred through our White skin as a birthright. What Garvey is arguing for is what many of us inherited and will unwittingly pass on.

\section{Critical Black Studies}

A central work in critical Black studies — one that belongs here as well as in the Critical Race Studies section above, is Cedric Robinson's (2020) Black Marxism: The Making of the

\section{Black Radical Tradition}

While the South African liberation movement was popularizing the phrase "racial capitalism" in the 1970s and '80s, Robinson was a student at Berkeley, following the antiapartheid movement from California while studying Indigenous communities alongside anthropologist Laura Nader (Robinson, 2020, p. xxii). This book argues for a theory of racial capitalism counterposed to what Robinson described as "Eurocentric" Marxism. Simply put, 


\section{THE NEBRASKA EDUCATOR, VOLUME 6}

traditional or "White" Marxism imagines the universal worker as a White male, whereas Black Marxism imagines the universal worker as a Black female, whose body and labor were literally used to reproduce capital in the form of offspring born into enslavement (R. D. G. Kelley, 2017). Concurrent with a variety of anti-apartheid movements - some of which espoused a weak form of multiculturalism that did not center racial oppression-Robinson rejected anti-capitalist efforts that could be "economically radical but racially conservative" (Gordon, 2010). This precise limitation is one that Leonardo (2004) refers to as a failure in Marx's original conceptions of class.

To connect critical Black studies to the earlier section on racial capitalism, it is important to note that Neville Alexander in South Africa and Cedric Robinson in the United States did not use 'racial capitalism' in the same ways. Neville Alexander felt that their use of the term was specific to South Africa and apartheid, while Robinson's brought the conditions of all racialized workers under one umbrella. Both signal that non-racial capitalism is too narrowly centered on economic considerations of capital rather than liberation and reunification for Black peoples who sought repatriation rather than upward (class) mobility (Robinson, 2020).

Applying Black Marxism’s notions of liberation and reunification, and in alignment with the family separation tragedies at the center of Garvey's 'Back to Africa' ethos, the case for reparations for slavery — and the attendant segregation and racism that endure — is self-evident. Coates (2014) provides exhaustive historical detail recounting the "second slavery" that ensued in the South after slaves were ostensibly freed (Coates, 2014, p. 22). These conditions have included housing/zoning discrimination (Rothstein, 2017), employment discrimination, police brutality, and other injustices that leave us divided by the unrepaired racial schism on which our country was literally and figuratively built: slavery. Cotton fragments in our midst-woven 


\section{THE NEBRASKA EDUCATOR, VOLUME 6}

throughout our clothes, shoes, towels, and furniture — all serve to remind us on a daily basis of what enslaved Africans built on stolen Indigenous land, and how the U.S. economy got its start.

To synthesize the forgoing sections, what connects Garvey to Coates to CRT and education is the institution of slavery and its still unattended-to legacy. For this reason, students doing deep, internal race work must endeavor to bridge historical accounts such as GolashBoza's and present-day policy pieces such as Coates's by way of critical Black thinkers such as Garvey and Robinson. Absent these links, some could risk believing that Black Lives Matter and other contemporary movements have arisen spontaneously, from the most recent heinous events, instead of understanding that slavery is the untreated wound at the root of it all. Along the way, and with some basic themes considered, a student might then be ready to contend with more challenging works such as those penned by Malcolm X and W.E.B. Du Bois, as detailed below.

\section{Africans in America}

After learning some basics about Black studies, I was prepared to take on unsettling and innocence-shattering statements such as that the White man is "a piratical opportunist" (X \& Haley, 1964, p. 181) or that "Election expenses today include not only direct bribery but indirect influences" (Du Bois, 1972, p. 3). The Autobiography of Malcolm X and W.E.B. Du Bois's speech on Socialism and the American Negro force us to consider the economic and legislative policies that continue to shackle Black Americans. X describes his existence as the 'mascot' to White people as well as to what it truly means for a man to be self-made, as he was during his prison transformation. Alongside Du Bois's geopolitically inspired lamentation of the American Negro's economic plight, X's treatise on how history has been "whitened” (X \& Haley, 1964, p. 177) extends one's understanding of racism from the individual level to the societal level, as in the work of Scheurich and Young (1997) cited above. "What then is the next step?" asked Du 
THE NEBRASKA EDUCATOR, VOLUME 6

Bois (1972), "It is for American Negroes in increasing numbers and more and more widely to insist upon the legal rights which are already theirs and then to add to that increasingly socialistic form of government an insistence upon the welfare state which denies the further carrying out of industry for the profit of those corporations which monopolize wealth and power?" (p. 4).

Du Bois's piece is as important to critical Black studies for beginners as it is to questioning modern-day fears surrounding socialism, as is Kelley's (1999) overview of Black History's Global Vision. Kelley enlightens our understanding of "the hyphen" in identifiers such as African-American, making possible an illuminated understanding of how global systems of race and imperialism spawned essentialist thinking that manifested in "a bounded national history" for Africans and their descendants around the world. Spanning the years 1883-1950, Kelley's account plumbs the complexities of "citizenship" in countries that do not grant equal rights to people of all races. It is thus that Kelley establishes that, for example, Malcolm X and H. Ford Douglass could not reasonably be seen as traitors to the United States if they were not truly protected as citizens. Not only is a pointed disloyalty understandable in such cases where one's nation has failed him, Douglass averred that, "I can join a foreign enemy and fight against it, without being a traitor, because it treats me as an ALIEN and a STRANGER" (as cited in Kelley, 1999, p. 1049, emphasis in the original). This idea is leveraged to argue that domestic racism results from imperialism (pp. 1053-1054), which is among the tough principles that students must grapple with in contemplating basic critical Black studies before applying this body of knowledge to curriculum and pedagogy.

\section{Afro-Centric Curriculum Studies}

A White student undertaking an introduction to critical Black studies would do well to reflect on the fact that, with this knowledge, we know more now and we also know better. One 


\section{THE NEBRASKA EDUCATOR, VOLUME 6}

cannot unknow (but could simply choose to ignore) the racialized character of our founding. The student therefore could not claim to know the history of the United States of America but rather $a$ history, one of many facets of the "master narrative" (Berry, 2017) composed by the dominant race and class.

Watkins (2009), for instance, guides readers toward releasing ourselves likewise of any conceptions of "the curriculum" which is merely code for the mainstream curriculum movement (p. 321, emphasis added). Watkins enlightens us to six additional orientations to curriculum we might not have considered, each of which is geared toward particular circumstances of Black Americans' experiences of slavery and oppression. These Black curriculum orientations include functionalism, accommodationism, liberalism, reconstructionism, Afrocentrism, and Black Nationalism. It is vital for a student such as myself to read Watkins' account of these isms, lest I be swayed by shallow or ignorant public opinions suggesting that Afrocentrism is discriminatory against White students or that Black Nationalism is radical or on a par with White nationalism.

\section{Reawakening: A Tentative Conclusion}

Given what I have learned about my privileges social position, the history or racial hierarchies in this country, racial capitalism, slavery, and critical race theory, it is not a mystery to me now that the story of Helen and her class on race stayed with me all these years. Looking back, I would not have had the courage or awareness to attempt something like that or even to ask her about it. As for my improv partner's fear of White people, this was yet another tear in the fabric of whatever scenery I had been living in front of and mistaking for real and threedimensional. Proceeding through the vulnerable terrain of my White awakening has revealed a more disturbing landscape that is both fragile and fraught. Studying race, particularly from my White point of view, is work that cannot be accomplished only academically; race work, 


\section{THE NEBRASKA EDUCATOR, VOLUME 6}

especially for people who are unaccustomed to being raced, is uncomfortable personal work that transcends the intellectual.

In the personal inventory that must be done first before teaching others about race, one encounters a stage of learning referred to in therapeutic contexts as the grief of the educationthat moment of crestfallen learning before empowerment takes place. It is the feeling of having eclipsed one's opportunity to act on newfound wisdom because the damage of what has already been lived is so profound. This grief, however, resolves itself — as all grief does — and what rises in its wake is an illumination of conscience, if not action. Perhaps the shame and guilt and demoralization are requisite steps to go through before I can claim to be "using my privilege for good," which is fast becoming yet another privileged trope. Given these conditions, how do we sustain our involvement in that struggle? The answer, Saad (2020) has written to their White audiences, is that "You cannot go back to sleep" (p. 199). The work of waking is never finished. 
THE NEBRASKA EDUCATOR, VOLUME 6

\section{References}

Ardoin, S., \& Martinez, B. (2019). Straddling class in the academy: 26 stories of students, administrators, and faculty from poor and working-class backgrounds and their compelling lessons for higher education policy and practice. Stylus Publishing, LLC.

Baptist, E. E. (2016). The half has never been told: Slavery and the making of American capitalism. Hachette UK.

Bell Jr, D. A. (1980). Brown v. Board of Education and the interest-convergence dilemma. Harvard Law Review, 93(3), 518-533.

Berger, R. (2015). Now I see it, now I don't: Researcher's position and reflexivity in qualitative research. Qualitative Research, 15(2), 219-234.

Berry, T. R. (2017). The intersections of Africana studies and curriculum theory: A counterWestern narrative for social justice. Journal of Curriculum Theorizing, 32(1).

Boswell, E. (2021, April 12). The qualitative imperative: Searching for positionality and reflexivity in mixed methods-grounded theory studies. American Educational Research Association annual meeting.

Casey, Z. A. (2016). A pedagogy of anticapitalist antiracism: Whiteness, neoliberalism, and resistance in education. SUNY Press.

Coates, T.-N. (2014). The case for reparations. The Atlantic, 313(5), 54-71.

Coates, T.-N. (2015). Between the world and me. Spiegel \& Gram.

Cole, T. (2012, March 21). The white-savior industrial complex. The Atlantic. https://www.theatlantic.com/international/archive/2012/03/the-white-savior-industrialcomplex/254843

Crenshaw, K. W. (1990). Mapping the margins: Intersectionality, identity politics, and violence against women of color. Stan. L. Rev., 43, 1241. 


\section{THE NEBRASKA EDUCATOR, VOLUME 6}

Crenshaw, K. W. (1997). Intersectionality and identity politics: Learning from violence against women of color.

Crenshaw, K. W. (2017). On intersectionality: Essential writings. The New Press.

Gee, J. P. (2004). An introduction to discourse analysis: Theory and method. Routledge.

Gee, J. P. (2015). Social linguistics and literacies: Ideology in discourses (Fifth). Routledge.

Goffman, E. (1959). The presentation of self in everyday life. Doubleday.

Golash-Boza, T. M. (2016). The origin of the idea of race. In Race \& racisms: A critical approach (pp. 1-29). Oxford University Press.

Gordon, L. R. (2015). What Fanon said. Fordham University Press.

Grbich, C. (2013). Qualitative data analysis: An introduction (second). Sage.

Hill Collins, P., \& Bilge, S. (2020). Intersectionality. John Wiley \& Sons.

Hoong Sin, C. (2007). Ethnic-matching in qualitative research: Reversing the gaze on "white others" and "white" as "other." Qualitative Research, 7(4), 477-499.

Ignatiev, N. (2009). How the Irish became white. Routledge.

Johnson, W. (2009). Soul by soul. Harvard University Press.

Johnson, W. (2013). River of dark dreams. Harvard University Press.

Johnson, W. (2018, February 20). To remake the world: Slavery, racial capitalism, and justice. Boston Review. http://bostonreview.net/forum/walter-johnson-to-remake-the-world

Jupp, J. C. (2020). First-wave critical White studies. In Z. Casey (Ed.), Critical whiteness studies: Critical understandings in education encyclopedia (pp. 1-13). Brill Publishers.

Kelley, R. D. (1999). "But a local phase of a world problem”: Black history's global vision, 1883-1950. The Journal of American History, 86(3), 1045-1077. 
THE NEBRASKA EDUCATOR, VOLUME 6

Kelley, R. D. G. (2017, January 12). What did Cedric Robinson mean by racial capitalism? Boston Review. http://bostonreview.net/race/robin-d-g-kelley-what-did-cedric-robinsonmean-racial-capitalism

Kendi, I. X. (2019). How to be an antiracist. One world.

Kubota, R. (2020). Confronting epistemological racism, decolonizing scholarly knowledge: Race and gender in applied linguistics. Applied Linguistics, 41(5), 712-732.

Legassick, M., \& Hemson, D. (1976). Foreign investment and the reproduction of racial capitalism in South Africa (Foreign investment in South Africa: A discussion series).

Lensmire, T. J. (2017). White folks: Race and identity in rural America. Routledge.

Lensmire, T. J., McManimon, S., Tierney, J. D., Lee-Nichols, M., Casey, Z., Lensmire, A., \& Davis, B. (2013). McIntosh as synecdoche: How teacher education's focus on White privilege undermines antiracism. Harvard Educational Review, 83(3), 410-431.

Leonardo, Z. (2004). The color of supremacy: Beyond the discourse of 'white privilege.' Educational Philosophy and Theory, 36(2), 137-152.

Milner IV, H. R. (2007). Race, culture, and researcher positionality: Working through dangers seen, unseen, and unforeseen. Educational Researcher, 36(7), 388-400.

Newman, C. (2007). Unguided, on Challengers. Matador.

Pérez Huber, L. (2009). Challenging racist nativist framing: Acknowledging the community cultural wealth of undocumented Chicana college students to reframe the immigration debate. Harvard Educational Review, 79(4), 704-730.

Picower, B. (2009). The unexamined whiteness of teaching: How white teachers maintain and enact dominant racial ideologies. Race Ethnicity and Education, 12(2), 197-215. 


\section{THE NEBRASKA EDUCATOR, VOLUME 6}

Reyes, V. (2018). Three models of transparency in ethnographic research: Naming places, naming people, and sharing data. Ethnography, 19(2), 204-226.

Ribeiro, G. (2011). Why (post)colonialism and (de)coloniality are not enough: A post-imperialist perspective. Postcolonial Studies, 14(3), 285-297.

Robinson, C. J. (2020). Black Marxism: The making of the Black radical tradition. University of North Carolina Press.

Rothstein, R. (2017). The color of law: A forgotten history of how our government segregated America. Liveright Publishing.

Saad, L. F. (2020). Me and White supremacy: Combat racism, change the world, and become a good ancestor. Sourcebooks, Inc.

Saldaña, J. (2018). Researcher, analyze thyself. International Journal of Qualitative Methods, $17(1), 1-7$.

Sarroub, L. K. (2005). All American Yemeni girls: Being Muslim in a public school. University of Pennsylvania Press.

Scheurich, J. J., \& Young, M. D. (1997). Coloring epistemologies: Are our research epistemologies racially biased? Educational Researcher, 26(4), 4-16.

Taylor, K. B., \& Reynolds, D. J. (2019). Dissonance. Chapter 9 in E. S. Abes, S. R. Jones, \& D. L. Stewart (Eds.), Rethinking college student development theory using critical frameworks. Stylus Publishing, LLC, pp. 94-109.

Tippett, K. (2020, April 30). Ocean Vuong-A life worthy of our breath [Radio]. https://onbeing.org/programs/ocean-vuong-a-life-worthy-of-our-breath/

Watkins, W. H. (2009). Black curriculum orientations: A preliminary inquiry. In New Curriculum History (pp. 117-139). Brill Sense. 


\section{THE NEBRASKA EDUCATOR, VOLUME 6}

Wilder, C. S. (2014). Ebony and ivy: Race, slavery, and the troubled history of America's universities. Bloomsbury Publishing USA.

Wilkerson, I. (2020). Caste: The origins of our discontents. Random House. 


\section{Appendix A}

\section{Resource Collections by Topic Area ${ }^{8}$}

\section{Positionality ${ }^{9}$ and Reflexivity_Personal and Institutional}

- Berger, R. (2015). Now I see it, now I don't: Researcher's position and reflexivity in qualitative research. Qualitative Research, 15(2), 219-234.

- Kubota, R. (2020). Confronting epistemological racism, decolonizing scholarly knowledge: Race and gender in applied linguistics. Applied Linguistics, 41(5), 712-732.

- Milner, H. R. (2007). Race, culture, and researcher positionality: Working through dangers seen, unseen, and unforeseen. Educational Researcher, 36(7), 388-400.

- Patel, L. (2015). Decolonizing educational research: From ownership to answerability. Routledge.

- Scheurich, J. J., \& Young, M. D. (1997). Coloring epistemologies: Are our research epistemologies racially biased? Educational Researcher, 26(4), 4-16.

\section{History and Origins of Race/-ism(s) in the United States}

- Golash-Boza, T. M. (2016). The origin of the idea of race. In Race \& racisms: A critical approach (pp. 1-29). Oxford University Press.

- Omi, M., \& Winant, H. (2014). Racial formation in the United States. Routledge.

- Painter, N. I. (2010). The history of White people. WW Norton \& Company.

\footnotetext{
${ }^{8}$ Many of these resources pertain to more than one category, but they are presented here in the topic areas for which they were grouped in the body of the paper.

${ }^{9}$ Sample Positionality Statements, as compiled by the author, are available at: https://bit.ly/PositionalityExemplars
} 
THE NEBRASKA EDUCATOR, VOLUME 6

\section{Critical Race Theory and Critical Whiteness Studies}

- Casey, Z. A. (2016). A pedagogy of anticapitalist antiracism: Whiteness, neoliberalism, and resistance in education. SUNY Press.

- Jupp, J. C. (2020). First-wave critical White studies. In Z. Casey (Ed.), Critical whiteness studies: Critical understandings in education encyclopedia (pp. 1-13). Leiden, The Netherlands: Brill Publishers.

- Jupp, J. C., Berry, T. R., Morales, A., \& Mason, A. M. (2018). What is to be done with curriculum and educational foundations' critical knowledges? Toward critical and decolonizing education sciences. Teaching Education, 29(4), 305-317. https://doi.org/10.1080/10476210.2018.1510484

- Ladson-Billings, G., \& Tate, W. F. (1995). Toward a critical race theory of education. In Critical Race Theory in Education (pp. 10-31). Routledge.

- Picower, B. (2009). The unexamined whiteness of teaching: How white teachers maintain and enact dominant racial ideologies. Race Ethnicity and Education, 12(2), 197-215.

- Taylor, K. B., \& Reynolds, D. J. (2019). Dissonance. In E. S. Abes, S. R. Jones, \& D. L. Stewart (Eds.), Rethinking college student development theory using critical frameworks. Stylus Publishing, LLC.

\section{Africana}

- Coates, T.-N. (2014). The case for reparations. The Atlantic, 313(5), 54-71.

- Du Bois, W. E. B. (1972). Socialism and the American negro: Speech before audience in Great Hall, Madison Wisconsin Memorial Union, April 9, 1960. Folkways Records. 
THE NEBRASKA EDUCATOR, VOLUME 6

- Garvey, M. (1920). "Declaration of the Rights of the Negro Peoples of the World": The Principles of the Universal Negro Improvement Association. Retrieved from http://historymatters.gmu.edu/d/5122/

- Kelley, R. D. (1999). "But a local phase of a world problem": Black history's global vision, 1883-1950. The Journal of American History, 86(3), 1045-1077.

- Robinson, C. J. (2020). Black Marxism: The making of the Black radical tradition. University of North Carolina Press.

- Watkins, W. H. (2009). Black curriculum orientations: A preliminary inquiry. In New Curriculum History (pp. 117-139). Brill Sense.

- X, M., \& Haley, A. (1964). The autobiography of Malcolm X. New York: Ballantine. 
THE NEBRASKA EDUCATOR, VOLUME 6

\section{Appendix B}

\section{Sample Positionality Statements}

\section{Teju Cole's Positionality Statement}

"I write all this from multiple positions. I write as an African, a black man living in America. I am every day subject to the many microaggressions of American racism. I also write this as an American, enjoying the many privileges that the American passport affords and that residence in this country makes possible. I involve myself in this critique of privilege: My own privileges of class, gender, and sexuality are insufficiently examined. My cellphone was likely manufactured by poorly treated workers in a Chinese factory. The coltan in the phone can probably be traced to the conflict-riven Democratic Republic of Congo. I don't fool myself that I am not implicated in these transnational networks of oppressive practices." (Cole, 2012, para. 11)

\section{Johnny Saldaña’s Positionality Statement (Truncated)}

“[...] As an elder gay man of color without a $\mathrm{PhD}$ in theatre — an art form usually perceived by university administrators as a field not as worthy as the hard sciences or other high-incomegenerating disciplines-my "lesser than" statuses have relegated me to the margins for over 40 years as a student and professor in higher education. I have waited so long for equality and social justice. I'll spare you the stories of microaggressions, overt hostility, and discrimination I've experienced, but know that there are some people in the United States who would literally exile or even exterminate me if they could. I've been fighting the good fight for decades and have surprisingly little to show for it. [...]" (Saldaña, 2018, pp. 2-3) 


\title{
Exploration of Lived Experiences of Science Teachers of English Language Learners: A Transcendental Phenomenological Study
}

\author{
Uma Ganesan \\ Department of Teaching, Learning, and Teacher Education \\ University of Nebraska-Lincoln
}

\begin{abstract}
English language learners (ELLs) are a talented pool of culturally and linguistically diverse students who are persistently increasing both in absolute size and percentage in the U.S. school population; however, they are underrepresented in science, technology, engineering, and mathematics (STEM) fields in college as well as in the workforce (National Academies of Sciences, Engineering, and Medicine, 2018). Education and scientific communities have found it challenging to improve students' participation in STEM fields (Martinez et al., 2011). Exploring science teachers' experiences could aid in improving academic achievement of ELLs and promoting educational equity. The purpose of this transcendental phenomenological study is to explore and describe the extrinsic and intrinsic aspects, support systems, and challenges that science teachers of ELLs experience at a public high school in a large Midwestern city in the United States. Data collection methods include individual in-depth, semi-structured and focus group interviews to analyze and search for dominant themes. The anticipated findings and discussion describe dominant themes, i.e., the overall essence of the phenomenon of teaching science to ELLs. Insights into teachers' experiences will help educators, educational leaders, policy makers, and researchers to better understand methods to improve ELLs' science outcomes. Potential limitations, implications, and possible areas for future research that could pave ways for increasing participation of ELLs in STEM fields and related careers are addressed.
\end{abstract}

Keywords: English language learners, STEM education, 5E inquiry-based instructional model, NCLB, NGSS, NCCRS-S 
THE NEBRASKA EDUCATOR, VOLUME 6

\section{Introduction and Statement of the Problem}

\section{Context of the Problem}

Science educators and educational institutions have long been concerned about the status of science content being taught in K-12 schools and the delivery of the content. Educational reformers in the United States continue to strive to solve the problem on how to best teach science for optimal success in learning for all students. With mandatory testing nationwide, along with an increase in science, technology, engineering, and mathematics (STEM) jobs and little workforce to fulfill these needs, the question of what to teach and how to teach science remains a concern among educators and all stakeholders (McWright, 2017).

In the educational context of the USA, there have been sweeping educational reforms that focus on high academic standards and achievement for all students (Buxton \& Lee, 2014). There has been an increased urgency to raise the standards of science education due to four primary factors: (a) the growing linguistic and cultural diversity of the U.S. student population, (b) persisting gaps in standardized and high-stakes testing across the demographic subgroups that is intensified by No Child Left Behind Act (NCLB) and Race To The Top (RT ${ }^{3}$ ) initiatives by the government, (c) evolving social and personal motives for learning advanced science for making informed decisions and for career and college readiness, and (d) the increase in linguistic and cognitive demands which are present in Next Generation Science Standards (NGSS) and NRC's (2012) Framework for K-12 Science Education (Buxton \& Lee, 2014). As the site of my research will be a public high school in a large Midwestern city in the state of Nebraska, my paper includes Nebraska's College and Career Ready Standards for Science (NCCRS-S), which mirrors the three dimensions of NGSS of disciplinary core ideas, cross-cutting concepts, and science and engineering practices (see Appendix A). 


\section{THE NEBRASKA EDUCATOR, VOLUME 6}

The creation of NGSS and implementation of Common Core education have been in the spotlight as ways to improve K-12 education. The purpose of NGSS is to better prepare students for the workforce and college by developing critical-thinking skills and scientific literacy and building interest in science, technology, engineering, and mathematics (McWright, 2017).

The USA ranks $20^{\text {th }}$ among all nations in the proportion of 24-year-olds who earn degrees in natural science or engineering (Cadle, 2020). According to the projections for 2012-2022 of the United States Department of Education and the United States Department of Labor, STEM jobs are likely to grow by $13 \%$, with mathematical and scientific fields projected to have the highest growth at $26 \%$, followed by computer and mathematical sciences at $18 \%$, life sciences and social sciences at 10\%, and architectural and engineering fields at 7.3\%. STEM-related jobs grew at three times the rate of non-STEM jobs between 2000 and 2010 ("The STEM Imperative," 2016). As the demand for STEM jobs is increasing, the number of students entering STEM fields, especially people of color and minoritized students, is not increasing. The number of students entering STEM fields majoring in STEM fields in college is low, and the number of students taking science classes, such as physics and chemistry, is extremely low for many states (McWright, 2017). In the U.S. job market, nearly 2.4 million STEM jobs went unfilled in 2018 (Moseley, 2019). At the same time, minoritized populations are very much underrepresented in STEM fields-just $2.2 \%$ of Latinos, $2.7 \%$ of African Americans, and 3.3\% of Native Americans and Alaska Natives have managed to earn a university degree in STEM fields. This underrepresentation means that minoritized populations lack qualifications to access STEMrelated jobs, which are also better paid than many other jobs (“The STEM Imperative," 2016). Moreover, there could be more job opportunities for the minoritized populations who can potentially take up unfilled STEM jobs (U.S. Department of Education, n.d.). They could gain 
THE NEBRASKA EDUCATOR, VOLUME 6

upward economic mobility as the average salaries of STEM jobs is $70 \%$ more than the national average (U.S. Department of Education, n.d.). This could result in the development of technical skills for the minoritized populations, as the U.S. Bureau of Statistics says that in the next 20 years $80 \%$ of jobs will require technical skills (U.S. Department of Education, n.d.). Bybee (2010) emphasizes that by enrolling in STEM disciplines, students can develop $21^{\text {st }}$ century skills such as adaptability, complex communication, social skills, nonroutine problem solving, selfmanagement/self-development, and systems thinking (NRC, 2010). Bybee (2010) also adds that in STEM programs, student investigations and projects present the time and opportunity for teachers to help students develop 21st century skills.

The reason to select emergent bilinguals as this paper's target student population is because they mostly belong to the minoritized populations of the USA, and also because science teachers experience many problems while teaching science to ELL students. The Hispanic or Latinx students are the majority among the ELL student population, and Spanish is the most commonly spoken language in the USA (“Our Nation's English Learners,” n.d.). The percentage of ELL students studying in public schools in the United States has increased from $8.1 \%$ in Fall 2000 to 9.6\% in Fall 2016 (“English Language Learners in Public Schools” [NCES, 2019]).

Many skills required for STEM jobs and other jobs can be developed in inquiry science classrooms (Bybee, 2013). Based on the conception of equity and social justice from a cultural anthropology or cross-cultural perspective, I want to address issues of equity in science learning and teaching for students from diverse languages and cultures.

\section{Significance of the Study}

The ELLs embark on a personal journey when they learn science, which becomes their lived experiences that shape what they become and how they interact with others (Torres-Ovrick, 
THE NEBRASKA EDUCATOR, VOLUME 6

2014). Learning about the underrepresentation of minoritized populations and ELLs in STEM fields emphasizes the fact that ELL students might miss out on becoming important contributors in our society. They might also lose out on the opportunities to improve their socioeconomic status when they are not able to pursue their education in STEM fields. This paper's literature review section addresses how teachers play an important role in encouraging minoritized populations to pursue their studies and become employed in the STEM fields. This is because students' interest in STEM topics are fostered in grades K-12. However, as discussed in the literature review section, most teachers of ELLs report that they have difficulty connecting or relating with their students. As Bandura (1993) has posited that the task of creating environments conducive to learning rests heavily on the talents and self-efficacy of teachers, understanding the lived experiences of teachers of ELL students is critical for understanding how to improve STEM teachers' approach to working with ELL students.

The need for science teachers to engage in critical reflections about their beliefs is imperative. Hence, with my research, I hope to add to the body of literature concerned with the need to provide opportunities to engage science teachers in the process of self-reflection, deconstruction, and reconstruction of their held beliefs regarding teaching the culturally and linguistically diverse students. Thus, by researching on the lived experiences of science teachers, I hope to gain insights that could pave new ways for increasing participation of ELLs in STEM fields and related careers.

\section{Definitions of Key Terms}

\section{English Language Learners}

Emergent bilinguals, English language learners (ELLs), or English learners (ELs) are a diverse group representing different cultures, languages, ethnicities, and nationalities ("Our 
THE NEBRASKA EDUCATOR, VOLUME 6

Nation's English Learners," n.d.). They are learners who are in the developing stages of acquiring their native language (L1) and/or a second language (L2), and who have the ability to tap into both languages as resources. The term "emergent bilingual" signifies a positive description of these students as it indicates that the student is learning in two languages, and that both languages are of value ("What is Emergent Bilingual," 2020).

\section{STEM Education}

According to Hom (2014), STEM is a curriculum based on the idea of educating students in four specific disciplines_-science, technology, engineering, and mathematics — in an interdisciplinary and applied approach. The U.S. Department of Education emphasizes that in an ever-changing, increasingly complex world, it is more important than ever that the nation's youth are prepared to bring knowledge and skills to solve problems, make sense of information, and know how to gather and evaluate evidence to make decisions. These are the kinds of skills that students develop in STEM.

\section{E Inquiry-Based Instructional Model}

Since the late 1980s, Biological Sciences Curriculum Study (BSCS) has used one instructional model extensively in the development of new curriculum materials and professional development experiences. That model is commonly referred to as the BSCS 5E Instructional Model, or the 5E Inquiry-Based Model. It consists of the following phases: engagement, exploration, explanation, elaboration, and evaluation. Each phase has a specific function and contributes to the teacher's coherent instruction and to the learners' formulation of a better understanding of scientific and technological knowledge, attitudes, and skills. This model helps science teachers to improve their instructional practices to enhance student learning (Bybee et al., 2006). 
THE NEBRASKA EDUCATOR, VOLUME 6

\section{No Child Left Behind Act (NCLB)}

No Child Left Behind (NCLB) Act was the main law for K-12 general education in the United States from 2002-2015. NCLB Act of 2001 was a version of the Elementary and Secondary Education Act (ESEA). NCLB was replaced by Every Student Succeeds Act (ESSA) in 2015. When NCLB was the law, it affected every public school in the United States. Its goal was to level the playing field for students who are disadvantaged, including students in poverty, minoritized populations, students receiving services, and those who speak and understand limited or no English. The law held schools accountable for how kids learned and achieved. The law was controversial partly because it penalized schools that did not show improvement (Lee, 2020).

\section{Next Generation Science Standards (NGSS)}

The Next Generation Science Standards (NGSS) are K-12 science content standards. Standards set the expectations for what students should know and be able to do. The NGSS were developed by the states to improve science education for all students. A goal for developing the NGSS was to create a set of research-based, up-to-date K-12 science standards ("Next Generation Science Standards,” 2020).

\section{Nebraska's College and Career Ready Standards for Science (NCCRS-S)}

Nebraska's College and Career Ready Standards for Science (NCCRS-S) were adopted by the Nebraska State Board of Education on September 8, 2017. The development of Nebraska's College and Career Ready Standards for Science were guided by The National Research Council's A Framework for K-12 Science Education. Nebraska's vision for science education is aimed at all students having meaningful access to the educational resources they need at the right moment, at the right level, and with the right intensity supported by high quality instructional materials (“Science Education [NCCRS-S],” 2017). 
THE NEBRASKA EDUCATOR, VOLUME 6

\section{Philosophical Assumptions and Theoretical Framework}

Before elaborating on the theoretical framework for this study, it is important to address my philosophical assumptions regarding qualitative research. Considering the philosophical and epistemological perspectives and paradigms is critical both for evaluating others' research as well as the ability to conceptualize and operationalize one's own research designs (Babchuk \& Badiee, 2011). My study will use social constructivism or interpretivism as the framework (Creswell \& Poth, 2018) because as a researcher, my goal is to interpret the participants' (science teachers') constructions of meaning of teaching science to ELLs. My philosophical assumptions align well with Denzin and Lincoln's (2011) statement that constructivist paradigm assumes a relativist ontology (i.e., there are multiple realities), a subjectivist epistemology (i.e., the knower and respondent co-create understanding), and a naturalistic set of methodological procedures. Creswell \& Poth (2018) also stated that social constructivism is an interpretivist framework which relate to the ontological, epistemological, axiological, and methodological philosophical beliefs. I agree with Neuman's (2011) stance of epistemology that the best knowledge about the world is produced when we carefully consider the interpretations of specific people in specific settings. I will use the above-mentioned philosophical assumptions to guide my study.

To understand the underpinnings of science teachers' beliefs, a socio-constructivists' framework is assumed in which knowledge is constructed and mediated within sociocultural contexts. Gonzalez (1997) assumed a socio-constructivist stance when analyzing teachers' beliefs. From this ideology, I recognize that knowledge is constructed on two mental planes, i.e., interpsychological and intrapsychological (Vygotsky, 1978). People’s conventional ideas, beliefs, and conceptualizations are formulated from experiences they have within a sociocultural context, such as familial and educational experiences. In essence, the social structure becomes 
THE NEBRASKA EDUCATOR, VOLUME 6

the mechanism for modeling expectations and standards of the norms of a given community or society (Flores, 2001).

The framework for this paper is based on the social constructivist learning theory of Vygotsky using the 5E Inquiry-based Instructional Model for scaffolding instruction and Krashen's theories of second language acquisition. Sociocultural theory (SCT) has its origins in the writings of the Russian psychologist L. S. Vygotsky and his colleagues (Lantolf, Thorne, \& Poehner, 2015). Vygotsky's $(1978,1986)$ sociocultural theory of cognitive development and human learning describes learning as a social process and the origination of human intelligence in society or culture (Lantolf, Thorne, \& Poehner, 2015). Weinburgh, Silva, Smith, Groulx, and Nettles (2014) mention that science educators have used social constructivism as a theoretical framework for research and practice for several decades. Their constructivist learning theory suggests that new knowledge is built by learners by integrating new ideas into what they had previously learned. The major theme of Vygotsky's theoretical framework is that social interaction plays a fundamental role in the development of cognition. This theory stresses the interaction between developing people and the culture in which they live. SCT argues that human mental functioning is fundamentally a mediated process that is organized by cultural artifacts, activities, and concepts. For example, a child cannot learn many things (like language skills) without society. They need to be with people to learn how to use language. Practically speaking, developmental processes take place through participation in cultural, linguistic, and historically formed settings such as family life, peer group interaction, and institutional contexts like schooling, organized social activities, and workplaces (Lantolf, Thorne, \& Poehner, 2015). SCT argues that the most important forms of human cognitive activity develop through 


\section{THE NEBRASKA EDUCATOR, VOLUME 6}

interactions and conditions found in instructional settings (Engeström, 2019), which is quite relevant for ELL students to learn science in a school/classroom setting.

Vygotsky focused on social interactions and language as tools to scaffold instruction for the students to promote their understanding. There are useful models that can be used to teach science for ELLs based on Vygotsky's theory. In the era of NGSS, Rodger W. Bybee and a team of his colleagues proposed the BSCS 5E Instructional Model. The 5E Instructional model is based on the psychology of learning (NRC, 1999) and the observation that students need time and opportunities to formulate or reconstruct concepts and abilities. These two factors justify the perspective for each phase and the sequence of 5E. Using the 5E model, science teachers of emergent bilinguals can effectively engage the students, explore phenomena, explain phenomena, elaborate scientific concepts and abilities, and evaluate ELLs (Bybee, 2014). The 5E Inquiry-Based Instructional Model on Scaffolding Instruction is based upon cognitive psychology, constructivist theory to learning (Vygotsky’s ZPD principle), and best practices in STEM instruction. The conceptual framework of Vygotsky can be found in Appendix B. Vygotsky proposed that children and adults are both active agents in the process of the child's learning and development, and it is the quality of teacher-learner interaction that is most crucial in the child's learning (Vygotsky, 1978). The two principles of Vygotsky's work are: (a) “More Knowledgeable Others" (MKO) and (b) "Zone of Proximal or Potential Development” (ZPD). The teachers or more skilled peers are the MKO, and they are integrally linked to the second principle of ZPD. ZPD is defined by Vygotsky as "the difference between actual level of development as determined by independent problem solving and the higher level of potential development as determined through problem solving under guidance or in collaboration with more capable peers" (Verenikina, 2010, p. 3). According to Vygotsky, the key processes in 


\section{THE NEBRASKA EDUCATOR, VOLUME 6}

development and learning of children are zone of proximal development, scaffolding, language/dialogue, and tools of culture (McLeod, 2018). The teaching implications for Vygotsky's theory are that it establishes opportunities for children to learn with the teacher and more skilled peers. To put it simply, ZPD relates to the difference between what a child can achieve independently and what a child can achieve with guidance and encouragement from a skilled teacher or partner (McLeod, 2018). According to Vygotsky, "good learning" occurs in the Zone of Proximal Development (Verenikina, 2010).

Furthermore, in his Acquisition-Learning Hypothesis, Krashen $(1981,1982)$ proposes that language acquisition is a natural and subconscious process similar to first language acquisition through explicit instruction and casual interactions with the language. Second language learners acquire language from their social environment through meaningful interactions (Torres-Ovrick, 2014). Krashen (1982) asserts that we acquire language when we receive messages that we can comprehend. This is known as the Comprehensible Input Hypothesis. Students need to understand what they hear or read in order to learn. Therefore, it is quite possible that an ELL might not have enough English knowledge to learn English or to learn subject matter (science) taught in the second language. Krashen (1996) found that it is easier for children to learn to read in a language they understand and then transfer that knowledge to English, and he stresses the importance of acquiring content knowledge, which is especially important for learning science that has many challenging scientific terminologies, equations, and concepts. Aikenhead (2001) also explains that science is easily understood by students if there is similarity between their own culture and experiences and culture of modern school science, which he terms as "cultural border crossings of students into school science" (Aikenhead, 2001, 
THE NEBRASKA EDUCATOR, VOLUME 6

p. 1). His statements help us to understand the science meaning-making process of emergent bilinguals.

\section{Literature Review}

In the extant literature relevant to this study, there were some references to benefits of teaching science/STEM to ELLs. In the following paragraph, I have synthesized salient points of the literature related to the urgent need to improve science literacy for ELL students, the “achievement gap" between the white race and other minoritized populations in STEM education, science teachers' beliefs and perceptions of teaching ELL students, need for family/community engagement models for ELLs, and the need for professional development for science teachers who teach ELLs.

As the school student population in the USA is becoming more linguistically and culturally diverse, it is essential to set up a knowledge base that enhances academic achievement and equity for all students (Lee, 2003). With increasing demand and need for students to enroll and succeed in STEM subjects, it is imperative that science education research focuses on the strategies to improve the scientific literacy of ELL students who are the fastest growing K-12 student population (Turkan \& Liu, 2012). There is an urgent need for effective family and community engagement models for ELLs in STEM to recognize and make connections to families' and communities' cultural and linguistic practices and study their relationship to STEM topics (Francis \& Stephens, 2018). Santau et al. (2010) identified that there is an urgent need in the USA and other countries of the world for science education reforms due to the rapidly changing technological and economic demands of the modern era. Caucasian and AsianAmerican students outperformed African American and Latino/Hispanic-American students in science achievement tests (Lawrenz et al., 2001). Hart and Lee (2010) indicate that teachers will 


\section{THE NEBRASKA EDUCATOR, VOLUME 6}

need more professional development programs to be able to implement and maintain reformoriented practices that will enhance science achievement of linguistically and culturally diverse students. Kirmaci, Allexsaht-Snider, and Buxton (2018) state that teacher-parent collaboration can play a critical role in promoting diverse students' post-secondary education attendance and academic success. Their findings highlight the potential for designing new professional development opportunities to support secondary teachers in collaborating with parents who bring a wide range of cultural, ethnic, socioeconomic, and linguistic resources in supporting their children's learning and schooling. Another study by Tandon, Viesca, Hueston, and Milbourn (2017) examined data from 36 teacher candidates and novice teachers of multilanguage learners (MLLs) to explore their perceptions and understandings of linguistic responsiveness. The findings illustrate that there are challenges faced by teachers in demonstrating linguistically responsive teaching practices in the early and initial stages of entering the teaching profession, and that more research is necessary to understand how to support teachers in this complex mission.

Thus, the overall findings of the literature reveal that the capability of ELL students to demonstrate high levels of scientific achievement and possible careers in scientific fields is enhanced when the teachers demonstrate self-efficacy and possess unique qualities that help ELLs; use culturally and linguistically responsive teaching methods; have good support systems from the school administration, parents, and educational policies; have professional development opportunities; and provide the students with equitable and favorable learning and assessment opportunities by using scaffolding and inquiry method in their instruction. The four overarching benefits of teaching STEM for ELL students were also identified: a) improving the academic outcomes of ELLs, b) meeting the requirements of NGSS, NCLB, and other state and national 
THE NEBRASKA EDUCATOR, VOLUME 6

science standards, c) improving college readiness among the ELL population, and d) creating competent scientific workforce (Turkan \& Liu, 2012; Francis \& Stephens, 2018; Lawrenz et al., 2001; Hart \& Lee, 2010; Lee, 2003, Santau et al., 2010).

\section{The Present Study}

\section{Researcher Positioning and Reflexivity}

It is important for all qualitative researchers to position themselves in their study and writing. Being reflexive means that a writer must engage in self-understanding about the biases, values, and experiences that he or she brings to a qualitative research study (Creswell \& Poth, 2018). As my study is a phenomenological study, I am going to use epoché or bracketing (Moustakas, 1994) to set aside my own personal experiences regarding teaching science to ELL students while collecting and analyzing data to be able to view the data without any personal bias or preconceived notions. Epoché or bracketing involves placing one's own thoughts about the topic in suspense or out of question, and it involves the deliberate suspension of judgment (Lichtman, 2013). Merriam and Tisdell (2016) and Creswell and Poth (2018) have also stated that the researchers must suspend their personal experiences, biases, and assumptions with or towards the phenomenon, and they must approach the phenomenon from a new perspective to understand the meaning the participants have created and to discover elements that have been “taken for granted" as being true (Bogdan \& Biklen, 2007, p. 25).

Taking all the views of these scholars into consideration, I would like to position myself in this study as an Asian woman of color, a Ph. D. student aspiring to become a university professor, who has lived in India, D. R. Congo, and the USA. I have traveled widely to different parts of the world, in effect I have encountered and interacted with people of diverse races, ethnicities, socioeconomic classes, religions, cultures, and nationalities. I have two master's 


\section{THE NEBRASKA EDUCATOR, VOLUME 6}

degrees, one in environmental toxicology and another in business administration. I have been in the teaching profession for a major part of my career, having taught in high schools in D. R. Congo, pharmacy colleges in India, and is presently teaching "Multicultural Education" and "Teaching Science in the Elementary School" at our university. Due to my overall work and teaching experience of 26 years, I have had the opportunity to teach diverse international students. For almost 6 years, I have taught biology and chemistry to English language learners in an American International High School in Lubumbashi, D. R. Congo. I would say that teaching scientific vocabulary-rich subjects has not been easy to these students who were either culturally or linguistically diverse (many of them were Swahili or French speakers). As my educational background is in formal sciences, I used to have a postpositivist mindset, but now I am increasingly getting attracted to the constructivist worldview because of my continuing education. Hence, because there is a possibility of my perceptions affecting the study (because of the probability of shared experiences with the participating teachers), I would like to take necessary steps and precautions to suspend my judgments during the data collection and analysis stages. I understand that my perceptions and assumptions could be biased and maybe incorrect, so I will work to bracket my ideas and thoughts in order to understand the participants' point of view. My own lived experiences and understandings as a science teacher will aid my hearing and understanding the perceptions of the participants. One way that I could bracket myself is by journaling my own feelings, thoughts, biases, assumptions, and experiences while I am in the process of interviewing and analyzing the data so that I can reflect on some elements that may interfere with unbiased interpretation of participants' views and subsequent findings of the study. I will also ensure to follow up with validation strategies to support my data and to make my study trustworthy. 
THE NEBRASKA EDUCATOR, VOLUME 6

\section{Purpose Statement}

The purpose of this transcendental phenomenological study is to describe the lived experiences of science teachers of ELLs at a public high school in a large Midwestern city in the USA.

\section{Research Questions}

\section{Central Question}

What are the common lived experiences of science teachers teaching English language learners?

\section{Sub-Questions (SQ)}

SQ1: What supports are available to the teachers for teaching science to ELLs?

SQ2: What are the challenges experienced by the teachers in teaching science to ELLs?

SQ3: In what ways do extrinsic aspects (e.g., parents, school administration, and educational policies) and intrinsic aspects (e.g., motivation and self-efficacy) influence the teacher's ability to teach science to ELLs?

\section{Methodology}

\section{Conceptual Framework}

Science teachers aid in the construction of knowledge of emergent bilinguals by various social interactions and their own beliefs and perceptions. I hypothesize that teachers' knowledge, perceptions, and scaffolding of instruction could increase the ELLs' understanding of science. Based on the conceptual framework of Vygotsky's classical social constructivist theory, Bybee's 5E Inquiry-Based Instructional Model, and Krashen's theories of second-language acquisition that I have already described in the theoretical framework section, I have proposed the conceptual framework for my study (see Appendix C). While researching about the perceptions of science teachers in the extant literature, I identified six major stakeholders, and the 
THE NEBRASKA EDUCATOR, VOLUME 6

interconnections between them highlights the importance of using the inquiry method and other theories for teaching science for ELLs, as is illustrated in the overlapping Venn diagram. All the stakeholders are linked to each other by arrows that outlines the purpose of their interaction, further emphasizing the need for scaffolding instruction for ELLs to improve their academic outcomes and their interest in pursuing STEM careers, as I have mentioned in my abstract. "Each "E" helps in building the scaffolding necessary for students to construct their own knowledge" (Shelton, 2014). Science teachers need to be explicit and intentional in planning the scaffolding and should layer it appropriately, so that scaffolding addresses the students' misconceptions and aids in closing the gaps in students' learning. During a 5E's sequence, students begin by connecting to their own experiences or by tapping into their own curiosity and continually build on and revise their understanding. As previously stated, the framework is also supported by two hypotheses of Krashen (1981, 1982, 1996).

\section{Rationale for a Qualitative Research Design}

Merriam and Tisdell (2016) state that qualitative research is implemented when researchers are particularly interested in exploring how people interpret their experiences, how they construct their worlds, and what meaning they attribute to their experiences. According to Creswell and Poth (2018), qualitative research begins with assumptions and the use of interpretive/theoretical frameworks that inform the study of research problems addressing meaning individuals or groups ascribe to a social or human problem. Bogdan and Biklen (2007) define qualitative research as an approach to social science research that emphasizes collecting descriptive data in natural settings, uses inductive thinking, and emphasizes understanding the subjects' point of view. Denzin and Lincoln (2011) illustrate that the role of qualitative researchers is to "study things in their natural settings, attempting to make sense of or interpret 
THE NEBRASKA EDUCATOR, VOLUME 6

phenomena in terms of the meanings people bring to them" (p. 3). The above-mentioned guidelines compliment my goals in this study for me to understand how science teachers ascribe meanings to their unique experiences working with ELL students. Using a qualitative design will help me collect rich information on the science teachers' interpretations of their lived experiences, how they perceive their challenges and support systems, and how their ability to teach ELL students is affected by extrinsic and intrinsic aspects. I also hope to describe the essence of the lived experiences in a literary form of writing that allows the reader to explore the complexities of the topic (Creswell \& Poth, 2018). So, a qualitative design fits my study and its requirements.

\section{Rationale for a Transcendental Phenomenological Approach}

Although there are many choices of approaches of qualitative research, I specifically chose phenomenological approach because of the following reasons: a) phenomenology emphasizes the participant's experience and their interpretation of that experience (Merriam \& Tisdell, 2016), b) it describes a common meaning for the individuals who have lived experiences of the same phenomenon (Lichtman, 2013; Creswell \& Poth, 2018), and c) the practice of phenomenology is rooted in the idea that all of us construct our own reality (Bogdan \& Biklen, 2007). Among the sub-approaches of phenomenology, my research study is well suited for a transcendental approach since it satisfies most requirements of this sub-approach. To elaborate further, my research focus is to understand the essence of the experience of teaching science to ELLs, and my research problem is to describe the essence of a lived phenomenon, i.e., teaching science to ELLs. Moustakas' (1994) transcendental approach focuses less on the researchers' interpretations and more on the description of participants' (science teachers') experiences (emic perspective). "Transcendental" means "in which everything is perceived freshly, as if for the first 
THE NEBRASKA EDUCATOR, VOLUME 6

time" (Moustakas, 1994, p. 34). It also involves setting aside (bracketing) one's own judgments or bias and focusing on the way the participants understand and experience a particular phenomenon (Creswell \& Poth, 2018). I would also analyze the data and reduce it to significant statements and quotes and combine them into themes. Then I will develop textural description of experiences of the science teachers (what they experienced) and structural description (how they experienced it in terms of conditions, situations, or contexts), and the overall essence will be conveyed by combining both the textural and structural descriptions (Creswell \& Poth, 2018).

\section{IRB and Ethical Considerations}

To ensure that I am conducting an ethical study, I will seek approval from the Institutional Review Board (IRB) of University of Nebraska-Lincoln before commencing my data collection procedures. I will first submit a proposal detailing my research procedures to the IRB. All personnel, including myself, working on this project will complete all of the required CITI course training for the University of Nebraska-Lincoln IRB committee. As the participants will be chosen purposefully using a criterion sampling, I will ensure that all participants are adult teachers (above 19 years of age) who will be interviewed individually and as a focus group. It will be emphasized that there will be no identified risks to the participants, and the study does not pose any harm/discomfort to the participants. However, as Neuman (2011) has pointed out, I will follow several procedures to ensure privacy, anonymity, and confidentiality during and after the study is completed. All the participants will be sent a recruitment email, requested to sign an informed consent form, and will be given opportunities to ask any questions related to the project (Creswell \& Poth, 2018). It will be stressed that participation is completely voluntary. The informed consent form, as per IRB guidelines, will detail the purpose and procedures of the research and provide statements on the risk, confidentiality, compensation, and their freedom to 
THE NEBRASKA EDUCATOR, VOLUME 6

withdraw from the study at any time. I am planning to incorporate a "reciprocity" component to the participants (for graciously agreeing to participate in my study) of compensating each participant with a \$15 gift card from Barnes \& Noble for each participant. Because all participants are science teachers, I anticipate that they would appreciate this gesture. All participants will be assigned a pseudonym in the study to protect their identities and locations, and any information that is collected that could potentially identify the participants will be left out of the final research report. A sheet containing real names and the related pseudonyms, signed informed consent forms, collected data (audio files and the transcripts), data analysis records, and personal information such as names and email addresses will be stored in a locked drawer in my office where only my advisor and myself will have access to, and they will be deleted and destroyed after three years of completion of the study. All paper copies of research and disclosure forms signed when receiving compensation will be kept in a locked cabinet in the voice lab for seven years, per UNL Accounting and Bursars Office requirements. The information obtained in this study may be published in journals or presented at conferences; however, the data will be reported as aggregated data, and only pseudonyms will be used. Additionally, OneDrive will be used for storing data because UNL has a contract with this website, and it is more secure than any other online ways of storing information, such as Google Drive or Dropbox.

\section{Sample Selection and Details of Participants}

Creswell and Poth (2018) have stated that the number of participants in a phenomenological study can range between 1 and 325. However, they mentioned that Dukes (1984) only recommends studying around 3-10 participants. Based on this guideline, I will choose 5-10 science teachers (or until data saturation is reached) who will be chosen 
THE NEBRASKA EDUCATOR, VOLUME 6

purposefully from a high school in a large Midwestern city. More people will be recruited if the data has not reached saturation after that point. As I need to find teachers, who have taught science to ELL students (same criterion), I will use "criterion sampling" as this will be useful for quality assurance (Creswell \& Poth, 2018, p. 159). I will use "maximum variation" sampling as it will allow diverse variations of individuals or sites based on specific characteristics (Creswell \& Poth, 2018, p. 159). Hence, I will select a mix of novice and experienced teachers belonging to diverse ethnic/cultural groups and genders, and I will verify whether they are ELL certified. I will ensure that all the teachers recruited to participate in this study are adults (above 19 years of age) and will have the experience of teaching science to ELL students. The participants will be invited to participate in the study using a recruitment e-mail. IRB-approved procedures will be followed to obtain permission from the participants. They will sign the informed consent forms if they agree to participate in the study. They will also receive a follow-up thank you email once the data collection procedure is completed, and they will be notified that they will be contacted for member-checking via an email, before reporting the findings of the study.

\section{Data Collection Methods and Instruments}

For my study, I will employ primary and secondary data collection procedures.

Primary data collection. The primary data collection instrument will involve individual in-depth and semi-structured interviews of 30-45 minutes' duration with high school science teachers conducted by myself and another researcher from my team (to offer a different viewpoint and to improve the study's internal validity and credibility). This structure allows the interviewer to have a guide, but it also allows the interviewer to be flexible in the use and order of questions (Merriam \& Tisdell, 2016). Creswell \& Guetterman (2019) state that data recording protocols are forms designed and used by qualitative researchers to record information during 


\section{THE NEBRASKA EDUCATOR, VOLUME 6}

observations and interviews. During interviewing, it is important to have some means for structuring the interview and taking careful notes. Creswell (2016) states that an interview protocol is a form designed by the researcher that contains instructions for the process of the interview, the questions to be asked, and space to take notes of responses of the interviewee. Hence, a peer-reviewed semi-structured interview protocol will be used, and all the interviews will be audio-recorded and transcribed. The sites of interviews will be calm and quiet places, as determined by the participants. During the interviews, the interviewer will also be taking notes of thoughts, ideas, and observations of the interviewee. All the participants will be given opportunities to ask questions and engage in another follow-up interview when they will be given the $\$ 15$ bookstore gift card, thanked for their cooperation and participation in the study, and shown the preliminary findings to member-check with them.

Secondary data collection. Secondary data collection tool will involve focus group interviews at the end of the academic year. According to Creswell and Guetterman (2019), a focus group interview is the process of collecting data through interviews with a group of people, typically four to six. The researcher asks a small number of general questions and elicits responses from all individuals in the group. Thus, a focus group interview protocol will further guide my interview process. The focus group interviews will be conducted in a mutually agreedupon place (between the participants and the interviewer/s) for a duration of approximately one hour; this will also be audio-recorded and transcribed for data analysis. Since the goal of my study is to determine the essence of the shared experience of teaching science to ELLs, focus group interviews would offer a rich description of the shared lived experience. This could generate some new themes that do not come up in individual interviews. Hence, focus group interviews are appropriate for this study. Since both individual and focus group interviews are 
THE NEBRASKA EDUCATOR, VOLUME 6

conducted by at least two researchers, it will add multiple perspectives and also help in triangulating the data.

\section{Data Analysis Methods}

The data analysis in Moustakas' (1994) transcendental phenomenology complements the search for understanding (Moerer-Urdahl \& Creswell, 2004) and will fit my exploration to understand the phenomenon of teaching science to ELLs. After the data collection stage, I will commence the data analysis by first assigning pseudonyms for the participants and then transcribe all the recorded individual and focus group interviews. I will put aside (epoché or bracketing) all my own experiences and preconceived notions about teaching science to ELLs to better examine this phenomenon (Moustakas, 1994). I will then focus on identifying descriptions of the phenomenon of teaching science to ELLs (Starks \& Trinidad, 2007). I will then cluster these descriptions into categories and will then describe the "essence" or core commonality that participants experienced of the phenomenon (Starks \& Trinidad, 2007). I will analyze the transcribed data by uploading the transcripts into the computer program called MAXQDA and reduce the information to significant statements. Significant statements/quotations that the teachers make will be pulled out and interpreted later. This process is called the "horizonalization" of the data (Creswell \& Poth, 2018). I will then categorize this information into meaning units and ultimately create dominant themes. I will also use Microsoft Word and Microsoft Excel for analyzing the data. Since I am following Moustakas' (1994) transcendental phenomenological approach, I will create a textural description of "what" participants experienced as well as a structural description of "how" participants experienced the phenomenon (Creswell \& Poth, 2018, p. 77). Both structural and textural descriptions will help me to arrive at the essence of the phenomenon. 
THE NEBRASKA EDUCATOR, VOLUME 6

\section{Standards of Validation}

After data analysis, every qualitative researcher should ensure that the study is rigorous, trustworthy, reliable, and credible. Creswell and Poth (2018) have tabulated eleven different validation perspectives and corresponding terms used in qualitative research. They also present nine generally accepted validation strategies through the lenses of the participant, researcher, and the reader (Creswell \& Poth, 2018), and I will use some of them and the others proposed by other scholars in my study as given below:

a) Multiple interviews (two individual and one focus group with diverse participants in my study) with the same participant (i.e., triangulation of data sources in my study), with "repeated listenings to taped interviews and readings of transcripts," and focused analysis of the critical "episodes" will be used. This is to verify "internal consistency" (Loh, 2013, p. 9). Hence, triangulation of data will be done in my study by including multiple sources and adding multiple perspectives (team of two researchers to collect data). This could improve the study's internal validity and credibility. Peer validation will also be done by requesting peers (who share the common field of research with me) to review my writing and research.

b) Reliability will be checked by verifying whether the findings are consistent with the data collected.

c) Dependability will be established by an outside researcher conducting an inquiry audit, called as external audit, on my research study.

d) I will generate rich, thick descriptions of the participants and the setting (maximum variation sampling) to allow the reader to make decisions about transferability and external validity. 
THE NEBRASKA EDUCATOR, VOLUME 6

e) I will be disclosing my own biases, values, and prior experience of teaching science to ELLs (reflexivity) so that the reader can understand the assumptions that may impact my inquiry.

f) After arriving at the essence or findings, member checking or seeking the participants' feedback will be done.

\section{Discussion}

\section{Potential Research Findings}

After completing the data analysis, I will prepare a detailed report of the findings of my research project. I plan to use teachers' quotes extensively and present an organized description of identified themes and their relation to my research questions. I will also include how my findings evolved during the course of the data collection and analysis and incorporate my role as the researcher in the findings. I will create tables and figures to enhance the presentation of my findings. Some of the themes that could emerge are science teachers' self-efficacy and unique qualities, teachers' cultural responsiveness and linguistic competence, teachers' support systems and professional development programs, and teachers' pedagogical practices and use of scaffolding for ELLs (Kirmaci et al., 2018; Tandon et al., 2017).

\section{Possible Strengths and Limitations}

There would always be strengths and limitations to any research study. I envision some strengths in my study such as gaining insights into science teachers' perceptions of teaching ELLs by understanding their lived experiences, which is an underrepresented topic in the extant literature. As majority of the ELL student population have historically been the oppressed class, belong to the low socioeconomic class, and do not have many opportunities to excel in STEM careers, this study could inform the academia and policy makers about the ways to improve the 
THE NEBRASKA EDUCATOR, VOLUME 6

academic outcomes of ELL students and their interest in pursuing STEM careers. Interview data itself is a great strength for this study as it upholds the voice of the participants. There are also some limitations to this study; the first one being the sample size, which is 5-10 (or until data saturation is reached). Only individual interviews and focus groups are used as data collection methods in my study, so maybe triangulating with more data collection procedures, such as site observations, teacher reflections, and their journals could be used in future studies. Another limitation is that epoché is difficult to achieve, and participant biases could also arise from individual interviews and focus group interviews. I also foresee that some participants may not share personal experiences for which I need to be prepared with alternate questions to collect as much rich data as possible. Another limitation could be that all teachers will be recruited from the same city in the Midwest, and they could share similar school/community variables and resources. So, some findings might not be generalizable to the entire teaching community around the world.

\section{Suggestions for Future Research}

As I have already stated, this topic is underrepresented in the literature, and this study will hopefully open the doors for more research in this area. Some researchers have examined how students' perception of teachers' support may influence student engagement, motivation, and achievement (Kelly \& Zhang, 2016). Future studies in this area could consider the interactions between science teachers and their ELL students through researcher observations. Classroom observations could add another dimension to the data and serve to provide a more comprehensive view of the way science teachers operate within their classrooms. Studies could be conducted about ELL students' perceptions too. This could also pave new ways to look into the benefits of scaffolding, use of inquiry methods, and use of culturally and linguistically 


\section{THE NEBRASKA EDUCATOR, VOLUME 6}

responsive teaching methods to teach science for ELL students. This research could also look into interactions between the teachers and their co-workers, parents, school administration, educational policy makers, and the wider community. This could lead to better support systems for science teachers in the way of science-content-based professional development programs to prevent "teacher burnout," in the present-day, high-pressure "standardized-testing-based" educational scenario. This could lead to better teacher retention in critical school environments, such as the rural and urban settings. In light of the rapidly changing demographics of the US student population, urgent need for improving the science achievement of all students, highstakes assessment and accountability policies, and the underrepresentation of this topic in the research literature, more research on science teachers' perceptions on teaching emergent bilinguals is definitely warranted, and that this topic is a fertile area for future research.

\section{Implications of the Study and Conclusion}

As the demographics of United States continues to shift towards people who are culturally and linguistically diverse and growing need for scientifically trained workforce in the future, there is a pressing need for educating English language learners in STEM-related fields. STEM education can provide a significant pathway toward economic advancement_and social contribution for youth of historically marginalized communities. As the number of emergent bilingual students continues to increase in U.S. public schools (UN DESA, 2015), it becomes important for researchers to gain insights into science teachers' experiences, which could aid in improving academic achievement of ELLs and promoting educational equity. This might help educators, educational leaders, policy makers, and researchers to better understand methods to improve ELLs' science outcomes (Calabrese Barton et al., 2017; Kirmaci et al., 2018; Tandon et al., 2017; UN DESA, 2015). I strongly believe that all students in the United States can realize 


\section{THE NEBRASKA EDUCATOR, VOLUME 6}

their "American Dream" if educators create ways and means for them to succeed. Hence, I would like to conclude that equity and social justice for ELLs or emergent bilinguals can be enacted when educators support, nurture, and guide them in knowledge construction, particularly while teaching science. Overall, ELL students face unique challenges but also represent a tremendous asset for the USA if their full potential can be unlocked and harnessed. 
THE NEBRASKA EDUCATOR, VOLUME 6

\section{References}

Aikenhead, G. S. (2001). Students ease in crossing cultural borders into school science. Science Education, 85(2), 180-188. doi: 10.1002/1098-237x(200103)85:2<180::aidsce $50>3.0 . \operatorname{co} ; 2-1$

Babchuk, W. A., \& Badiee, M. (2011). Realizing the potential of qualitative designs in education: Guidelines for research and practice. In Proceedings of the 29th Annual Midwest Research Research-to-Practice Conference in Adult, Continuing, and Community Education (pp. 25-31).

Bandura, A. (1993). Perceived self-efficacy in cognitive development and functioning. Educational Psychologist, 28, 117-148.

Bogdan, R.C., \& Biklen, S.K. (2007). Qualitative research for education: An introduction to theories and methods (5th ed.). Boston: Pearson Education, Inc.

Buxton, C. A., \& Lee, O. (2014). English learners in science education. In Abell, S. K., \& Lederman, N. G. (Eds.). Handbook of research on science education (Vol. 2, pp. 204-222). New York: Routledge.

Bybee, B. (2010). Advancing STEM education: A 2020 vision. Technology and engineering teacher, 70(1), 30-35.

Bybee, R. W. (2013). The case for STEM education challenges and opportunities. Arlington, VA: NSTA.

Bybee, R. W., Taylor, J. A., Gardner, A., Van Scotter, P., Powell, J. C., Westbrook, A., \& Landes, N. (2006). The BSCS 5E instructional model: Origins and effectiveness. Colorado Springs, Co: BSCS, 5, 88-98. 
THE NEBRASKA EDUCATOR, VOLUME 6

Cadle, J. (2020). STEM vs. STEAM: Should Education Be Creative? Retrieved June 23, 2020, from http://portfolios.mica.edu/gallery/73342989/STEM-vs-STEAM-Should-EducationBe-Creative

Calabrese Barton, A., Tan, E., Greenberg, D. (2017). The makerspace movement: Sites of possibilities for equitable opportunities to engage underrepresented youth in STEM. Teachers College Record, 119(7), 1-44.

Creswell, J. W., \& Poth, C.N. (2018). Qualitative inquiry and research design: Choosing among five approaches (4th ed.). Thousand Oaks, CA: Sage.

Creswell, J. W., Guetterman, T.C. (2019). Educational research: Planning, conducting, and evaluating quantitative and qualitative research (6th ed.). Boston: Pearson Education.

Denzin, N.K., \& Lincoln, Y.S. (2011). Introduction: The discipline and practice of qualitative research. In N.K. Denzin \& Y.S. Lincoln (Eds.), The Sage handbook of qualitative research (4th ed.). Thousand Oaks, CA: Sage.

Engeström, Y. (2019). Learning by expanding: An activity-theoretical approach to developmental research. Cambridge: Cambridge University Press.

English Language Learners in Public Schools. (2019). Retrieved April 17, 2020, from https://nces.ed.gov/programs/coe/indicator_cgf.asp

Francis, D. J., \& Stephens, A. (2018). English learners in STEM subjects: Transforming classrooms, schools, and lives. Washington, DC: The National Academies Press.

Gonzalez, V. (1997). Using critical thinking to stimulate in-service teachers' cognitive growth in multicultural education. NYSABE Journal, 11, 92-119. 
THE NEBRASKA EDUCATOR, VOLUME 6

Hart, J. E., \& Lee, O. (2003). Teacher professional development to improve the science and literacy achievement of English language learners. Bilingual Research Journal, 27(3), 475-501. https://doi.org/10.1080/15235882.2003.10162604

Hom, E. (2014, February 11). What is STEM Education? Retrieved June 27, 2020, from https://www.livescience.com/43296-what-is-stem-education.html

Kelly, S. \& Zhang, Y. (2016). Teacher support and engagement in math and science: Evidence from the high school longitudinal study. High School Journal, 99(2), 141-165.

Kirmaci, M., Allexsaht-Snider, M., \& Buxton, C. A. (2018). Teachers' experiences with Spanish-speaking, bilingual families in a science learning context: Empowering teachers through home-school partnerships. Journal of Family Diversity in Education, 3(1), 23-47.

Krashen, S. D. (1981). Second language acquisition and second language learning. University of Southern California.

Krashen, S. (1982). Principles and practice in second language acquisition. University of Southern California.

Krashen, S. (1996). Surveys of opinions on bilingual education: Some current issues. Bilingual Research Journal, 20(3-4), 411-431.

Lantolf, J. P., Thorne, S. L., \& Poehner, M. E. (2015). Sociocultural theory and second language development. In VanPatten, B., \& Williams, J. (Eds.). Theories in Second Language Acquisition: An Introduction (2nd ed., pp. 207-226). New York, NY: Routledge.

Lee, O. (2003). Equity for linguistically and culturally diverse students in science education: A research agenda. Teachers College Record, 105(3), 465-489. https://doi.org/10.1111/1467-9620.00247 
THE NEBRASKA EDUCATOR, VOLUME 6

Lee, A. (2020, April 17). No Child Left Behind (NCLB): What You Need to Know. Retrieved June 28, 2020, from https://www.understood.org/en/school-learning/your-childsrights/basics-about-childs-rights/no-child-left-behind-nclb-what-you-need-to-know

Lichtman, M. (2013). Designing your research: Five Popular Approaches. In Qualitative research in education: A user's guide (3rd ed.). Thousand Oaks: Sage.

Loh, J. (2013). Inquiry into issues of trustworthiness and quality in narrative studies: A perspective. The Qualitative Report 18, 1-15.

Martinez, A., Rhodes, H., Copson, E., Tiano, M., DellaRocco, N., Donoghue, N., \& Marco, L. (2011). Math and Science Education with English Language Learners: Contributions of the DR K-12 Program: Targeted Study Group Working Paper. Abt Associates, 1-53.

McLeod, S. (2018). Lev Vygotsky. Retrieved April 29, 2020, from https://www.simplypsychology.org/vygotsky.html

McWright, C. N. (2017). A comparative study teaching chemistry using the 5E learning cycle and traditional teaching with a large English language population in a middle-school setting (Doctoral dissertation, The University of Southern Mississippi).

Merriam, S. B., \& Tisdell, E. J. (2016). Qualitative research: A guide to design and implementation. San Francisco, CA: Jossey-Bass.

Moerer-Urdahl, T., \& Creswell, J.W. (2004). Using transcendental phenomenology to explore the "ripple effect" in a leadership mentoring program. International Journal of Qualitative Methods 3(2), pp. 19-35.

Moseley, B. (2019, September 24). Roby: 2.4 million STEM jobs went unfilled last year. Retrieved June 27, 2020, from https://www.alreporter.com/2019/09/24/roby-2-4-millionstem-jobs-went-unfilled-last-year/ 
THE NEBRASKA EDUCATOR, VOLUME 6

Moustakas, C. (1994). Phenomenological research methods. Thousand Oaks, CA: Sage.

National Academies of Sciences, Engineering, and Medicine. (2018). English learners in STEM subjects: Transforming classrooms, schools, and lives. National Academies Press.

National Research Council (NRC). (1999). How people learn: Brain, mind, experience, and school. Washington, DC: National Academies Press.

National Research Council (NRC). (2010). Exploring the intersection of science education and 2lst century skills: A workshop summary. Washington, DC: National Academies Press.

National Research Council. (2012). A framework for K-12 science education: Practices, crosscutting concepts, and core ideas. National Academies Press.

Nebraska's College and Career Ready standards for science, 2017 (NCCRS-S). (2017). Lincoln, NE: Nebraska Department of Education.

Neuman, W.L. (2011). The meanings of methodology. In Social research methods: Qualitative and quantitative approaches ( $7^{\text {th }}$ ed.). Boston: Pearson Education Inc.

Next Generation Science Standards. (2020, June 04). Retrieved June 27, 2020, from https://www.nextgenscience.org/

NAEP-2015 Science Assessment. (2015). Retrieved June 23, 2020, from https://www.nationsreportcard.gov/science_2015/

Our Nation's English Learners. (n.d.). Retrieved April 18, 2020, from https://www2.ed.gov/datastory/el-characteristics/index.html

Santau, A. O., Secada, W., Maerten- Rivera, J., Cone, N., \& Lee, O. (2010). US urban elementary teachers' knowledge and practices in teaching science to English language learners: Results from the first year of a professional development intervention. 
THE NEBRASKA EDUCATOR, VOLUME 6

International Journal of Science Education, 32(15), 2007-2032.

https://doi.org/10.1080/09500690903280588

Shelton, T. (2014, September 1). Using the 5E's instructional framework to implement the NGSS in your classroom. Retrieved May 5, 2020, from https://tdishelton.wordpress.com/2014/08/30/using-the-5es-instructional-framework-toimplement-the-ngss-in-your-classroom/

Science Education. (2020, April). Retrieved June 27, 2020, from https://www.education.ne.gov/science/

Science, Technology, Engineering, and Math, including Computer Science (STEM). (n.d.). Retrieved June 27, 2020, from https://www.ed.gov/stem

The STEM Imperative. (2016, March 25). Retrieved June 27, 2020, from https://ssec.si.edu/stem-imperative.

Starks, H., \& Trinidad, S.B. (2007). Choose your method: A comparison of phenomenology, discourse analysis, and grounded theory. Qualitative Health Research, 17(10), 13721380.

Tandon, M., Viesca, K. M., Hueston, C., \& Milbourn, T. (2017). Perceptions of linguistically responsive teaching in teacher candidates/novice teachers. Bilingual Research Journal, 40(2), 154-168.

Torres-Ovrick, M. (2014). The lived experiences of bilingual dual language teachers: A phenomenological study. (Doctoral dissertation, New Mexico State University).

Turkan, S., \& Liu, O. L. (2012). Differential performance by English language learners on an inquiry-based science assessment. International Journal of Science Education, 34(15), 2343-2369. https://doi.org/10.1080/09500693.2012.705046 
THE NEBRASKA EDUCATOR, VOLUME 6

United Nations Department of Economic and Social Affairs (UN DESA). (2015). International migration report 2015. Retrieved from http://www.un.org/en/development/desa/population/migration/publications/ migration report/docs/MigrationReport2015.pdf

U.S. Department of Education. (n.d.). Retrieved June 23, 2020, from https://www.ed.gov/

U.S. Department of Labor. (n.d.). Retrieved June 24, 2020, from https://www.usa.gov/federalagencies/u-s-department-of-labor

Verenikina, I. (2010). Vygotsky in Twenty-First-Century research. In J. Herrington \& B. Hunter (Eds.). Proceedings of world conference on educational multimedia, hypermedia, and telecommunications (pp. 16-25). Chesapeake, VA: AACE.

van Manen, M. (1990). Researching lived experience: Human science for an action sensitive pedagogy. Albany: State University of New York Press.

Vygotsky, L. (1978). Mind in society: The development of higher psychological processes. Cambridge, MA: Harvard University Press.

Vygotsky, L. (1986). Thought and language. Cambridge, MA: MIT Press.

Weinburgh, M., Silva, C., Smith, K. H., Groulx, J., \& Nettles, J. (2014). The intersection of inquiry-based science and language: Preparing teachers for ELL classrooms. Journal of Science Teacher Education, 25(5), 519-541. https://doi.org/10.1007/s10972-014-9389-9

What is Emergent Bilingual. (2020). Retrieved June 28, 2020, from https://www.igiglobal.com/dictionary/understanding-diverse-bilingual-learners/72631 
THE NEBRASKA EDUCATOR, VOLUME 6

\section{Appendices}

Appendix A: Nebraska's College and Career Ready Standards for Science, 2017

The following table lists the disciplinary core ideas, crosscutting concepts, and science and engineering practices:

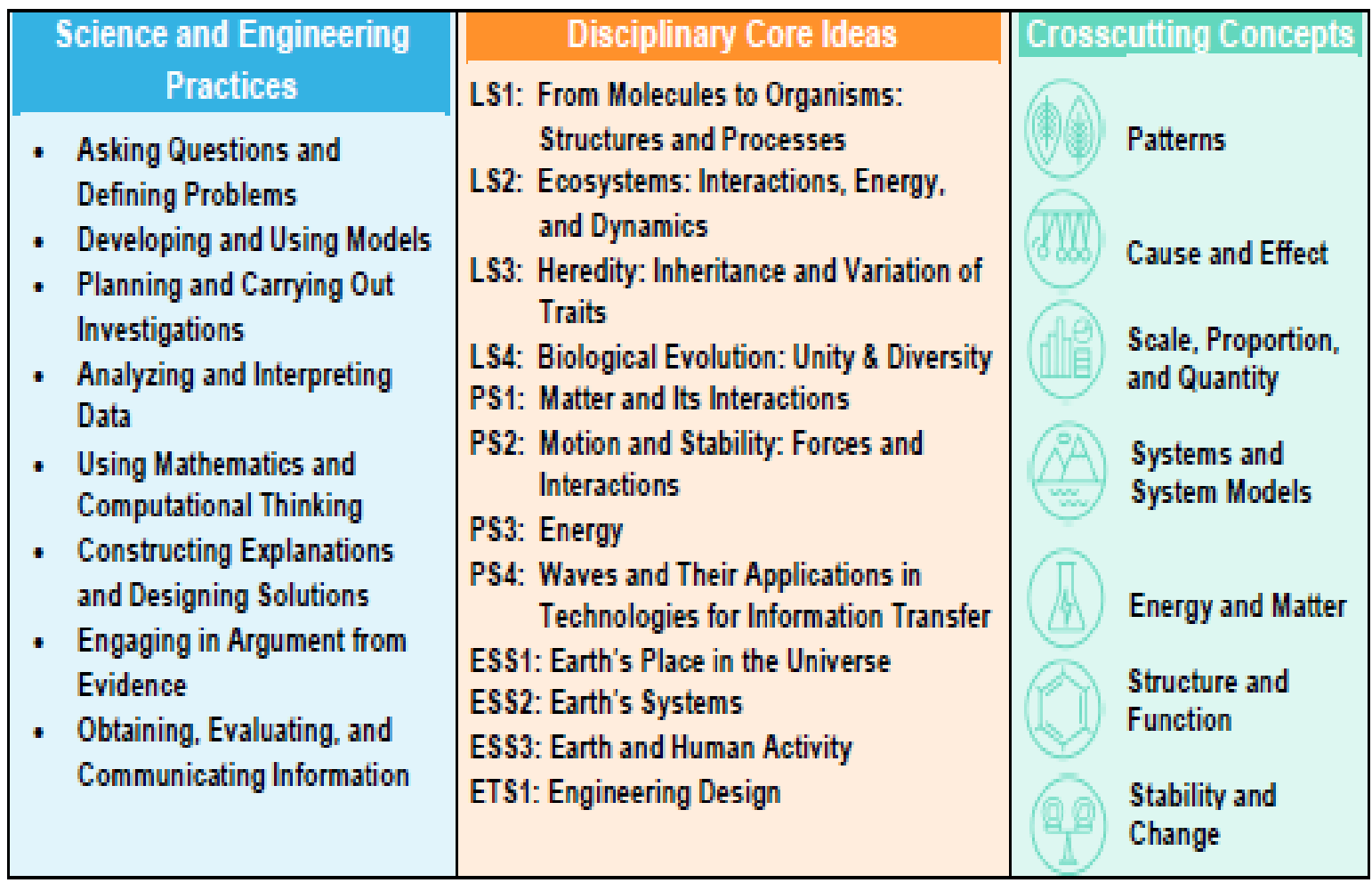

(NCCRS-S, 2017) 
THE NEBRASKA EDUCATOR, VOLUME 6

Appendix B: ZPD and its Relationship to Scaffolding

\section{ZPD and scaffolding}

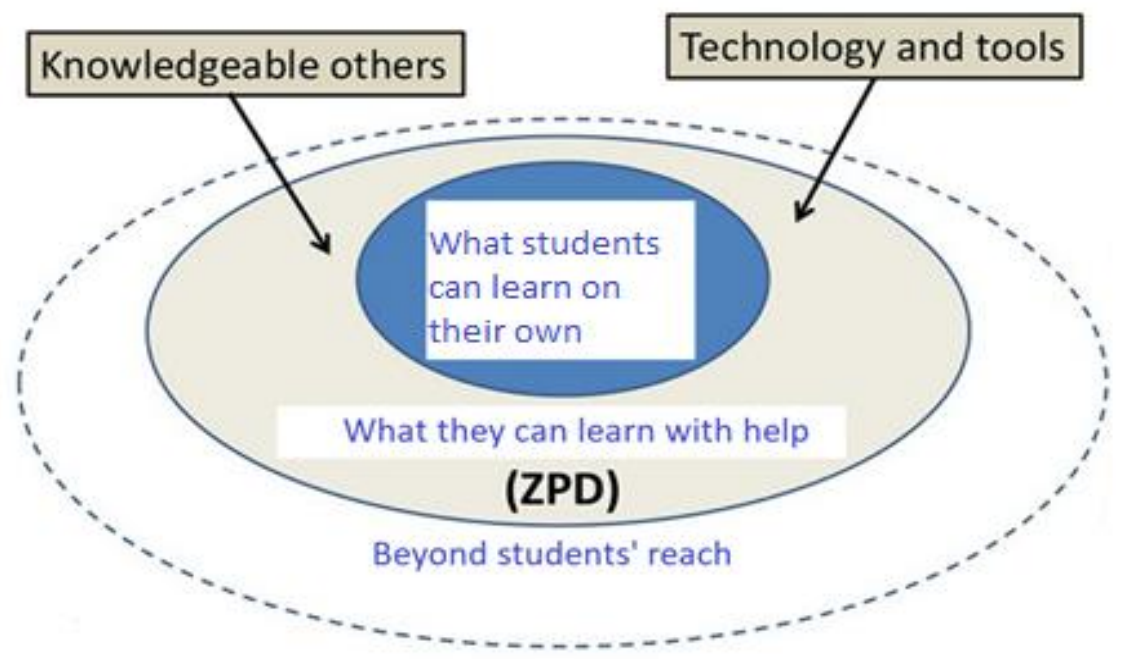


Appendix C: Conceptual Framework for Teaching Science for ELLs based on Vygotsky's ZPD using the 5E Inquiry-based model and Krashen's theories

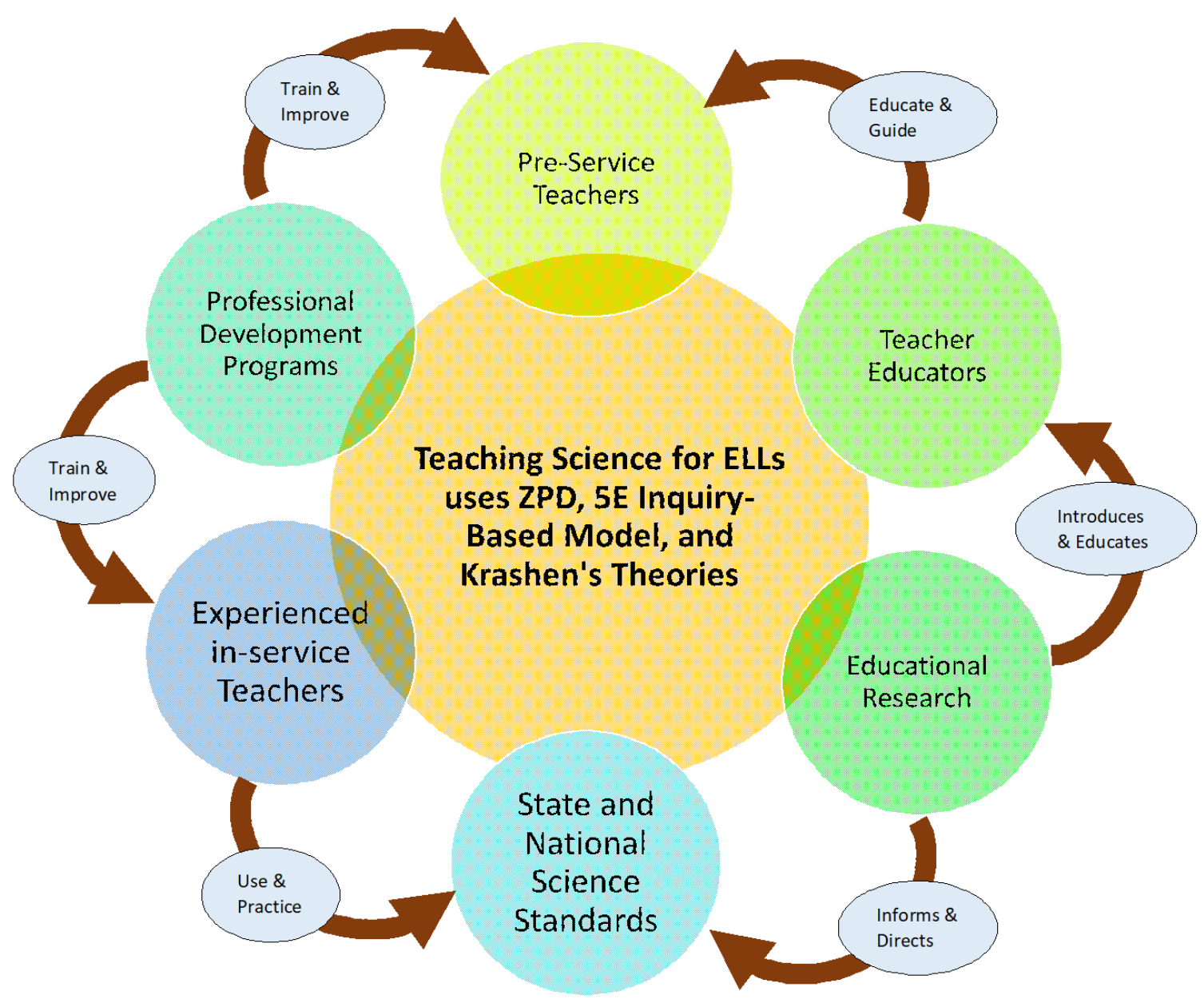




\title{
Confronting the Past, Challenging the Future: Linguistic Hegemony, Capitalism, and Neoliberalism in TESOL
}

\author{
Crystal Bock Thiessen \\ Department of Teaching, Learning, and Teacher Education \\ University of Nebraska-Lincoln
}

\begin{abstract}
Western capitalistic values that have given shape to contemporary neoliberal ideologies have, for too long now, greatly influenced the field of teaching English to speakers of other languages (TESOL) as a whole, essentially working to continue cycles of injustice and inequality throughout the field despite well-meaning intentions to the contrary. Dominant language ideologies and linguistic hegemony have greatly shaped both socialized and institutional discourse in English and have worked together to help commodify the idea of upward mobility and success for anyone and everyone who "buys-in" to learning English, reflecting neoliberal selling points that are often taken for granted as natural realities. This has resulted in a pervasive maintenance of global social hierarchies despite the fact that the field regularly promotes and markets egalitarian efforts. This critical essay draws upon contemporary research and realities within the field of TESOL to examine the current gap that exists between where the field says it is versus the neoliberal inequalities it inadvertently promotes and maintains. It argues for more deliberate and critical analysis on how these ideological systems have shaped and continue to inform the field as we know it, and how it will be impossible for TESOL to truly serve in the equitable and just capacities in which it strives to place itself without more critical reflection leading to actual and meaningful change.
\end{abstract}

Keywords: TESOL, English language education, language education, neoliberalism, ESL, EFL 


\section{THE NEBRASKA EDUCATOR, VOLUME 6}

White supremacist and colonized ideologies in the field of teaching English to speakers of other languages (TESOL) have existed and informed the profession long before its formal organization, something with which the international TESOL community is really beginning to grapple. Dominant language ideologies and linguistic hegemony have greatly shaped both socialized and institutional discourse in English and have worked together to help commodify the idea of upward mobility and success for anyone and everyone who "buys-in" to learning English, reflecting neoliberal selling points that are often taken for granted as natural realities. It is primarily those who are within the circle (namely White native speakers of English) and who follow the rules of the standardized version of the dominant discourse, however, that truly ever benefit in the manner marketed and sold world over. English language ideologies, and in turn the social and institutional systems that they inform and replicate, reflect the Western capitalistic values contributing to pervasive neoliberal social injustice that must be critically evaluated and challenged for the field of TESOL to meaningfully move forward.

Institutional settings within the English-dominant and capitalistic discourse system repeatedly expose and maintain social inequalities, particularly affecting those who do not fully participate in them. Global capitalism places value in efficiency, progress, increased wealth and happiness for most, with the individual as the basis of society and equal rights granted to all individual members. This egalitarian aspect, however, at the same time denies that very equality, freedom of expression, and individuality to anyone deemed to be outside of the system, a principle that aids in subjugation, discrimination, and "othering" (Bonvillian, 2020; Scollon, Scollon, and Jones, 2012). A capitalistic system inherently requires inequality-much of which stems from racism--to function and grow and has always been informed by the practice of clearly identifying the circles in which equality applies as well as to whom it is granted. In this regard, 


\section{THE NEBRASKA EDUCATOR, VOLUME 6}

the languages of those on the outside of these circles also become othered while languages of power and prestige, such as English, become the "legitimate" languages for progress. In the field of English language education, a neoliberal market is fueled by rhetoric such as "accent reduction," "business English," and "English for academic purposes" that keeps it in a loop of linguistic imperialism hypostatizing white supremacist systems and ideologies (Gerald, 2020). Like the narratives that surround capitalism and neoliberal ventures, pervasive myths of the global spread of the English language are packaged as natural, neutral, and beneficial when they should instead be viewed as cultural constructs produced, promoted, and maintained by colonialism (Pennycook, 2007). There is nothing natural about a language's power; it must be sold and packaged as such through education.

Institutional systems built on inequity work vociferously to maintain that very inequity. A capitalist-bred dominance and control of knowledge by the Global North over the rest of the world perpetuates the hegemony maintained by colonized languages such as English and ensures that the goal of language education is not to "gain a deeper understanding of and empathy for the worldview of speakers of other languages" (Kramsch, 2019, p. 60) but to capitalize on its neocolonial benefits. These benefits, including greed, inequality, and indifference to local and global environments, are "extraordinarily resistant to change" (Klees, 2020, p. 17) and now make up global discourses that "have become the new common sense" (12) and have dominated worldwide agendas for so long. Commodification of the English language as a tangible and individualized asset and the perceived success that comes with it has resulted in English language programs needing to conform to and run off of a business model prioritizing client satisfaction for profitability and sustainability (Litzenberg, 2020). This has also presented a 


\section{THE NEBRASKA EDUCATOR, VOLUME 6}

neoliberal framing of English global educational models worldwide, packaging itself as a crucial component to anyone wanting upward economic and social mobility.

Although the United States has a history of immigration and multiculturalism itself, the loss of immigrant (and Native) mother tongues stemming from linguistic hegemony that recognized "standard American" English as being the authoritative and only path to the innerAmerican circle and ensuring, through its institutions, that it was and still is the dominant discourse (Bonvillian, 2020). Those who "choose" not to partake in this ideology essentially face discrimination that could lead to social and economic disadvantages. Even within the Englishspeaking circle, certain varieties and speakers, namely those that are regarded as "standard" and "White," are given the most authority and stand to receive the most capitalistic gain, namely those who are fluent in the standard variety and look the "part" to use it. This can especially be seen globally in the field of TESOL through concepts such as nativespeakerism, Whiteness (including white supremacy, white normativity, and racism), and native speaker fallacies that inform English language teacher hiring practices and English language educational materials around the world (Gerald, 2020). In this sense, linguistic hegemony is preserved and disseminated through "both the use of the standard [language] and the recognition of its prestige and authority, even by those who don't use it" (Bonvillian, 2020, p. 415). The Colonized systems from which English language education took root has ensured that, despite the best of intentions from many educators, inner and outer circles of English language speakers and learners still exist, despite what is being sold to them.

When it comes to educating ESOL students of color in a neoliberal globalized world, racial biases and inequalities are reproduced in everything from teaching materials and teacher employment to practices and preferences in teaching and learning. The preoccupation with 


\section{THE NEBRASKA EDUCATOR, VOLUME 6}

curriculum in the U.S. promoting "white studies" or rather, "white male studies," is only one part of the civilizational racism that dominates education and that serves to undermine global local knowledges and even replace them altogether, leading to colonial exclusion of knowledge that strives to contain academic knowledge to a Westernized pool (Kubota, 2019). In applied linguistics, this is reproduced through dominant discourse practices and ideas about linguistic legitimacy.

This colonial exclusion of knowledge, however, has dominated the world through systems of slavery, capitalism, and neoliberalism that trickle down into every social, cultural, educational, and economic aspect. A neoliberal approach to child rearing, for example, sees children as investments into which parents need to pour time, money, and resources in order to maximize the greatest return (Gee, 2002). Those who hold the dominant narrative or powerful discourse have the say on what those investments actually look like and whose investments actually benefit from the system once those children become adults, again perpetuating the social inequalities that a truly egalitarian system should supposedly work to dismantle. Learning English then has become the ultimate investment in which those with the means can invest and through which those without the means face disenfranchisement. Stakeholders in the business of English language education--textbook writers, curriculum developers, and the like--profit from reproducing this ideology and packaging "great Western deeds and thoughts" while abstaining from critically evaluating or addressing its savage past (Pennycook, 2007; Macedo, 2019). As a colonized foreign/second language, English language instruction often overly relies on grammar and superficial communication skills, and educators can easily "fall prey to a paternalistic zeal to save their students from their non-colonial language-speaker's status" (Macedo, 2019, p. 15) 


\section{THE NEBRASKA EDUCATOR, VOLUME 6}

much in the same way that former colonists attempted to inoculate convictions of inferiority into the physical, spiritual, cultural, and linguistic beliefs of the conquered people.

When languages, dialects, and accents are "othered" within a Utilitarian and neoliberal system, injustices against those speakers often become the natural order of things and are replicated and maintained throughout the institutions of the dominant discourse. After neoliberalism gets involved, that "natural order" then gets packaged, marketed, and sold to those willing to pay for it, which, in contemporary times, is done so through required English language courses, expensive English language tutoring, high stakes proficiency exams like the TOEFL or IELTS, and Intensive English Program enrollment. The lifelong process of human socialization takes place through and in relation to institutions, such as education, healthcare, and law, acculturating those who both choose or are denied participation (Scollon, Scollon, and Jones, 2012). Traditionally in a capitalist system, education itself is seen as necessary to the productivity and employability of an individual. The neoliberal "human capital discourse" reflects this as well, almost completely ignoring education's value outside of skills for work (Klees, 2020, p. 11). Under this system, learning English is packaged and sold as the ultimate educational tool one needs for success in life (also known in neoliberal terms as the workforce). While the field of TESOL works to "prepare for success" those who are often systemically oppressed--or at least the full benefits--of being within the dominant circle, the current Black Lives Matter civil rights movement has highlighted just how many are truly left out of it and are actually harmed by it altogether. Bonvillian (2020) has updated her own text on language, culture, and communication to address it directly, stating that institutional portrayals of the dominant society as tolerant and acceptable "provide the context to criticize people who point out racism and other forms of discrimination... [ensuring that] it is the antiracist positions that 


\section{THE NEBRASKA EDUCATOR, VOLUME 6}

can be described as being extreme" (445). This pushback on the dominant discourse, through means such as protesting and trangressive texts (Scollon, Scollon, and Jones, 2012), becomes a major (and for many in power, an uncomfortable) pushback on Utilitarianism/capitalism and the white supremacist and racist ideologies that both created it and are necessary for its survival in the current state.

Although there are many English language professionals who are concerned with addressing these ideologies, "there is significantly less work done unpacking whiteness and how it has always served as the driving force behind ELT" (Gerald, 45), which is actually detrimental to the very population TESOL claims to serve. Privileges of Whiteness and nativerspeaker-like status are the promised prizes of acceptance and success sold in a neoliberal market, but are actually grounded in unattainable realities. The prestige that is often afforded to white native English speakers such as English language teaching positions (with or without teaching experience) ensures that nonnative English-speaking English language teachers, who constitute the majority of the world's English teachers, often find themselves contending both socially and professionally with the perfectly-situated monolingual/monocultural native speaker abstraction (Kramsch, 1998). This results in global hiring practices that favor Whiteness and nativism over teaching experience and local knowledge of educational and cultural values.

How can those involved in English language education challenge these systems and ideologies in a way that confronts their Capitalist histories and neoliberal realities in an effort to decolonize the field? We first need to look at the packaged promises of equality and advancement through English that are currently being sold through global and Westernized capitalism to educators and consumers all over the world. The field of TESOL, and in turn systems, policies, and practices of English language education, has continued to maintain the 
THE NEBRASKA EDUCATOR, VOLUME 6

"good-deeds" aspect of the job rather than "considering the way our field centers and values whiteness above all else, even to the point that we are willing to begrudgingly accept forms of discrimination" (Gerald, 2020, p. 47) through language learning materials, teacher-hiring practices, and gatekeepers of published knowledge. Utilitarian discourses and resulting neoliberal practices to English language education must be recognized for what they are and evaluated as to who they truly benefit.

Becoming (and staying) critically aware of our own teaching and research practices through reflection and critical scholarship offer educators and researchers strategies to help decolonize the field. ELT educators need to do the work of educating themselves on racial identity, race and language scholarship, and interdisciplinary literature so that they're better equipped to both understand the need for change and work towards meaningful action to challenge and bring about those changes in the field of English language education (Kramsch, 2019; Kubota, 2019). In order to de-center Whiteness and redistribute active voices and power in the field, journals and conferences need to include more non-White and non-native Englishspeakers. These individuals should also hold prominent seats on their respective boards and commissions and their voices, opinions, and experiences prioritized. Additionally, organizations such as TESOL and educational institutions need to be committed to moving forward at the faster pace of those seeking meaningful change instead of merely keeping the slow (and often immobile) pace of those most resistant to it. Merely, forming diversity committees and writing mission statements only serve to shield any discomfort that would come from challenging and actually changing the status quo.

ELT program curricula should focus on frameworks such as Critical Race Theory (CRT) in order to challenge the "good-deeds" approach and encourage critical reflection of the 


\section{THE NEBRASKA EDUCATOR, VOLUME 6}

Whiteness pervasive within the field (Macedo, 2019; Gerald, 2020). Practices of anti-racism such as prioritizing the agency of subjugated and minoritized people, making a commitment to uncover and promote their positioning, and validating worldviews and traditions of knowledge that challenge Euro-centric thinking can be effective in challenging the Westernized and colonial exclusion of knowledge. Scholars of both racial majority and minority groups should be committed to recognizing and challenging the entrenched status quo of racial and gender-based hierarchies and discourses in academia. It is only then that we can begin to untangle and unwind the epistemological, institutional, and individual racism that guides and informs so much of our work and practice. The field of TESOL and the entities under its umbrella cannot

Western capitalistic values that have given shape to contemporary neoliberal ideologies have, for too long now, greatly influenced the field of TESOL as a whole, essentially working to continue the cycle of injustice and inequality despite intentions to the contrary. Without more deliberate and critical analysis on how these discourse and ideological systems have shaped and continue to inform the field as we know it, it will be impossible for the field to truly serve in the equitable and just capacities in which it strives to place itself. The Black Lives Matter civil rights protests of 2020 are currently forcing many institutions operating within a Utilitarian discourse system to reckon with the colonized, racist, and neoliberal systems from which they grew. They have reminded us, once again, that these issues of inequality are layered under the repeated callouses of history, and we won't be able to dismantle current problems and move forward without a hard look at where we came from and how we got here. The "natural truths" about hard work and English language learning for upward mobility need to be recognized for the mythical and marketed neoliberal selling points that they truly are. As English language education and the field of TESOL itself has both benefited from and helped to perpetuate this 


\section{THE NEBRASKA EDUCATOR, VOLUME 6}

ideological marketing on a massive global scale, it is going to take quite a bit of active disruption to push the field and our practice forward into a place that truly can benefit and serve all equally. 
THE NEBRASKA EDUCATOR, VOLUME 6

\section{References}

Agar, M. (1996). Language shock: Understanding the culture of conversation.

Bonvillain, N. (2020). Language and institutional encounters. In Language, culture, and communication: The meaning of messages. Lanham, MD: Rowman \& Littlefield. pp. $354-388$

Gee, J. P. (2002). Millennials and Bobos, Blue's Clues and Sesame Street: A story for our times. Adolescents and literacies in a digital world, 51-67.

Gerald, J. (2020). Worth the risk: Towards decentering Whiteness in English language teaching. BC TEAL, 5(1). https://ojso.library.ubc.ca/index.php/BCTJ/article/view/345

Klees, S. J. (2020). Beyond neoliberalism: Reflections on capitalism and education. Policy Futures in Education, 18(1), 9-29.

Kramsch, C. (1998). "Language and culture.” Oxford University Press

Kramsch, C. (2019). Between globalization and decolonization. Decolonizing foreign language education: The misteaching of English and other imperial languages, 50-73.

Kubota, R. (2019). Confronting epistemological racism, decolonizing scholarly knowledge: Race and gender in applied linguistics. Applied Linguistics, amz033. https://doi.org/10.1093/applin/amz033

Litzenberg, J. (2020). "If I don't do it, somebody else will”: Covert neoliberal policy discourses in the decision-making processes of an intensive English program. TESOL Quarterly, n/a(n/a). https://doi.org/10.1002/tesq.563

Macedo, D. (2019). Rupturing the yoke of colonialism in foreign language education. Decolonizing Foreign Language Education. The misteaching of English and other imperial languages, 1-49. 


\section{THE NEBRASKA EDUCATOR, VOLUME 6}

Pennycook, A. (2007). The myth of English as an international language. Disinventing and reconstituting languages, 62, 90-115.

Scollon, R., Scollon, S. W., \& Jones, R. H. (2011). Intercultural communication: A discourse approach. John Wiley \& Sons. 


\title{
The Effects of Self-Regulated Strategy Development on Students with Emotional/Behavioral Disorders: A Literature Review
}

\author{
Danika Lang \\ Department of Special Education and Communication Disorders \\ University of Nebraska-Lincoln
}

\begin{abstract}
Students identified with or at risk for emotional/behavioral disorders (EBD) face a number of challenges, both academic and behavioral (Trout et al., 2003). Individuals in this disability category especially struggle due to their challenges with self-regulation skills. These difficulties make it strenuous for students with EBD to regulate their thoughts, feelings, actions, and environments that may serve as distractions when attempting to attend to key learning tasks, including written expression. Self-regulated strategy development (SRSD) is a general framework of intervention designed to guide students through the complex process of writing while embedding necessary strategy instruction in self-monitoring, self-instruction, goal setting, and self-reinforcement (Harris \& Graham, 1996). In this literature review, I examine ten studies of the efficacy of SRSD strategy instruction for students identified with or at risk of EBD. Based on the evidence provided by these studies, I venture to make the claim that SRSD is a highly effective writing intervention for students with EBD across grade levels, writing genres, namely narrative, informative, and persuasive, and educational settings such as public schools, specialized private schools, and residential treatment facilities (RTFs).
\end{abstract}

Keywords: emotional/behavioral disorders, self-regulated strategy development, writing 
THE NEBRASKA EDUCATOR, VOLUME 6

\section{Defining Self-Regulated Strategy Development}

One of the primary challenges of students identified with or at risk of emotional/behavioral disorders (EBD) is self-regulation. This population of students has difficulty monitoring their thoughts, feelings, and actions as well as regulating their physical environments (Little et al., 2010). These challenges with self-regulation skills may typically present themselves in one of two ways. Students with EBD may exhibit patterns of either externalizing or internalizing behavior. Students with externalizing behavior patterns tend to be more readily diagnosed than their peers with internalizing behavior patterns because their disability usually manifests itself as outward displays of disruptive behavior or aggression. Students with internalizing behavior patterns, on the other hand, often struggle with more internal difficulties such as anxiety and depression (Gresham et al., 1999), leading this subgroup of students with EBD to more frequently remain undiagnosed.

Self-regulated strategy development (SRSD) is a general framework of intervention designed to guide students through the complex process of writing. As reflected in the name, strategies in self-regulatory procedures such as self-monitoring, self-instruction, and selfreinforcement are embedded within a broader context of writing composition instruction (Harris \& Graham, 1996). Students are taught a general planning strategy that enables them to select a writing topic, organize their thought process by taking notes in a graphic organizer, and then expand upon their notes to fully develop their ideas.

The general planning strategy is taught first with explicit modeling, then guided practice, and eventually independent practice so students can generalize the strategy to different writing genres (What Works Clearinghouse, 2017). The general planning strategy is accompanied by genre-specific strategy instruction that guides students through the process of composing 


\section{THE NEBRASKA EDUCATOR, VOLUME 6}

different types of writing. This design allows students to grow in their capabilities to express themselves through a variety of writing genres such as informative, narrative, and persuasive writing while at the same time strengthening their capacity to independently monitor their progress as they write. SRSD provides embedded instruction in self-regulation skills so that students can eventually implement the strategies without teacher guidance. This particular intervention framework may be particularly well-suited for individuals with EBD because it targets their inability to self-regulate while providing supplementary support in a fundamental academic skill that they often struggle with, namely, written expression.

Originally designed as an intervention for students with learning disabilities and struggling writers, SRSD is now recognized as an evidence-based practice for improving the composition and self-regulation skills for a broad range of students, including typicallydeveloping learners (Graham et al., 2012). In this review of the literature, I make the case that self-regulated strategy development is an effective academic intervention for students identified with or at risk of EBD. In addition, I provide evidence that the benefits of the intervention for this population remain fairly consistent across several writing genres, including informative, persuasive, and narrative, both elementary and secondary grade levels, and different educational settings including typical public schools, private facilities specifically designed to teach students with EBD, and residential treatment facilities (RTFs).

Regardless of the writing genre being taught, SRSD is generally made up of six stages: 1.) Develop background knowledge, 2.) Discuss it, 3.) Model it, 4.) Memorize it, 5.) Support it, and 6.) Independent performance (Harris \& Graham, 1996). This process makes up the general framework of the intervention and allows it to be applied flexibly not only to writing instruction but to other academic skills as well (What Works Clearinghouse, 2017). As instructors and 


\section{THE NEBRASKA EDUCATOR, VOLUME 6}

students progress through each stage, scaffolds are put in place to support acquisition of the particular strategy mnemonics as well as the application of these strategies to their own writing. These stages are designed to provide explicit writing lessons to students, with the primary responsibility of instruction beginning initially with the teacher and gradually transferring over to the student as the strategy is internalized. Additionally, supports such as graphic organizers, transition word lists, and examples of self-statements to provide positive reinforcement are progressively faded. The purpose of this is to encourage students to regulate the writing process themselves without the help of external prompts.

\section{SRSD for Students with Emotional/Behavioral Disorders}

In terms of studying the efficacy of SRSD for students with emotional and/or behavioral concerns, the literature generally divides this population into several groups. These include students who have been identified with EBD, those who present significant levels of internalizing or externalizing behaviors and are therefore at risk, or a mixture of students identified and at risk. Seven of the ten studies covered in this literature review examined the outcomes of SRSD for students who have been identified with EBD (Ennis et al., 2015; Mastropieri et al., 2009; Mastropieri et al., 2014; Ennis, 2016; Garwood et al., 2019; Adkins \& Gavins, 2012; Ennis, Jolivette, \& Boden, 2013). All seven studies demonstrated significant gains in writing achievement for students with EBD, specifically in the areas of total number of essay elements included (Ennis et al., 2015; Mastropieri et al., 2009; Ennis, 2016; Garwood et al., 2019; Adkins \& Gavins, 2012; Ennis, Jolivette, \& Boden, 2013), holistic quality (Ennis et al., 2015; Mastropieri et al., 2009; Mastropieri et al., 2014; Ennis, 2016; Garwood et al., 2019; Adkins \& Gavins, 2012; Ennis, Jolivette \& Boden, 2013), and overall length (Mastropieri et al., 
THE NEBRASKA EDUCATOR, VOLUME 6

2014; Ennis, 2016; Garwood et al., 2019; Adkins \& Gavins, 2012; Ennis, Jolivette, \& Boden. 2013).

Two additional studies examined outcomes of SRSD for students with internalizing or externalizing behavior patterns (Little et al., 2010; Lane et al., 2010), while one looked at a mixed sample of students identified and those at risk (Mason \& Shriner, 2008). The sample of mixed participants showed moderate gains in inclusion of essay parts as well as substantial gains in overall quality, total number of words written, and number of transition words used. The gains in quality, length, and transition words remained consistent as students progressed from baseline to post-instruction and maintenance phases of assessment (Mason \& Shriner, 2008). For students identified as at risk, SRSD demonstrated a positive effect for those with both internalizing and externalizing behavior patterns. Both groups of students showed gains in terms of their number of story (Lane et al., 2010) and persuasive elements, respectively (Little et al., 2010).

In terms of design, eight of the ten studies employed either a multiple probe (Little et al., 2010; Lane et al., 2010; Mason \& Shriner, 2008), multiple baseline (Mastropieri et al., 2009), or multiple probes, multiple baseline single-subject design (Mastropieri et al., 2014; Ennis, 2016; Garwood et al., 2019; Adkins \& Gavins, 2012). Although the remaining two studies utilized some variation of group design (Ennis et al., 2015; Ennis, Jolivette, \& Boden, 2013), the effect of the intervention on students both identified or at risk for EBD was a remarkably positive one from baseline to maintenance or pretest to posttest.

These gains in writing achievement also remained fairly consistent when comparing the writing performance of students at the elementary and secondary grade levels. In terms of age range, the studies were evenly divided between students in grades $\mathrm{K}$ through six (Little et al., 2010; Lane et al., 2010; Adkins \& Gavins, 2012; Ennis, Jolivette, \& Boden, 2013; Mason \& 
THE NEBRASKA EDUCATOR, VOLUME 6

Shriner, 2008) and those in grades seven through twelve (Ennis et al., 2015; Mastropieri et al., 2009; Mastropieri et al., 2014; Ennis, 2016; Garwood et al., 2019). In the reviewed studies, elementary school students were taught how to use the POW and TREE (Little et al., 2010; Mason \& Shriner, 2008) and STOP and DARE (Ennis, Jolivette, \& Boden, 2013) strategies of SRSD to guide the composition of their persuasive writing. The overarching purpose of the strategy mnemonics included in SRSD is to provide a salient way for students to ensure that their writing has all the necessary components such as a topic sentence and supporting evidence in a persuasive essay or the main characters and setting for a narrative piece of writing. With the POW and TREE mnemonics, students are equipped with a general planning strategy (POW) where P stands for "Pick my idea," O for "Organize my notes," and W for "Write and say more." TREE is an additional strategy mnemonic that is specifically geared towards the persuasive writing genre. The $\mathrm{T}$ in TREE stands for "Topic sentence" in which the primary argument is stated, R for "Reasons, three or more" to provide supporting evidence for the argument, the first E for "Ending" to make sure the essay has a succinct conclusion, and the second E for "Examine" the writing to make sure all necessary parts were included (Harris et al., 2006).

\section{Effects on Elementary Students}

For the elementary students identified or at risk of EBD, instruction in the POW and TREE strategy mnemonics resulted in an increase in the number of persuasive elements included from baseline to post-instruction. This much was true for students with internalizing behavior patterns in the study conducted by Little et al. (2010). Additionally, students with externalizing behavior patterns (Little et al., 2010) and five of the six students identified with EBD in a study by Mason \& Shriner (2008) showed gains in number of persuasive elements, overall quality, and length of essays assessed in post-instruction and maintenance phases. 
THE NEBRASKA EDUCATOR, VOLUME 6

The STOP and DARE strategy mnemonics take a slightly different approach to the guidance of persuasive writing, with a greater emphasis on the inclusion of counterarguments. The S in STOP stands for "Suspend judgment," T for "Take a side," O for "Organize ideas," and P for "Plan more as you write." The D in DARE stands for "Develop your topic sentence," A for "Add supporting ideas," R for "Reject at least one argument for the other side," and E for "End with a conclusion (Harris et al., 2008). This persuasive writing strategy provides an additional challenge for students to consider the lines of reasoning for an opposite viewpoint and then to provide an effective argument for their own opinion in the face of strong counterarguments. In their study of the impact of the STOP and DARE strategy mnemonics for elementary students with EBD, Ennis, Jolivette, \& Boden (2013) found that participants in the experimental group outperformed those in the control group on measures of the number of persuasive elements included, overall quality, and total words written with post-instruction effect sizes of $1.35,1.06$, and 1.27 , respectively.

For narrative writing (Adkins \& Gavins, 2012; Lane et al., 2010) students were taught to use the POW and WWW, What=2, How=2 strategies of SRSD. The POW mnemonic remains the same and serves as a general planning strategy while WWW What $=2$, How $=2$ is a genrespecific strategy for narrative writing. In using this strategy mnemonic, students are challenged to provide answers to the questions: "Who is the main character?" "When does the story take place?" "Where does the story take place?" "What does the main character do or want to do?" "What happens when the main character tries to achieve their goal?" "How does the story end?" and "How does the main character feel?" (Harris et al., 2008). Following these guidelines reminds students to include all of the key components of narrative writing including characters and setting as well as the essential elements of plot, namely exposition, rising action, climax, 
THE NEBRASKA EDUCATOR, VOLUME 6

falling action, and resolution. Overall, instruction in the POW and WWW, What $=2$, How $=2$ strategy mnemonics resulted in an increased number of story elements included in the narrative writing of students at risk for EBD who demonstrated externalizing behavior patterns (Lane et al., 2010). Additionally, gains were demonstrated in story length as well as quality for four of the five students with internalizing behavior patterns. These increases in number of story elements, length, and overall quality were consistent for elementary students identified with EBD (Adkins \& Gavins, 2012).

\section{Effects on Secondary Students}

When looking at the effects of SRSD on secondary students with EBD, the outcomes are similarly positive. The key difference between studies involving secondary versus elementary students is the genre selected for instruction. Of the reviewed studies, one taught students to summarize informational text (Ennis, 2016) while the other four provided instruction in persuasive writing using the STOP and DARE (Ennis et al., 2015) or the POW and TREE (Garwood et al., 2019; Mastropieri et al., 2009; Mastropieri et al., 2014) strategy mnemonics outlined above. Students were taught to summarize informational text in social studies using the TWA+PLANS SRSD strategy mnemonic. The TWA portion of the strategy provides a framework for organizing ideas while reading informational text, where T stands for "Think before reading," W for "Think while reading," and A for "Think after reading." To complement the reading aspect, the PLANS portion of the strategy targets formulation of a written summary

from the information read. In the PLANS mnemonic, P stands for "Pick goals," L for "List ways to meet goals," A and N for "And make notes," and S for "Sequence notes."

In the study that investigated the effectiveness of this strategy on secondary students' ability to summarize informational text, the authors found that participants increased in number 
THE NEBRASKA EDUCATOR, VOLUME 6

of summary elements, holistic quality, and total words written from baseline to post-instruction (Ennis, 2016). However, due to the small sample size of this study ( $n=3)$ and its lack of replication, these findings must be interpreted with caution. In order to more clearly show a causal relationship between SRSD instruction and gains in informational text writing for this population, additional generalization to other groups of students with EBD is required. In terms of the effectiveness of the POW and TREE strategies on the persuasive writing of secondary students with EBD, there was only a uniform finding of increased overall quality across the three included studies (Garwood et al., 2019; Mastropieri et al., 2009; Mastropieri et al., 2014). Additionally, Garwood et al. (2019) and Mastropieri et al. (2009) found an increase in number of persuasive elements included. These conclusions are also limited due to a total sample size of 35 students across the three studies examined in this literature review. Finally, for students instructed in the STOP and DARE persuasive writing strategies, the authors found statistically significant gains in number of persuasive elements, overall quality, and number of correct word sequences (CWS) from pretest to posttest. These gains in persuasive writing measures generalized to gains in their performance on the Writing Fluency and Writing Samples subtests of the Woodcock-Johnson Tests of Achievement, Third Edition, with moderate and large descriptive effect sizes, respectively (Ennis et al., 2015).

\section{Effects for Different Writing Genres}

In a breakdown of studies by genre, the effects of SRSD strategy instruction are similarly positive for students with EBD, although there were substantially more studies across grade levels and educational settings that provided evidence of the positive effects of persuasive writing instruction $(n=7)$. With a total sample size of 114 participants across seven studies, five of which were single-subject design studies, more credence may be afforded to the findings 
THE NEBRASKA EDUCATOR, VOLUME 6

surrounding these strategies (Little et al., 2010; Mason \& Shriner, 2008; Ennis, Jolivette, \& Boden, 2013; Garwood et al., 2019; Ennis et al., 2015; Mastropieri et al., 2009; Mastropieri et al., 2014). For participants in all but one of the seven studies that taught persuasive writing strategies (Mastropieri et al., 2014), those who received the treatment condition of SRSD demonstrated gains in number of persuasive elements included from baseline to post-instruction. Further, all participants with the exception of those exhibiting internalizing behavior patterns in the Little et al. study (2010) showed improvement in overall quality from baseline scores, with some or all of the participants in four of the seven studies indicating additional gains in terms of essay length (Little et al., 2010; Mason \& Shriner, 2008; Ennis, Jolivette, \& Boden, 2013; Garwood et al., 2019).

The three remaining studies included analyses of the effectiveness of narrative $(n=2)$ and informative $(n=1)$ writing strategies using the framework of SRSD with total sample sizes of three, 13, and three, respectively (Adkins \& Gavins, 2012; Lane et al., 2010; Ennis, 2016). For the studies that examined outcomes of narrative writing instruction, all students demonstrated gains in number of story elements included. Four of the five students who exhibited internalizing behavior patterns in the Lane et al. (2010) study demonstrated additional gains in essay length and overall quality. This is in contrast to the findings of Little et al. (2010) where students with externalizing behavior patterns exhibited a greater number of gains in terms of all considered outcome measures. This discrepancy may be due to differences in writing genre or age of students as only elementary students were evaluated in terms of narrative writing strategy instruction (Adkins \& Gavins, 2012; Lane et al., 2010). Conversely, only secondary students were evaluated in terms of informative writing strategy instruction, where the author found gains in number of summary elements included as well as overall quality and total words written 


\section{THE NEBRASKA EDUCATOR, VOLUME 6}

(TWW) (Ennis, 2016). However, the findings from studies that included narrative or informative writing strategy instruction must be interpreted with caution because of very small sample sizes and a lack of replication with this population of students.

The effects of SRSD on students with EBD have thus far been analyzed based on grade level and writing genre. These effects can also be considered in terms of the educational setting where instruction took place. In the studies examined for this literature review, students received intervention in one of three settings: a typical public school, a special school for students with EBD, or a residential treatment facility (RTF). When aggregating the findings across these three settings, there are some small differences in the effects of treatment. For example, some or all of the students educated in public school settings in each study demonstrated increases in overall essay quality (Little et al., 2010; Mastropieri et al. 2014; Lane et al., 2010; Adkins \& Gavins, 2012; Mason \& Shriner, 2008). The majority of these students were at the elementary level, with only one of the five studies examining outcomes for secondary students in this setting (Mastropieri et al., 2014).

Further, this group included students both identified for and at risk of EBD. In comparison, students who received intervention in RTFs displayed gains in both quality and the number of included elements, either persuasive (Ennis et al., 2015; Ennis, Jolivette, \& Boden, 2013; Garwood et al., 2019) or informative/summary (Ennis, 2016). These added benefits may be explained by the difference in diagnosis, given that all students educated in RTFs were identified as having EBD as a prerequisite condition of entering the facility. The impact of SRSD instruction on students served in a special school was only examined in one of the ten studies (Mastropieri et al., 2009). Therefore, any conclusions drawn from it are limited by small sample size $(n=12)$ and a lack of replication for students taught in this particular educational setting. To 
THE NEBRASKA EDUCATOR, VOLUME 6

strengthen the validity of the current findings of this study, further research is necessary on the impact of SRSD instruction for students with EBD educated in special schools.

\section{Positive Behavior Interventions and Supports}

Finally, it is noteworthy to comment on the influence of Positive Behavior Interventions and Supports (PBIS) programs implemented within schools in addition to SRSD intervention. PBIS programs are based on a three-tiered model of supports, with each level providing an increasing amount of individualized support. At the first level, all students receive direct instruction in school-wide behavioral expectations such as being safe, responsible, and respectful (Sugai et al., 2000). Teachers, administrators, and other school personnel typically promote adherence to these expectations by rewarding exemplary behavior with positive reinforcement in the form of tokens or tickets. These are usually given in conjunction with behavior-specific praise about how the student is following school expectations. The tokens or tickets may then be used to "purchase" rewards such as computer time, extra recess, snacks, or other small prizes.

Data is collected on the implementation of these behavioral supports, and students who appear unresponsive to the primary tier of PBIS may receive secondary or tertiary supports. These supports include small group or potentially individualized instruction in social skills, anger management, or positive coping strategies. Progress is continuously monitored by way of direct observation and curriculum-based measurement, and students continue to receive behavioral supports according to their level of need in order to prevent or remediate possible internalizing or externalizing behavior patterns that may indicate potential risk for EBD (Sugai et al., 2000). In seven of the ten studies, participating schools had existing PBIS programs in place at the time of intervention (Little et al., 2010; Ennis et al., 2015; Mastropieri et al., 2009; Mastropieri et al., 2014; Lane et al., 2010; Ennis, 2016; Ennis, Jolivette, \& Boden, 2013). For the 


\section{THE NEBRASKA EDUCATOR, VOLUME 6}

remaining three studies (Garwood et al., 2019; Adkins \& Gavins, 2012; Mason \& Shriner, 2008), PBIS may have been implemented but this was not explicitly stated in the research findings. As these behavioral interventions were often delivered alongside specific strategy instruction in writing, the inclusion of such supports may account for some of the positive academic outcomes of SRSD in these cases. By establishing clear expectations and actively rewarding prosocial behavior, PBIS may have worked in conjunction with SRSD instruction to create an environment that was more conducive to learning for this population of students. However, without explicitly exploring the impact of SRSD on behavioral outcomes or controlling for the presence of an intervention with both academic and behavioral components, it is beyond the scope of this review to state, with any degree of certainty, that SRSD was responsible for gains in selfregulation skills. In order to make that claim, the included studies would need to have separate measures of specific behavioral outcomes in addition to the written expression outcome measures.

In summary, for the group of studies outlined in this review, self-regulated strategy development has proven to be an effective writing intervention for students at risk for or identified with emotional/behavioral disorders. The benefits of the intervention for this population remain fairly positive and consistent across several writing genres, including informative, persuasive, and narrative, at both elementary and secondary grade levels, and in different educational settings including typical public schools, private facilities specifically designed to teach students with EBD, and residential treatment facilities (RTFs). To strengthen these results, nine of the ten studies reported favorable ratings in terms of the social validity of the intervention by students and teachers (Adkins \& Gavins, 2012; Ennis, Jolivette, \& Boden, 2013; Ennis et al., 2015; Garwood et al., 2019; Lane et al., 2010; Little et al., 2010; Mason \& 


\section{THE NEBRASKA EDUCATOR, VOLUME 6}

Shriner, 2008; Mastropieri et al, 2009; Mastropieri et al., 2014). The only study that did not report favorable ratings of social validity at baseline and post-assessment (Ennis, 2016) showed no record of including such measures in the study design. 
THE NEBRASKA EDUCATOR, VOLUME 6

\section{References}

Adkins, M. H., \& Gavins, M. V. (2012). Self-regulated strategy development and generalization instruction: Effects on story writing and personal narratives among students with severe emotional and behavioral disorders. Exceptionality, 20(4), 235-249. https://doi.org/10.1080/09362835.2012.724625.

Ennis, R. P. (2016). Using self-regulated strategy development to help high school students with EBD summarize informational text in social studies. Education and Treatment of Children, 39(4), 545-568. https://doi:10.1353/etc.2016.0024.

Ennis, R., Jolivette, K., \& Boden, L. (2013). STOP and DARE: Self-regulated strategy development for persuasive writing with elementary students with E/BD in a residential facility. Education and Treatment of Children, 81-99. Retrieved April 21, 2020, from www.jstor.org/stable/42900213.

Ennis, R., Jolivette, K., Terry, N., Fredrick, L., \& Alberto, P. (2015). Classwide teacher implementation of self-regulated strategy development for writing with students with E/BD in a residential facility. Journal of Behavioral Education, 24(1), 88-111. https://doi.org/10.1007/s10864-014-9207-7.

Garwood, J., Werts, M., Mason, L., Harris, B., Austin, M., Ciullo, S., ... Shin, M. (2019). Improving persuasive science writing for secondary students with emotional and behavioral disorders educated in residential treatment facilities. Behavioral Disorders, 44(4), 227-240. https://doi.org/10.1177/0198742918809341.

Graham, S., McKeown, D., Kiuhara, S., \& Harris, K. R. (2012). A meta-analysis of writing instruction for students in the elementary grades. Journal of educational psychology, 104(4), 879. https://doi.org.libproxy.unl.edu/10.1037/a0029185. 


\section{THE NEBRASKA EDUCATOR, VOLUME 6}

Gresham, F. M., Lane, K. L., MacMillan, D.L., \& Bocian, K. M. (1999). Social and academic profiles of externalizing and internalizing groups: Risk factors for emotional and behavioral disorders. Behavioral Disorders,24,231-246. https://doi.org/10.1177/019874299902400303

Harris, K., \& Graham, S. (1996). Making the writing process work: Strategies for composition and self-regulation (2nd ed.). Cambridge: Brookline Books.

Harris, K. R., Graham, S., \& Mason, L. H. (2006). Improving the writing performance, knowledge, and motivation of struggling writers in second grade: The effects of selfregulated strategy development. American Educational Research Journal, 42, 295-340. https://doi.org/10.3102/00028312043002295.

Harris, K. R., Graham, S., Mason, L., \& Friedlander, B. (2008). Powerful writing strategies for all students. Baltimore: Brookes.

Lane, K., Graham, S., Harris, K., Little, M., Sandmel, K., \& Brindle, M. (2010). Story writing: The effects of self-regulated strategy development for second-grade students with writing and behavioral difficulties. The Journal of Special Education, 44(2), 107128. https://doi.org/10.1177/0022466908331044.

What Works Clearinghouse (2017). Self-Regulated Strategy Development. What Works Clearinghouse Intervention Report. Retrieved July 19, 2021, from https://ies.ed.gov/ncee/wwc/interventionreport/680.

Little, M., Lane, K., Harris, K., Graham, S., Story, M., \& Sandmel, K. (2010). Selfregulated strategies development for persuasive writing in tandem with schoolwide positive behavioral support: Effects for second-grade students with behavioral and 


\section{THE NEBRASKA EDUCATOR, VOLUME 6}

writing difficulties. Behavioral Disorders, 35(2), 157 -179.

https://doi.org/10.1177/019874291003500206.

Mason, L. H., \& Shriner, J. G. (2008). Self-regulated strategy development instruction for writing an opinion essay: Effects for six students with emotional/behavior disorders. Reading and Writing, 21(1-2), 71-93. https://doi.org/10.1007/s11145-0079065-y.

Mastropieri, M. A., Scruggs, T. E., Cerar, N. I., Allen-Bronaugh, D., Thompson, C., Guckert, M., ... \& Cuenca-Sanchez, Y. (2014). Fluent persuasive writing with counterarguments for students with emotional disturbance. The Journal of Special Education, 48(1), 17-31. https://doi.org/10.1177/0022466912440456.

Mastropieri, M., Scruggs, T., Mills, S., Cerar, N., Cuenca-Sanchez, Y., Allen-Bronaugh, D., ... Regan, K. (2009). Persuading students with emotional disabilities to write fluently. Behavioral Disorders, 35(1), 19-40.

https://doi.org/10.1177/019874290903500102.

Sugai, G., Horner, R. H., Dunlap, G., Hieneman, M., Lewis, T. J., Nelson, C. M., ... Ruef, M. (2000). Applying positive behavior support and functional behavioral assessment in schools. Journal of Positive Behavior Interventions, 2(3), 131-143. https://doi.org/10.1177/109830070000200302. 


\title{
Assessment and Accommodations for English Language Learners: A Literature Review
}

\author{
Heidi Jo Bartlett \\ Department of Teaching, Learning, and Teacher Education \\ University of Nebraska-Lincoln
}

\begin{abstract}
While research in how English language learners (ELLs) use assessment accommodations is lacking, there are some general conclusions that one can draw. First, teachers must know their students' abilities. This includes knowledge of their English proficiency, knowledge of their first language skills, especially as it pertains to literacy skills, and knowledge of their content area understanding. If teachers are aware of areas of weakness in students' assessments, they should work to compensate for them by either changing their instruction or providing assessment accommodations. Second, it is important for teachers to recognize the various types of assessment accommodations that are available in their teaching situation. More vitally, teachers must be able to assign assessment accommodations appropriately to their students and know differences between ELL accommodations and Special Education accommodations. If accommodations are applied without regard to individual student differences, it can cause more harm to the assessment procedures and evaluations than benefits. Finally, there is a difference between high-stakes standardized tests and classroom assessments. While content-area teachers may have more freedom in modifying their classroom assessments, standardized tests are usually more constrained in their testing format and accommodations they are allowed to offer. Identifying gaps in research related to assessments for ELLs will benefit the field as content-area teachers continue to increase their work with students of diverse backgrounds.
\end{abstract}

Keywords: English language learner, ELL, content area, assessment, accommodations, standardized assessments 
THE NEBRASKA EDUCATOR, VOLUME 6

Starting with the 2001 legislation of No Child Left Behind, policies determining how schools and states were required to complete their annual testing for English language learner (ELL) students changed. With these changes, ELL students had to be tested annually for their English language proficiency and progress, and this population now had to be included in the process of state standardized testing (Office of Elementary and Secondary Education: U.S. Department of Education, 2002). This requirement made states' Departments of Education determine which types of accommodations would provide their ELL students with the support to accurately test them on their content knowledge.

Updated federal policy requirements from the 2015 Every Student Succeeds Act (ESSA) expanded on school responsibilities regarding testing, data collection, professional development, and community engagement. These updated policies continue to require standardized assessment and allow specific accommodations for ELL students (US Department of Education, 2016). Additionally, according to the Supreme Court decision Lau vs. Nichols in 1974, public schools are required to provide ELLs equal access to education and the accommodations necessary to learn both English and content subjects (Office for Civil Rights: US Department of Education, 2018).

Despite the fact that these policies have been in place for nearly 20 years, there is still limited research on which types of accommodations are the most useful for different types of ELLs, and on which types of accommodations are provided by content area teachers in their daily classrooms. In order for our ELL students to be academically successful, it needs to be determined what aspects of language (either form or function) is part of the assessments. Furthermore, how is that language either taught to students or modified to be more accessible to ELLs, and are there certain types of modifications that are more beneficial to different groups of 


\section{THE NEBRASKA EDUCATOR, VOLUME 6}

ELL students? While there are still vast areas open to more research in this field, the ideas laid out below were generally consistent with other research in the field.

This literature review explores what content area teachers are doing in their classrooms to ensure the academic success of their ELLs, especially in regard to assessments. Specifically, the focus is on differences between content areas and in the types of assessments (classroom-focused and high-stakes). Most state-mandated accommodations were uniformly available to all ELLs regardless of age. This article discusses results in the content areas of reading, writing, mathematics, and science. These results will be followed by variations in language assessments and implications for teaching strategies, and then differences between classroom and standardized assessments, inquiry-based assessments, and how test translations affect student assessment.

\section{Content Areas}

\section{Reading}

"One important challenge that we face in education is to identify which core set of language skills students know or do not know" (Uccelli \& Phillips Galloway, 2017, p. 397). This problem of identifying students' prior knowledge and how to test content skills rather than English ability runs throughout much research in working with English Language Learners. One of the most basic skills and content areas found in all U.S. classrooms is reading. As a literacy skill, having greater vocabulary recognition and knowledge helps students to become more fluent readers.

In their study, Dougherty Stahl and Bravo (2010) examined vocabulary tests and utilized pre-tests and post-tests to determine what it means to "know a word" (p. 567). They utilized a self-reporting scale with students that included categories such as 1) I haven't seen this word, 2) 


\section{THE NEBRASKA EDUCATOR, VOLUME 6}

I have seen this word, 3) I have seen this word and know a synonym or definition, and 4) I have seen this word and can use it in a sentence (Dougherty Stahl \& Bravo, 2010). Having students self-report their comfort level with lesson vocabulary words can indicate to teachers students' background knowledge and identify areas of potential difficulty.

One of their conclusions was that teachers have to know what the important content information and vocabulary are in order to determine what students know (Dougherty Stahl \& Bravo, 2010). Despite this conclusion, some content-area teachers may not be aware of their lessons also having a linguistic component as well as the content component. The authors recommended that teachers work with their colleagues to identify key words, concepts, and new vocabulary for their units as they plan their teaching (Dougherty Stahl \& Bravo, 2010). This suggestion is applicable to content areas outside of reading, as well. However, if teachers are unable to identify - either through teaching experience or through prior feedback/assessments with students - which words are unknown to students, this task becomes much harder and more ineffective for learning. Explicitly addressing key terms that may be unknown to ELLs is an accommodation that can help increase student scores in later assessments.

Other researchers agree that applying both direct and indirect linguistic support as a next step after identifying problem areas can be beneficial. According to Shafer Willner, Rivera, and Acosta (2009), “Accommodations for ELLs involve changes to testing procedures, testing materials, or the testing situation to allow students meaningful participation in an assessment" (p. 697). Based on recommendations from classroom teachers and ELL teachers, teams should make accommodation decisions to support individual students' linguistic needs, and those accommodations (such as dictionaries) should be introduced and/or taught to students before the test (Shafer Willner, Rivera, \& Acosta, 2009). 
THE NEBRASKA EDUCATOR, VOLUME 6

\section{Writing}

While reading and writing are language domains along with speaking and listening, here they are classified under the heading of content areas to reflect their focus in research. A consideration for validity in testing is whether the accommodations can provide unfair advantages to specific sets of students.

In a study by Oh (2020), the researcher posited that ELLs should be allowed to use writing tools such as dictionaries and spell-checkers during their writing assessments, as it more accurately reflects real-life and academic situations where those tools are widely available for their use. This study found that students of differing English language proficiency levels who had access to those tools still showed the differences in their levels while creating more accurate writing with more confidence. In other words, simply by providing more resources, student's abilities were not artificially inflated. In the survey administered after the two writing tasks, the majority of the students (35/39 total students) agreed with the statement "I think having access to the tools gave me the chance to show how well I can write in English", while some other students expressed concerns about perceived test fairness. In fact, the use of resources during the writing assessment actually provided more accurate writing that showcased what the student was able to do in realistic settings at their differing English proficiency levels (Oh, 2020).

In a rare study that compared ELL and non-ELL high school students in New York City, the researchers acknowledged that academic writing is a learned skill that traditional assessments (writing prompts with holistic grading) do not do enough to facilitate students' future learning (Llosa, Beck, \& Zhao, 2011). One of their findings concluded that, while teachers assign and work on a variety of writing genres throughout the school year, the writing prompts given as part of high-stakes assessments were much narrower in scope. If teachers were more aware of this, 


\section{THE NEBRASKA EDUCATOR, VOLUME 6}

they may be able to concentrate on the linguistic variation and expectations for the genres most frequently found on high-stakes tests (provided that passing such tests is one of the goals of the course). Given that many teachers do not analyze their tests to this degree, providing professional development in the areas of assessment literacy or linguistic expectations could improve student test results, especially for ELLs.

When the researchers employed a think-aloud protocol as students completed an exposition writing task, their interviews found that students identified "translating", or finding the right words for the essay, as overwhelmingly the most prevalent problem, with $90 \%$ of ELLs and $82 \%$ of non-ELLs reporting this. However, the distinction between the two groups was that "for ELLs more than for non-ELLs the challenge of finding appropriate words was more likely to prevent them from writing at all, or to force them to completely change their approach to articulating an idea" (Llosa et al., 2011, p. 268). Therefore, when thinking about assessments for high school students and writing, allowing the students the use of dictionaries (both bilingual and monolingual) during the task may be beneficial. Additionally, as supported by Dougherty Stahl and Bravo (2010), spending more instruction on using vocabulary in context may alleviate some of the translation issues that students encountered.

Another study led by Uccelli and Phillips Galloway (2017) worked with upper elementary and middle school students as they viewed this same question from a different viewpoint. When the researchers used their own assessment tool that focused on academic language, they concentrated on how students view language. Based on their ideas, and on feedback from students about the perception of their skill with academic language, teachers need to consider how they can leverage what skills the students have, regardless of whether they are strong in those skills or lacking them. Since reading and writing are used throughout education in 
THE NEBRASKA EDUCATOR, VOLUME 6

both learning and assessment, if student acquire those literacy skills, they will transfer into other academic areas as well.

\section{Mathematics}

One area of difficulty in working with ELLs in the content areas is the acknowledgment that there are multiple types of learning occurring at the same time. Unfortunately, some view mathematics as a "language-free" subject, thus ignoring the linguistic challenges that are present. "To achieve success [...], EL students must learn both mathematics and English simultaneously. This means that a teacher who has EL students in his or her classroom is not only a mathematics teacher but also a language teacher" (Leith, Rose, \& King, 2016, p. 670). However, many content-area teachers are not taught about the differences between linguistic knowledge and content knowledge, as teacher preparation programs in approximately 35 states require no specific coursework in working with ELL students (Education Commission of the States, 2014). Despite this lack, to provide appropriate testing accommodations for languages, teachers must evaluate students' content knowledge and be on the watch for test items that provide linguistic difficulty, such as polysemous words. This corresponds with conclusions drawn by Dougherty Stahl and Bravo as stated above. Vocabulary should be explicitly taught and practiced, especially those words that students will encounter on assessments. Overall, mathematics teachers need to be aware of the traps ELL students fall into and think about how they will modify their content to reach the students where they are at with the goal of moving them forward - both language-wise and mathematics-wise (Leith, Rose, \& King, 2016).

Schleppegrell (2007) supported this idea that mathematics vocabulary is important to explicitly teach, as well. In math, there is a variety of ways for students to receive information that involves many components of language. To be successful, students need to know math 


\section{THE NEBRASKA EDUCATOR, VOLUME 6}

jargon, graphic depictions of mathematical concepts, connections between ideas, and how to communicate their understanding of the theories and practical applications. Therefore, as a teaching or testing accommodation, teachers should be prepared to address these various components to help students advance from everyday use of vocabulary to their math-specific meanings (Schleppegrell, 2007).

In another study focusing on mathematics, researchers utilized survey responses along with some follow-up interviews to determine what teachers are actually doing in state mathematics ELL assessment accommodations (Wolf, Kao, Rivera, \& Chang, 2012). Eighthgrade math and ELL teachers were studied and the research included 165 respondents from two states, responding on high-stakes assessment from the 2007-08 academic year. Testing and accommodation decisions were often made by a team, but the makeup of the team varied between schools. "The authors' analysis revealed that most states did not focus on the unique linguistic needs of ELL students, making little distinction between ELL students and students with disabilities regarding test accommodations" (Wolf, Kao, Rivera, \& Chang, 2012, p. 3). Whole-class accommodations instead of individual accommodations were frequently applied due to logistics such as the lack of testing space or proctors.

ELL teachers and math teachers rated different types of accommodations as the most helpful, and other types of supports were mixed. An exception was the use of an English-only dictionary and a glossary, which were marked as among the least useful by both ELL and math teachers. Overall results promoted the belief that states should provide guidelines for ELL testing supports which are separate from IEP or 504 supports, and training should be provided for those responsible for making accommodation decisions. While IEP and 504 supports are determined by a team of involved professionals on an individual basis for each student with parent and 


\section{THE NEBRASKA EDUCATOR, VOLUME 6}

teacher inputs, the process to determine ELL testing supports, as evidenced by this study, are applied much more uniformly. From these results, all teachers that are involved in assessments should be made aware of the types of supports that are permitted and should work together to determine which assessments benefit students the most.

In another study, the researchers determined that accommodations on standardized assessments were most beneficial when students were aware of the social and academic content (Wolf, Kim, \& Kao, 2012). For the $8^{\text {th }}$ grade students in this study, this referred, too, to life situations, such as tipping at a restaurant, that students may not have understood as a societal concept before taking the assessment. Therefore, accommodations such as reading the test aloud to students becomes less useful if the overall context of the scenario being presented is a new one to students (Wolf, Kim, \& Kao, 2012), and should be considered by teachers who want to assess students content knowledge.

This conclusion aligns with those by Monarrez and Tschoshanov (2020) which state that the information being taught in the mathematics classroom must be converted to a way that is clear for students. Since student learning is dependent on teachers' abilities to translate new concepts to ELL students, teachers should be willing to provide information in multiple ways, such as using simplified language (Monarrez \& Tchoshanov, 2020). Expecting ELL students to be academically successful without using accommodations at the same level as non-ELL students is an expectation that is not often borne out.

\section{Science}

Like mathematics, the subject of science also faces linguistic and cultural challenges along with content. To support students, assessment should include visuals such as diagrams and 


\section{THE NEBRASKA EDUCATOR, VOLUME 6}

graphs. However, accommodations in science can go beyond direct linguistic supports and involve changes in how the test is designed.

Students need variety in test question types and opportunities to share their ideas in more formats than simply multiple choice. Teachers and test-designers should allow variety in answers while encouraging use of scientific discourse. Researchers claimed that the use of constructed response items helped "ELLs demonstrate their scientific knowledge on science assessments by allowing them to articulate ideas and justifications in their own words" (Turkan \& Liu, 2012, p. 2365). By allowing different types of responses, students are able to exhibit their understanding while compensating for smaller linguistic or grammatical errors. Additionally, within the classroom, teachers should ensure that they provide opportunities for ELL students to speak about what they're learning. Teachers should consider what is involved in the language of evaluation to ensure students know how to interpret rubrics and project guidelines (Bunch, Shaw, \& Geaney, 2010).

As a part of classroom assessments, inquiry assessments are especially useful in science, as students need access to the higher-level thinking and skills that such assessments provide (Turkan \& Liu, 2012). Students need to be able to apply information and justify their educational decisions in constructed responses. In this study, ELLs ( $n=313$ students) were significantly outperformed by non-ELLs ( $\mathrm{n}=1083$ students) in a computer-administered low-stakes test in a $7^{\text {th }}$ and $8^{\text {th }}$ grade life science course in 10 schools in California with an overall rate of $22.5 \%$ ELL population. While most items favored non-ELLs, there was one test item that favored ELLs, which may have been due to the additional visual support of a graph (Turkan \& Liu, 2012).

Despite these results that might appear negative, providing space for students to explain their ideas allows for cultural differences and variety in approaches to the same problem, thus 


\section{THE NEBRASKA EDUCATOR, VOLUME 6}

making it more likely that ELLs are able to share their understanding to the maximum extent possible given their linguistic constraints. If students are provided with only closed-response options, teachers are not able to investigate to determine the students' level of understanding. On the other hand, open-response, or constructed response questions (with visual and linguistic supports) can be more accurate indicators of how students are incorporating science information into their schemas.

Bunch et al. (2010) classified the type of language demands in science assessments to fall into three categories - participant structures, communicative modes, and written texts and genres. "The language demands of instruction and assessment in inquiry-based classrooms using performance assessment could present opportunities for students to develop a wider repertoire of language skills than would be present in classrooms focused on preparation for more traditional assessments” (Bunch et al., 2010, p. 205). From their conclusions, Bunch et al. (2010) emphasized that if classroom teachers are requiring students to explain their ideas and the process they utilized to develop their results, then those skills must be practiced and scaffolded for all students, and especially ELLs. Therefore, if constructed responses are more widely utilized, as Turkan and Liu (2012) recommend, then that is a linguistic skill that ELLs need to be taught.

Another aspect of assessment in science is considering test item linguistic simplification (Rivera \& Stansfield, 2004). In this study, Limited English Proficient (LEP) (n=108) and nonLEP students (nearly 11,200 in $4^{\text {th }}$ and $6^{\text {th }}$ grade) in Delaware were provided with a science test. Within the larger test, there was a subset of either simplified or regular questions that tested the same content. At the time of the test, most LEP students did not receive any testing accommodations. Analyzation of the short-answer and multiple-choice question results for the 
THE NEBRASKA EDUCATOR, VOLUME 6

state science assessments showed that the non-LEP students did not receive an unfair advantage in testing by providing test items using simplified English. Unfortunately, the number of LEP students was too small to make a generalization (Rivera \& Stansfield, 2004).

Therefore, test developers should consider that since the simplified test items did not provide an advantage or disadvantage to the non-LEP students, and could potentially provide more accurate results for LEP students, more simplified test items should be included in future tests. However, knowledge of linguistics and ELLs are needed to determine how best to simplify test items while still maintaining academic rigor, especially in states and content areas where ELL students are a larger percentage of the general school population.

\section{Additional Considerations}

\section{Standardized Assessments}

Apart from focusing on content areas, some research investigated how ELLs were affected by the type of assessment. For example, standardized assessments, classroom assessments, and inquiry or performance-based assessments would all have different types of modifications that might be beneficial to ELLs.

Standardized tests are commonly administered on an annual basis in all states. However, the standardized test itself, as well as their allowed accommodations, differ widely among states, districts, and schools. While classroom teachers may not make the initial decision about the general types of accommodations that are allowed by the testing company, they often influence the actual accommodation provided to the students.

Overall results stated that accommodations that were incorrectly provided to students were no more beneficial than having no accommodations provided at all (Kopriva, Emick, Hipolito-Delgado, \& Cameron, 2007). Therefore, Kopriva et al. (2007) suggested common 


\section{THE NEBRASKA EDUCATOR, VOLUME 6}

accommodations for standardized tests include translating tests into the L1, providing extra time, having the test read aloud, and using bilingual dictionaries, picture dictionaries, and word lists. "While teachers or specialists may not be able to clearly differentiate recommended accommodations, their "fall back" approach often seems to be to assign all possible accommodations" (Kopriva et al., 2007, p. 13). If an accommodation incorrectly applied leads to worse test scores than if no accommodations had been applied, then it is even more vital that teachers are educated to recognize which types of accommodations are available, and to know their students so that all appropriate accommodations are provided.

One area of difficulty was that policies sometimes differed between states and districts, which caused confusion when testing. For example, the state might have stricter or more permissive accommodation allowances than the district. Another issue was the documentation of accommodations - who made the decision and who kept track of paperwork - and which types of accommodations were allowed. "The interview data suggested that the variation in the use of accommodations may be due to limited guidelines, limited communication of guidelines, or limited resources" (Wolf, Kao, Rivera, \& Chang, 2012, p. 19). Those classroom teachers who are less informed about either their students or the assessment possibilities tend to provide no benefits to their ELL students by not matching them with their correct supports. If schools or districts were to have clear accommodation guidelines and ensure that the decision-makers had access to them, it would be more likely that students could receive the correct accommodations.

\section{Test translations}

An additional difficulty in considering the types of accommodations that would help ELLs is the variation in test translations. Translations can be difficult, as the test provider must determine if written or spoken translations are most appropriate for the ELL students (Stansfield, 
THE NEBRASKA EDUCATOR, VOLUME 6

2011). Factors affecting this include literacy skill of the ELLs' L1 and L2 as well as the language of instruction and content area being assessed. There is also a perception that providing test translations can also be very expensive, especially when multiple languages are needed. Written translations provide a resource that students can refer back to, but oral translations can be done in advance with the approval of an official source or on-the-spot with the high probability of variation between testing locations. Although more expensive, providing recorded official oral translations of the assessment to schools is more reliable as they limit issues related to pronunciation and fluency of the proctor (Bowles \& Stansfield, 2008). As of 2011, only Ohio, Michigan, and Wisconsin provided recorded oral translations for their state standardized tests in order for students to listen with a recording, but no results were provided as to if those oral translations led to more accurate testing of ELLs' content knowledge (Stansfield, 2011), thus making it an area of future research.

\section{Conclusion}

From reviewing some of the literature as it regarded assessment accommodations in the content areas, there were some key themes that emerged. There were some generalizable results of strategies to modify or teach material that led to greater success on standardized tests. Teachers should recognize that to teach English language learners means they must distinguish between content knowledge and language knowledge. It's difficult to ensure that students have the ability to demonstrate what they know about the subject while accounting for gaps in English. However, if teachers do not acknowledge this, then our ELL students are being placed in disadvantageous assessment situations. Providing scaffolded instruction as well as direct and indirect linguistic supports can help to alleviate this problem. 
THE NEBRASKA EDUCATOR, VOLUME 6

Whether accommodations are determined by the individual teacher or by set policy, it's important to ensure that they are appropriate for the student's English level and L1 level, as emphasized by Kopriva et al.: “Additionally, students who were given no test accommodations scored no differently than those students that received accommodation packages that were incomplete or not recommended, given the students' particular needs and challenges” (2007, p 11). If guidelines to determine the correct types of support are not followed, then the assessment would not be able to accurately reflect what the student is able to accomplish with either their content knowledge or language skills.

This is clearly an area that is open to research, and if a researcher is able to obtain permission to work with teachers at the high school level, there is the potential to investigate 1) which types of assessment modifications are being utilized and 2) which types of modifications are beneficial to ELLs. In addition, further distinctions between content areas and student demographics could also be investigated in order to distinguish assessment modifications that would help subsets of students or subjects while ensuring that English language learners are being tested on similar content compared with native-speaking English students. 
THE NEBRASKA EDUCATOR, VOLUME 6

\section{References}

Bowles, M. \& Stansfield, C.W. (2008). A practical guide to standards-based assessment in the native language. https://ncela.ed.gov/files/rcd/BE024208/A_Practical_Guide.pdf

Bunch, G. C., Shaw, J. M., \& Geaney, E. R. (2010). Documenting the language demands of mainstream content-area assessment for English learners: Participant structures, communicative modes and genre in science performance assessments. Language and Education, 24(3), 185-214. https://doi.org/10.1080/09500780903518986

Dougherty Stahl, K. A., \& Bravo, M. A. (2010). Contemporary classroom vocabulary assessment for content areas. The Reading Teacher, 63(7), 566-578. https://doi.org/10.1598/rt.63.7.4

Education Commission of the States. (2014). What ELL training, if any, is required of general classroom teachers? https://ecs.secure.force.com/mbdata/mbquestNB2?rep=ELL1415

Kopriva, R. J., Emick, J. E., Hipolito-Delgado, C. P., \& Cameron, C. A. (2007). Do proper accommodation assignments make a difference? Examining the impact of improved decision making on scores for English Language Learners. Educational Measurement: Issues and Practice, 26(3), 11-20. https://doi.org/10.1111/j.1745-3992.2007.00097.x

Leith, C., Rose, E., \& King, T. (2016). Teaching mathematics and language to English learners. The Mathematics Teacher, 109(9), 670-678.

Llosa, L., Beck, S. W., \& Zhao, C. G. (2011). An investigation of academic writing in secondary schools to inform the development of diagnostic classroom assessments. Assessing Writing, 16(4), 256-273. https://doi.org/10.1016/j.asw.2011.07.001

Monarrez, A., \& Tchoshanov, M. (2020). Unpacking teacher challenges in understanding and implementing cognitively demanding tasks in secondary school mathematics classrooms. 
THE NEBRASKA EDUCATOR, VOLUME 6

International Journal of Mathematical Education in Science and Technology, 1-17. https://doi.org/10.1080/0020739X.2020.1857860

Office for Civil Rights: U.S. Department of Education. (25 September 2018). Developing programs for English language learners: Lau v. Nichols. Retrieved from https://www2.ed.gov/about/offices/list/ocr/ell/lau.html

Office of Elementary and Secondary Education: U.S. Department of Education. (2002). No Child Left Behind: A desktop reference. https://www2.ed.gov/admins/lead/account/nclbreference/reference.pdf

Oh, S. (2020). Second language learners' use of writing resources in writing assessment. Language Assessment Quarterly, 17(1), 60-84. https://doi.org/10.1080/15434303.2019.1674854

Rivera, C., \& Stansfield, C. W. (2004). The effect of linguistic simplification of science test items on score comparability. Educational Assessment, 9(3-4), 79-105. https://doi.org/10.1080/10627197.2004.9652960

Schleppegrell, M. J. (2007). The linguistic challenges of mathematics teaching and learning: A research review. Reading and Writing Quarterly, 23(2), 139-159. https://doi.org/10.1080/10573560601158461

Shafer Willner, L., Rivera, C., \& Acosta, B. D. (2009). Ensuring accommodations used in content assessments are responsive to English-language learners. The Reading Teacher, 62(8), 696-698. https://doi.org/10.1598/rt.62.8.8

Stansfield, C. W. (2011). Oral translation as a test accommodation for ELLs. Language Testing, 28(3), 401-416. https://doi.org/10.1177/0265532211404191 
THE NEBRASKA EDUCATOR, VOLUME 6

Turkan, S., \& Liu, O. L. (2012). Differential performance by English language learners on an inquiry-based science assessment. International Journal of Science Education, 34(15), 2343-2369. https://doi.org/10.1080/09500693.2012.705046

Uccelli, P., \& Phillips Galloway, E. (2017). Academic language across content areas: Lessons from an innovative assessment and from students' reflections about language. Journal of Adolescent and Adult Literacy, 60(4), 395-404. https://doi.org/10.1002/jaal.553

U.S. Department of Education. (2016) Non-regulatory guidance: English Learners and Title III of the Elementary and Secondary Education Act (ESEA), as amended by the Every Student Succeeds Act (ESSA). https://www.education.ne.gov/wpcontent/uploads/2017/07/essatitleiiiguidenglishlearners92016.pdf

Wolf, M. K., Kao, J. C., Rivera, N. M., \& Chang, S. M. (2012). Accommodation practices for English language learners in states' mathematics assessments. Teachers College Record, $114(3), 1-26$.

Wolf, M. K., Kim, J., \& Kao, J. (2012). The effects of glossary and read-aloud accommodations on English language learners’ performance on a mathematics assessment. Applied Measurement in Education, 25(4), 347-374. https://doi.org/10.1080/08957347.2012.714693 
THE NEBRASKA EDUCATOR, VOLUME 6

\section{Appendix}

Definitions and Acronyms for Second Language Students and Programs

ELL - English Language Learner - A K-12 student who is classified through testing as being in need of English language support in school. Also known as an EL, or English Learner

ELLs - English Language Learners

ESL - English as a Second Language (more commonly used to refer to programs rather than the students)

ESOL - English to Speakers of Other Languages (more commonly used to refer to programs rather than the students)

L1 - First language; also known as a person's native language

L2 - Second language; refers to all languages learned after the first whether actually the second language or a subsequent one

LEP - Limited English Proficient; can be used as a synonym for an English Language Learner, but does not have to be in the K-12 setting or currently receiving English supports

Non-ELL - A student who is not currently classified as an English Language Learner. This may be a native English speaker or a student who was previously classified as an English Language Learner and has exited due to achieving English proficiency

Non-LEP - A person who is proficient in English 


\title{
Triangulating Research that Focuses on Decolonizing and Race-Based Educational Theories
}

\author{
Beth Dotan \\ Department of Teaching, Learning, and Teacher Education \\ University of Nebraska-Lincoln
}

\begin{abstract}
The normalization of white cultural and societal educational standards often produce uniform consumers of knowledge. In an effort to seek modification from conventional educational belief systems, this literature review looks at a collection of critical, race-based, and anti-/ de-colonial epistemologies and challenges traditions of inquiry. The research: 1) articulates how national culture perpetuates divisiveness through race and racism in colonized American society and institutions, 2) contemplates the amalgamation of Jewishness and whiteness, and 3) considers utilizing critical theory and social justice views to decolonize educational methodologies as a path to implement change. Historical context and the diverse array of scholarship on critical theories using the narratives of race-based epistemologies in this literature review suggest a directional shift to center marginalized voices and redefine how knowledge is acquired in our systems.
\end{abstract}

Keywords: decolonizing, race-based educational theories, critical theories, Jewish identity, whiteness studies, race-based epistemologies, race, racism 


\section{THE NEBRASKA EDUCATOR, VOLUME 6}

'Children are not future people, because they are people already...Children are people whose souls contain the seeds of all those thoughts and emotions that we possess. As these seeds develop, their growth must be gently directed.'10

\section{Dr. Janusz Korczak}

In an effort to seek a modification from a conventional white educational belief system, this literature review looks at critical, race-based, and anti-/ de-colonial epistemologies and challenges traditions of inquiry, in particular from the author's position at the intersection of whiteness and Jewishness. Although only a fraction of the extant literature on critical theories is included in this review, the collection can inspire educators to scrutinize what counts as knowledge (Delgado Bernal, 2002). The scholarship requires the reader to examine who is cultivating knowledge and who benefits from that knowledge (Berry, Summer-Fall, 2010; Berry, 2017; Delgado Bernal, 2002; Dixson et al., 2018; Patel, 2016; Tejeda-Espinoza, 2003). The research exposes how the normalization of While educational standards often produce uniform consumers of knowledge.

Polish and Jewish pedagogue Janusz Korczak's declaration that "children are not future people" (Lewowicki, T., 1994, p. 4) infers that children are individuals with rights beyond racial identity and socioeconomic status. At the turn of the last century, Korczak adhered to a progressive educational model that put the child and his/her engagement with the world as central to learning. He grounded his work in vilifying oppression of children to ensure the survival of their agency, dignity, and life. Korczak's legacy is vast, but he is most significantly remembered for the relentless care and respect of hundreds of children orphaned in the Warsaw Ghetto. In August, 1942 Korczak, along with 200 children and staff from his orphanage were forced to gather in the ghetto, transported by train, and murdered upon arrival at the Treblinka

10 Janusz [Korczak], 'Rozwòj idei milosci blizniego w xix wieku [Development of the love-thy-neighbour ideal in the nineteenth century]', Czytelnia dla Wszystkich [Universal Reader], no. 52, 1899 as cited in Lewowicki, T. 1994). 
THE NEBRASKA EDUCATOR, VOLUME 6

killing center. Through my personal work in Holocaust education, I have interacted and honored his lasting educational pedagogy. There is a profundity to Korczak's philosophical principles and foresight that energized my personal and educational values. Consequently, only upon validation of the introductory statement by Korczak, do I see the work of critical theorists succeeding in repudiating white institutionalism or placing a wedge in reconstructing perpetual educational disparities (Berry, 2017; Delgado Bernal, 2002, Ladson-Billings \& Tate, 1995; Omi \& Winant, 2014; Patel, 2016; Scheurich \& Young, 1997).

This literature review intends to triangulate the research and explore integrating decolonizing and race-based educational theories into teaching methodologies. The review 1) articulates how national culture perpetuates divisiveness through race and racism in colonized American society and institutions, 2) contemplates the amalgamation of Jewishness and whiteness, and 3) considers utilizing critical theory and social justice work to decolonize educational methodologies as a path to implement change. Through this process, I aim to establish clarity from my position as a Jewish female educator working in Holocaust Education and gain insight from diverse narratives that might inform appropriate cultural responsiveness toward future social justice work (Ladson-Billings \& Tate, 1995 Tejeda \& Espinoza, 2013).

\section{The Deconstruction of Race and the Impact on Colonized Hierarchy}

The first set of articles deconstructs the concept of race through its historical development, illuminating, particularly in the US, how the interpretation of the term over time has led to the segregation of peoples and the establishment of white hierarchy. Golash-Boza, (2019) specifies race as a modern social construction "referring to a group of people that share physical and cultural traits" (p.3). The term race and its interpretation as an idea is a "modern" construction, which can be tied to religious turmoil among European colonialists who regarded 


\section{THE NEBRASKA EDUCATOR, VOLUME 6}

their humanity as superior to "unredeemable" indigenous peoples (Golash-Boza, 2019; Omi \& Winant, 2014; Smedley, 2007). As a result of racial distinctions, "the expropriation of property, the denial of political rights, the introduction of slavery and other forms of coercive labor, as well as outright extermination, all presupposed a worldview which distinguished Europeans... from 'others"” (Omi \& Winant, 2014, p. 3). Society continues to make race and its historical interpretations normalized as a term, an idea, an ideology, and a theory.

From a historical perspective, Golash-Boza (2019) explains that race as an ideology was not a consideration among ancient people due to amicable, intellectual, and economic interactions and contributions among societies. Racialized classifications were later formulated simultaneously with emerging religious discrimination during the Inquisition in the $15^{\text {th }}$ century. Emerging concepts to distinguish human differences in Europe later equated to radical ideas that racial classifications could be based on 'purity of blood.' (Smedley, 2007; Golash-Boza, 2019). The literature provides an historical overview of Northern European enslavement, including descriptions of encounters with American Indigenous peoples and recollections of Spanish conquests. Along with the advance to occupy lands, the belief in manifest destiny (justified expansion in the Americas) perpetuated slavery. Additional laws and regulations were imposed upon multiple groups of people as reinforcement of white control. The brutality of the events accompanying land possession posited power and superiority in the drive to control and create race differentiations (Golash-Boza, 2019; Ladson-Billings \& Tate, 1995; Omi \& Winant, 2014; Smedley, 2007).

The invention of race and racial identity is one of the tragic outcomes of this corrupt history of seized lands. Smedley (2007) suggests that "race is a cultural construct, ...[that] should be analyzed as a social/cultural reality that exists in a realm independent of biological or 
THE NEBRASKA EDUCATOR, VOLUME 6

genetic variation" (p. 1, emphasis added). The historical accounts within the literature include additional discussion from Golash-Boza (2019) and Omi \& Winant (2014) regarding established scientific techniques from the $19^{\text {th }}$ and $20^{\text {th }}$ centuries that attempted to lay a foundation suggesting that distinguishable traits are inherent to the various races. (Smedley, 2007). Anthropologist Franz Boas refuted this scientific thought and others rejected the idea that race and culture are connected biologically (Omi and Winant, 2014). The impact of the attempts to scientifically identify categories of human beings resulted in dangerous presuppositions, namely that racism is "the belief that races are populations whose physical differences are linked to significant cultural and social differences within a hierarchy and the practice of subordinating races believed to be inferior" (Golash-Boza, 2013, p. 3). Despite Boas and others debunking the notion of a biological structure for race, racism became a social byproduct employed as a tool to enforce power and classification within white supremacy. One of the most extreme examples of race as a biological phenomenon to justify the elimination of "inferior" peoples is that of Hitler and the National Socialists' racial ideology that led to the murder of six million Jews. Genocidal practices throughout history have been driven by the misdirected concepts of race and racism and are deeply embedded within society today.

The historical foundation of race has allowed for prejudices to exist in a US culture that tolerates stereotyping and categorization. (Omi \& Winant, 2014). These inferences are often determined and redefined based on the interest of the dominant culture or group. There is overlap in the ideals of ethnicity, class, and nation (Ladson-Billings, 1995), at times even confusing within said cultural groups. ${ }^{11}$ Golash-Boza (2019) differentiates ethnicity from race as a group

11 Omi and Winant (2014) reference the unsuccessful lawsuit of Susie Guillory Phipps, 1982-83, to change her racial designation in her birth certificate from "black" to "white" in a challenge to racial classification and identity. (p. 3) 


\section{THE NEBRASKA EDUCATOR, VOLUME 6}

sharing history, culture, and kinship (Golash-Boza, 2019). Although the terms may occasionally be interpreted similarly, individuals self-identify within ethnic groups, while racial groups are externally established and imposed on a group by others usually outside of the group (GolashBoza, 2019). The interpretations remain complex.

The long and difficult history of race and racialized issues as an ideological, social construct is today evaluated within educational theories. Ladson-Billings and Tate (1995) began to theorize race in education through Critical Race Theory as a means to understand school inequity for non-white students. Their ground-breaking research was based on three positions that reflect the racial ideologies we have seen in the historical component of this literature review:

1. Race is a significant factor in determining inequity in the US

2. US society is based on property rights

3. The intersection of race and property creates an analytic tool to understand social (and, consequently, school) inequity (Ladson-Billings and Tate, 1995, p. 48).

Ladson-Billings and Tate (1995) utilized this research to push back against the ideological construct of race by using CRT as a tool for change. It might be said that they opened the door for future educational researchers, such as Berry, hooks, and Delgado Bernal, through discussion that "challenges the dominant paradigm of ethnicity" (p.50) and institutional racism (Scheurich \& Young, 1997). They advanced the narrative to the forefront through a deep examination of issues, such as the assumptions about civil rights today or the multiple truths of multiculturalism. Not unlike Theodorea Berry (2017) who integrated the inquiry of DeBois and Woodson into her research to center voices of historical narrative against issues of race inequity, Ladson-Billings and Tate (1995) turned to leading Black scholars "to uncover or decipher the social-structural 


\section{THE NEBRASKA EDUCATOR, VOLUME 6}

and cultural significance of race in education" (p. 50). Utilizing narrative reflects Delgado’s (1989) method to confront imposed structures and choose frameworks from our own experiences.

Ladson-Billings and Tate's (1995) main concern was to broaden the perspective for those who scrutinize racial inequities through educational research and critical thinking with voices that have been silenced. In their paper's third position on the intersection of race and property, Ladson-Billings and Tate (1995) confront what Scheurich \& Young (1997) consider "civilization racism" (p. 7). The historical development of race and racial ideology characterizes how white dominance has employed land rights, occupied the position of social and cultural privilege, and claimed the status of economic advantage. According to Omi and Winant (2014) "thinking of race strictly as an ideological construct denies the reality of a racialized society and its impact on 'raced' people in their everyday lives"' (p. 48).

The collection of literature in this paper introduces a variety of researchers whose methodologies push marginalization and racism away from the periphery by centering raced epistemologies as critical ways of knowing (Anzaldúa, 1987; Anzaldúa, 2009; Bhattacharya, 2015; Chávez, 2012; Delgado Bernal, 2002; Ladson-Billings \& Tate, 1995). These authors and others highlight how the intersection of race ideology and hegemonic forms of ideology shape identity in a hierarchal, white educational system that relentlessly replicates discrimination and assimilationism (Chavez, 2012) that skews student perceptions of the world to one a coherent perspective. Methods of navigating knowledge intake only from a white perspective do not nourish growth in learners but instead stifles it. This perspective is particularly true within dominant white groups and institutions (Atunes, 2017; Berry, 2010; Delgado Bernal, 2002; 2018, Golash-Boza, 2019; hooks, n.d.; Jupp et al., 2018; Jupp, 2020; Kohli, 2008; Matias, 2016; 


\section{THE NEBRASKA EDUCATOR, VOLUME 6}

Morales et al., 2019; Omi \& Winant, 2014; Picower, 2009). Only by studying the varied voices guiding Critical Race Theory (CRT), Critical Race Feminism (CRF), LatCrit, and others can researchers value the agency of women, people of color, and individuals of diverse ethnic entities including the Jewish community. Exposure to the work of these scholars, who create change through rigorous collaborative effort, provides a standard for the classroom educator and ultimately for the diversity in which students can learn and understand the world.

\section{Jewishness, Whiteness and Where They Might Meet}

Familiarity with the race-based theoretical literature mentioned above is formative to acknowledge how racist divisions became embedded in traditional theories of Western institutionalism, particularly within the educational system. The forthcoming section of reviewed literature will look at the Jewish community as a cultural and racialized entity. We do this with caution, as drawing parallels and comparisons of various racialized groups can contribute to unwarranted sensitivities. This author acknowledges that the Jewish experience in the United States is not comparable to that of other groups. Still, the intersection of the history of the Jews and aspired success as a cultural group presents countless issues.

As an American Jewish woman and Holocaust educator, it has been essential to explore the literature further to confront the realities of those "othered" within the dominant white culture. McIntosh (1988) noted that "as a white person, I realized I had been taught about racism as something that puts others at a disadvantage but had been taught not to see one of its corollary aspects, white privilege, which puts me at an advantage" (p. 29-30). Critical White Studies (CWS) exposes a deeper understanding of how the white community leverages race and racism to maintain superiority (Jupp, 2020). There are numerous examples of how the white Christian community standardized rules of acceptance, discriminating against Jews and others in numerous 


\section{THE NEBRASKA EDUCATOR, VOLUME 6}

ways, for example quietly blocking membership in places such as country clubs, denying access to housing, or creating quota systems at higher institutes of education. These were some of the ways that the white population maintained superiority.

Historically, Jews have been the victims of hatred and displacement caused by virulent antisemitism. Despite a reprieve from discrimination and persecution in Poland-Lithuania and the Iberian Peninsula in different historical periods, the Jew was considered an outsider even in kingdoms where they had been invited to emigrate. Jews settled in numerous European countries, yet they were consistently considered "non" white, as their ancestry was diasporic. In $15^{\text {th }}$ century Spain, religious discrimination was instigated by edict, ultimately establishing European racist ideologies before monarchical exploration to new territories and later colonialism (Smedley, 2007; Golash-Boza, 2019). When not expelled or murdered, Jews continued to be foreigners in adopted lands. How is Jewish "otherness" manifested in more recent cultural history?

One study based on CRT and CWS methodologies identified hegemonic responses among white preservice teachers working with students of color. In the analysis from the narrative of a Jewish student, Picower (2009) deduces that "one who has experienced negative remarks because of her religious affiliation, caused her to minimize the idea of racial discrimination and, in particular, to deny her identification as a member of the dominant racial group" (p. 201). We look closer at literature addressing the complexity and intersectionality of whiteness and Jewishness exemplified in the second-wave movement of CWS that considers a variety of social and historical issues to analyze data (Jupp, 2020). As evident in Picower's (2009) research, Jewishness can maintain an unclear status within American society yet can be dismissed under the guise of whiteness. 


\section{THE NEBRASKA EDUCATOR, VOLUME 6}

To better understand the positionality of whiteness and Jewishness, we will look at two pieces of literature. One, an article by Schraub (2019), titled "White Jews: An Intersectional Approach," and components from Goldstein's (2006) book titled The Price of Whiteness: Jews, Race, and American Identity. The review of these resources will look at highlights that address the issues of being Jewish in white America historically, the ramifications of Jewishness as a subgroup within an ethnic identity, and concerns regarding racism and antisemitism today.

The literature suggests that as race theories develop, those who confront the traditional and colonialist methodologies often find themselves at an intersection between cultural identity and socialized classifications. The Price of Whiteness (Goldstein, 2006) discusses the various developments in the integration of the Jewish community in the US since the colonial period. For the sake of this review, the focus will be on those chapters that specifically address Jewishness in its relation to the white community. A parallel theme, which will not be explored at this time, investigates how Jews interacted with the African American community.

Various periods mark the changes for the Jewish community throughout their integration into American society. Goldstein (2006a) discusses how the historical complexities of Jewishness in a racialized society must continue to be navigated amidst nuanced prejudices that have never fully dissipated. In a colonized society where racial ideology identifies people as either "white" or "non-white," this binary interplay is motivated by social, economic, and political forces (Omi \& Winant, 2014). As with other racially designated groups, this has often created misconceptions even within the Jewish community itself, particularly as immigration waves affected their status.

Up until the later part of the $19^{\text {th }}$ century, Jews had immigrated mainly from Central Europe, integrating into American life and acculturating readily to customs and society. This 
THE NEBRASKA EDUCATOR, VOLUME 6

acceptance allowed them to identify as a religious community in a way they had not experienced in recent history (Goldstein, 2006a). While socially accepted, increased interactions and economic opportunities remained available until the end of the Civil War. But later, new definitions regarding group identity both from within and without the community emerged, as did restrictions for Jews in social and civic organizations. During this time, racial terms for immigrants and groups of color were becoming part of the American discourse. Jews began to subscribe as a "race" to maintain acceptance in the non-Jewish world and were considered part of the white community (Goldstein, 2006a).

At the turn of the $20^{\text {th }}$ century, with increased immigration, industrialization, and white America's concern for renewed supremacy in a changing society, Jews began questioning whether to continue to identify "racially" (Goldstein, 2006c). Along with other newcomers, Eastern European Jewish immigration to the US increased exponentially, changing the assimilated Jewish community's landscape. Despite their desire to be integrated within the majority, Jews also wanted to maintain their religiosity. But, in the 1910 Census, "Jews feared that the government's adoption of a 'Hebrew' classification might be the first step toward their eventual exclusion from the rights of white American citizens" (p. 109) (See Table \#1). Even in 2019, the federal government was still attempting to define the status of Jews in America. ${ }^{12}$

\footnotetext{
12 There is still identification discussion today. An Executive Order (December 11, 2019) on antisemitism did two primary things:

- "It shall be the policy of the Executive Branch" to enforce Title VI of the Civil Rights Act of 1964, which prohibits discrimination in programs receiving federal funding, "against prohibited forms of discrimination rooted in antisemitism as vigorously as against all other forms of discrimination; prohibited by the statute"

- "The Executive Order does not define Jews as a nationality, but it prohibits discrimination against Jews, Muslims, Sikhs, and members of other religious groups when the discrimination is based on the group's actual or perceived shared ancestry or ethnic characteristics - or when the discrimination is based on actual or perceived citizenship or residence in a country whose residents share a dominant religion or a distinct religious identity."

Retrieved from: https://www.adl.org/resources/backgrounders/the-presidents-executive-order-on-antisemitism-frequently-asked-questions
} 
THE NEBRASKA EDUCATOR, VOLUME 6

By the end of WWII, increased American nationalism under the Roosevelt administration embraced Jews and other groups into the national culture. Jews were integrated into the military, whereas other groups, such as African Americans, were still divided as segregated units. Changes regarding race and ethnicity were distinguished, mainly to push against Hitler's racial, ideological theories (Goldstein, 2006d). As civil rights and struggles for minoritized groups pressed forward, the Jews, for the most part, had integrated into the fabric of America. African Americans saw them as part of the "racist power structure" (Goldstein, 2006e, p. 213). Goldstein presents the paradox of Jews in America:

“Jews' impressive economic mobility and their high degree of integration into universities, neighborhoods, professions and other central institutions of American life made it hard for them to claim the status of an 'oppressed minority' in anything other than a faint historical sense. Yet the more distant they became from their minority social status; the more Jews felt the need to highlight their difference from white society" ( $p$. 213).

This degree of integration into the larger American society, along with a complicated Jewish history, including the Holocaust, leaves Jews in a precarious social and ideological position. At this juncture, Schraub's (2019) article on the intersectionality of Jewishness and whiteness provides clarity on Jews as a minority in America.

The point of contention that lies at the heart of Schraub's (2019) discussion is, "What does 'Whiteness' do to 'Jewishness"' (p. 379)? He argues that intersecting the concepts of "Whiteness" and "Jewishness" when investigating Jews as a minority group in America provides a framework to assess political underpinnings and identify issues of Jewish in/equality (in particularly antisemitism) that might otherwise be unseen or misunderstood. (See Table \#2a) In 


\section{THE NEBRASKA EDUCATOR, VOLUME 6}

Crenshaw's (1991) case on the intersection of race and sex, Black Woman were marginalized by white women and African American men, as well as by an institution. Identifying the issues through the tool of intersectionality provides perspectives to see raced oppression differently (Schraub, 2019). The deep-rooted ideologies of the American binary "white" and "non-white" racial formation (Omi and Winant, 2014) as discussed earlier, are perpetuated within our socialized culture. Society responds through a color-blind lens, normalizing only whiteness. Therefore, negotiating the points of intersection attempts to reveal that which is not apparent. This is true also in educational settings.

European Jewish immigration and the historical integration into American society, as revealed in Goldstein's (2006) book, leaves little doubt that Jews in this country are considered white, yet still "raced" in certain situations. Schraub (2019) discusses how interconnecting these two terms "White Jew" can sometimes amplify forms of antisemitic assertions in some circumstances. Antiracism discourse works to "neutralize the power of whiteness, but Jewishness combined with whiteness can exacerbate the ideas of 'power, domination, or social control' leading to antisemitic tropes" (Schraub, 2019, p. 184). In other words, antiracist language that might be used to raise issue with white power in other racialized situations can be used to minoritize Jews or lead to stereotyped rhetoric about them. In this way, Jews are forced back into a binary system as outsiders and seen as potentially dangerous to the dominant culture. Subsequently, white supremacists play into this threat of Jewish power, cautioning that Jews should not be equated with the white majority. Schraub (2019) articulates concern regarding this formulation of intersectionality. He identifies a gap in the research on "antisemitism in progressive scholarship [linking] contemporary issues of discrimination, oppression, and identity-based marginalization" (p. 382-383). Jewish identity and antisemitism continue to be 
THE NEBRASKA EDUCATOR, VOLUME 6

redefined through current right-supremacy rhetoric that often becomes mainstream. Antisemitic occurrences continue to increase at an alarming level even in the past few years. ${ }^{13}$

On another level, white hegemony becomes an issue for Jewishness in America in the realm of multiculturalism. While Jews are considered among the hegemonic, dominant, white culture, they do separate themselves as a culturally identifiable group (Goldstein, 2006e). Within race-based epistemologies, it might be logical to identify among multicultural circles to better inform other groups about Jewish ethnic, cultural and religious ideals (even as the multicultural movement itself is waning and being redefined through Culturally Relevant and other pedagogical developments) (Ladson-Billings, 1995). Among scholarly researchers, Jewishness collides with whiteness for not being recognized or valued. On the other hand, Jews in the United States are considered white. "Jewishness is seen as adding nothing to a multicultural conversation; it is already implicitly included as part of the hegemonic 'White' conversation... There is no reason to devote any of our time to their particular experience" (Dollinger, 2018, as cited in Schraub, 2019, p.396) (See Table \#2b+c).

Jewish integration into colonized America meant that as light-skinned immigrants, they melded into the new world through acculturation and often at the compromise of Jewish religious convictions or erasure. White codes and laws of acceptance became part of the makeup of white supremacist culture, neutralizing peoples of all kinds along the way. White culture silently dictates the liminal space where Jews have resided to be both "inside" when defined as such and "outside" when unwanted. "The intersectionality of Jews is only being considered white when

\footnotetext{
13 An example of rising antisemitic incidents occurred in a three-month period in 2019: 80 tombstones toppled in the Omaha, Nebraska Jewish cemetery in late October; 100 gravestones desecrated in a Jewish French cemetery on Dec. 6, 2019; three people murdered in a shooting incident in a Kosher market in New Jersey on Dec. 12, $2019 ; 3$ Jewish students attacked at a fraternity in Bloomington, Indiana on Dec. 13, 2019; a synagogue ransacked and the Torah scrolls desecrated in Beverly Hills on Friday, Dec. 13, 2019. Does discourse shift when Jews are the target of racial (or antisemitic) acts?
} 
THE NEBRASKA EDUCATOR, VOLUME 6

issues of antisemitism does not exclude them" (Schraub, 2019, p. 398). People of color equate Jews as part of privilege and the dominant culture, not as a marginalized minority.

\section{Can Race-Based Epistemologies Provide more than a Lens for Color-blindness?}

After articulating the historical definitions of race and examining the blurred intersection of Jewishness and whiteness, we can now explore epistemologies that seek to modify whiteness in educational institutions. The final set of articles in this literature review will look at several female scholars who have contributed to anti- and decolonizing resources to understand how they deepen race-based work through narrative. Through their contributions, one can sift through the layers of the racial ideology embedded within educational epistemologies and consider avenues for action and change.

The narrative literature of women of color requires astute listening to the telling of what it means to be in liminal spaces, as described by Anzaldúa (2009) in La prieta, Chavez (2012) through her Chicana autoethnographic study and Bhattachariya (2015) through vulnerable personal accounts. Berry (2010 \& 2017) also leverages Critical Feminist Theory (CFT) and Africana studies to clarify how to center the voices of those previously not acknowledged within literature and the classroom. In their own way, each woman positions her story to provide a new consciousness of minoritized populations and the strength of self and truth in her own voice.

Anzaldúa (2009) brings the sacred and unspoken liminal space to the forefront and exposes "possibility" through uncomfortable and honest storytelling. The exposure of her soul in La prieta and the systematic, historical foundation she provides to define the mestiza within $L a$ Frontera relays the complexity of life at the Mexican/US borderland and crossroads. In $\mathrm{La}$ Prieta, Anzaldúa (2009) described herself as "a wind-swayed bridge, a crossroads inhabited by whirlwinds. Gloria, the facilitator, Gloria, the mediator, straddling the walls between abysses" 
THE NEBRASKA EDUCATOR, VOLUME 6

(p.45). Anzaldúa further articulates her struggle to balance the spaces between the dominant culture, as a woman of color, and at a continual juncture of varied identities. While there is no comparison to the reality of Gloria Anzaldúa's traumatic life experiences, nor the fraught marginalization of the Latino culture and history in this country, for this author, there are familiar tropes of racial separateness that are reminiscent of Jewish historical experiences.

Chávez (2012) reveals opportunities to position herself of marginalized Chicana spaces to produce autoethnographic testimonios as a vehicle for CRT methodology. Searching for the insight to understand the ideological constructs that drive hegemonic assimilation and silencing (Chávez, 2012), her work narrates personal experiences in white academia and other educational institutions where inequity and racism need to be flushed out. Chávez (2012) references the importance of narrative by quoting Ladson-Billings and Tate (1995) who "describe stories by people of color as a way to 'catalyze the necessary cognitive conflict to jar dysconscious racism' (Ladson-Billings and Tate, 1995, p. 58 as cited by Chávez, 2012, p. 342).

In much the same way, as a woman of color, Bhattacharya (2015) utilizes narrative to decolonize scholarship and to navigate a culture of racial marginalization within the academy. Referring to the use of her storytelling as a vulnerable space to explore inquiry, Bhattacharya's (2015) places of intersectionality provide the platform on which to challenge colonized discourse. Like Chávez, her experiences as a female, brown person have strengthened her determination in discovering and sharing that there are unique ways to imagine and obtain knowledge (Bhattacharya, 2015).

Finally, Berry (2017) notes that Western ideals meet the intersections of Africana Studies with languid enthusiasm. She reminds us that as education has become globally interconnected, it has "become more about Western competition and less about the exchange of ideas" (p. 54). 
THE NEBRASKA EDUCATOR, VOLUME 6

She uses her study to explain how Africana studies is a counter-narrative for social justice, bringing the archetypal "voices of Black, Africa studies' scholars - DuBois, Woodson, and Davis" to enrich the curriculum theory in her work (Berry 2017). She reminds us not only that narrative is critical as cultural enrichment but to remember that "there is more than one way to tell a story... and honor the multiple stories we bring to our learning experiences" (p.63).

Fortunately, increasing new scholarship on critical educational theories continues to expand on the foundations established by those mentioned above. Despite recent political attempts to maintain the status quo of the white establishment in our educational systems, marginalized voices continue to grow stronger. These female scholars lead by example to articulate how the intersection of identity provides a unique epistemology grounded in personal experience and narrative. They substantiate the idea that knowledge stemming from varied places and encounters can interrupt the hegemonic pattern dictating that there is only one way to know.

\section{Conclusion}

Research has exposed how the normalization of While educational standards often produce uniform consumers of knowledge. By clustering a seemingly disparate collection of scholarship, this literature review defined race and racism, explored the historical misconceptions that accompany the author's intersection of Jewishness and whiteness, and investigated race-based and decolonizing educational theories. The goal of presenting these concepts together was to acknowledge that a directional shift in centering marginalized voices might redefine how knowledge is acquired in our educational systems today.

Some researchers have leveraged critical theories to recognize the "intersectionality among whiteness, abuse, and teacher education" (Matias, 2016, p. 196). Matias (2016) explained 


\section{THE NEBRASKA EDUCATOR, VOLUME 6}

that identifying perpetuating theories that deflect whiteness is useful to deconstruct these recurring systems in our institutions and among teachers. Through her study, she implores us to reexamine our behavior and conceptualization of whiteness as we also embrace the differences of people and race. As exemplified in the literature review, methods to counteract sustained theories include introducing narrative and personal historical storytelling into classroom pedagogy.

Once more in my own scholarship, I marvel at the relevance and measures of humanity embraced by $20^{\text {th }}$ century, Polish (and Jewish) pedagogue Janusz Korczak. As we scrutinize the platforms discussed in this review in the $21^{\text {st }}$ century, Korczak questioned how social class, ethnicity, gender, and location impacted children's lives over 100 years ago. "Wading through his intersectionality, he found [that] the source of misery and oppression was often the imbalance of power between the worlds of the adult and the child" (Vucic, 2017, p. 163). A century after Korczak resisted the oppressive power structure he viewed as embedded within the European school system, we recognize these inequities in our own. Our task, therefore, is to continue to cultivate critical methodologies to counter the normalization of white cultural and social educational institutions. 
THE NEBRASKA EDUCATOR, VOLUME 6

\section{References}

Anzaldúa, G. (1987). Chapters 1\&2. Borderlands/La frontera (pp. 1-23). San Francisco, CA: Aunt Lute.

Anzaldúa, G. (2009). La prieta. In A. L. Keating (Ed.), The Gloria Anzaldúa reader (pp. 38-50). Durham, NC: Duke University Press

Bhattacharya, K. (2015). The vulnerable academic: Personal narratives and strategic de/colonizing of academic structures. Qualitative Inquiry, 22(5), 309-321.

Berry, T. R. (2010). Critical race feminism. In K. Kridel (Ed.), Encyclopedia of Curriculum Studies (1), 151-152. Thousand Oaks, CA: Sage.

Berry, T. R. (Summer-Fall, 2010). Engaged pedagogy and critical race feminism. Educational Foundations, 19-26.

Berry, T. R. (2017). The intersections of Africana studies and curriculum theory: A counterWestern narrative for social justice. Journal of Curriculum Theorizing, 32(1), 53-66.

Chavez, M. S. (2012). Autoethnography, a Chicana's methodological research tool: The role of storytelling for those who have no choice but to do critical race theory. Equity \& Excellence in Education, 45(2), 334-348.

Crenshaw, K. (1991). Mapping the margins: Intersectionality, identity politics, and violence against women of color. Standford Law Review, 45(6), 1241-99.

Delgado, R. \& Stefancic, J. (2001). Introduction. Critical Race Theory: An Introduction (pp. 115). New York: New York University Press.

Delgado Bernal, D. (2002). Critical race theory, Latino critical theory, and critical racedgendered epistemologies: Recognizing students of color as holders and creators of knowledge. Qualitative Inquiry, 8, 105-126. 


\section{THE NEBRASKA EDUCATOR, VOLUME 6}

Dictionary of Races or Peoples, (1911), Washington, DC: Government Printing Office, pp. 11-5, 73-74.

Dixson, A. D., James, A., \& Frieson, B. L. (2018). Taking it to the streets. Critical race theory, Participatory research and social justice. In Understanding Critical Race Research Methods and Methodologies, 64-75. doi: 10.4324/9781315100944-6

Golash-Boza, T. M. (2019). Race and racisms: a critical approach. (pp.3-31) New York: Oxford University Press.

Goldstein, E. L. (2006a). Introduction. The price of whiteness: Jews, race, and American identity. (pp.1-8). Princeton, NJ: Princeton University Press.

Goldstein, E. L. (2006b). "Different Blood Flows in our Veins": Race and Jewish Self-Definition in Late-Nineteenth-Century-America. The price of whiteness: Jews, race, and American identity. (pp.11 -31). Princeton, NJ: Princeton University Press.

Goldstein, E. L. (2006c). What are We?; Jewishness Between Race and Religion. The price of whiteness: Jews, race, and American identity. (pp. 68 - 115). Princeton, NJ: Princeton University Press.

Goldstein, E. L. (2006d). World War II and the Transformation of Jewish Racial Identity. The price of whiteness: Jews, race, and American identity. (pp.189 - 208). Princeton, NJ: Princeton University Press.

Goldstein, E. L. (2006e). Epilogue, Jews, Whiteness, and “Tribalism” in Multicultural America. The price of whiteness: Jews, race, and American identity. (pp. 211 - 239). Princeton, NJ: Princeton University Press.

hooks, b. (2004). Understanding patriarchy (pp. 17-33). The will to Change: Men, Masculinity, and Love. New York: Atria Books. 
THE NEBRASKA EDUCATOR, VOLUME 6

Jupp, J. C. (2020). First-wave critical white studies. In Encyclopedia of Critical Whiteness Studies in Education (pp. 222-230). Brill Sense.

Jupp, J. C.; Berry, T. R.; Morales, A; Mason, A. M. (2018). What is to be done with curriculum and educational foundations' critical knowledges? Toward critical and decolonizing education sciences. Teaching Education, 29, 305-317.

Kohli, R. (2008). Breaking the cycle of racism in the classroom: Critical race reflections from future teachers of color. Teacher Education Quarterly, 35(4), 177-188.

Ladson-Billings, G. \& Tate, W. F. (1995). Toward a critical race theory of education. Teachers College Record, 97, 47-68.

Lewowicki, T. (1994). Janusz Korczak. Prospects, 24(1-2), 37-48. doi: 10.1007/bf02199005

Matias, C. (2016). Why do you make me hate myself: Re-teaching whiteness, abuse, and love in urban teacher education, Teaching Education, 27, 194-211.

McIntosh, P. (1988). White privilege male privilege: A personal account of coming to see correspondences through work in women's studies (Working Paper No. 189). Wellesley, MA: Wellesley Center for Research on Women.

Morales, A., Abrica, E., \& Harrera, S. (2019). The Mañana Complex: A Revelatory Narrative of White Innocence and Racial Disgust Toward Mexican American Children. The Urban Review. DOI: https://rdcu.be/bmtTu

Omi M. \& Winant, H. (2014). Racial Formations in the United States. Book overview. (p. 3-13).

Patel, L. (2016). Chapter 1: Educational research as a site of coloniality, (pp. 11-28). Decolonizing Educational Research. New York: Routledge.

Picower, B. (2009). The unexamined whiteness of teaching: How white teachers maintain and enact dominant racial ideologies. Race Ethnicity and Education, 12(2), 197-215. 


\section{THE NEBRASKA EDUCATOR, VOLUME 6}

Scheurich, J. J. \& Young, M. (1997). Coloring epistemologies: Are our research epistemologies racially biased? Educational Researcher, 26(4).4-16.

Schraub, D. (2019). White Jews: An intersectional approach. AJS Review, 43(2), 379-407. doi:10.1017/S0364009419000461

Smedley, A. (2007). The history of the idea of race... and why it matters. At Race, Human Variation and Disease; Consensus and Frontiers. Address conducted at the American Anthropological Association (AAA) Conference. Warrenton, Virginia.

Vucic, B. (2017). The colonization of childhood: The critical pedagogy of Janusz Korczak. Symbolic violence in socio-educational contexts, 161. 
THE NEBRASKA EDUCATOR, VOLUME 6

\section{Appendix}

Table 1: Dictionary of Races or Peoples (Washington, DC: Government Printing Office, 1911, pp. 1, 2, 5, 73)

A. Title page and introductory pages
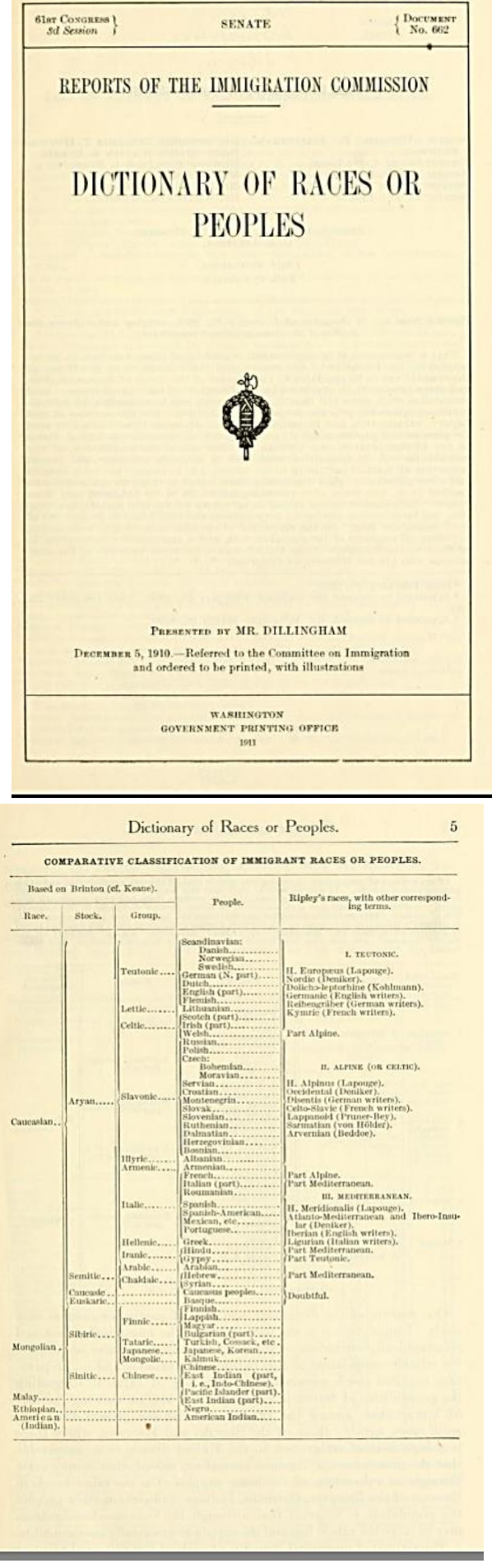

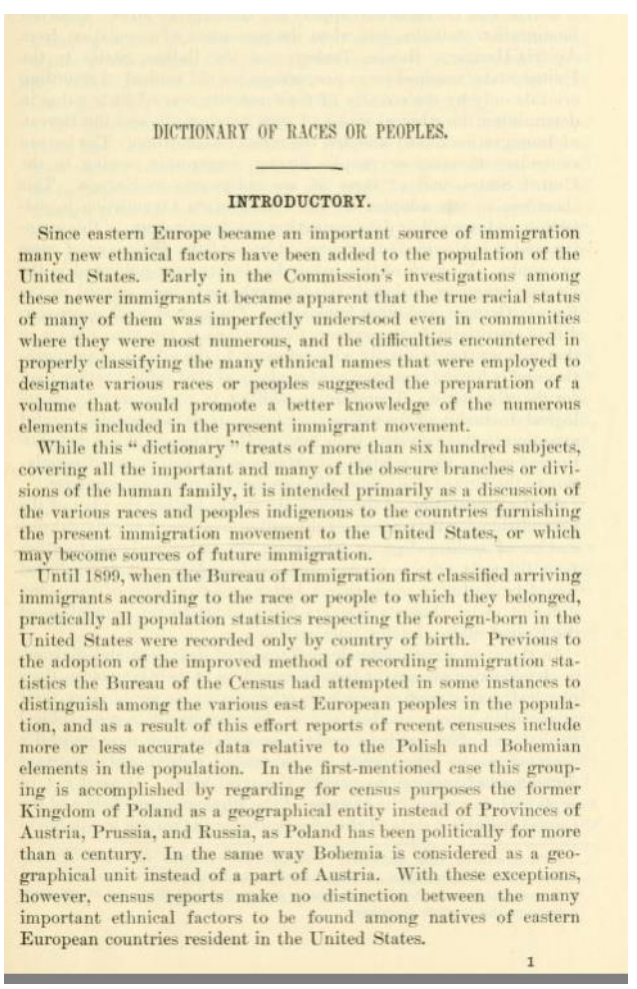

Since eastern Europe became an important source of immigration many new ethnical factors have been added to the population of the these newer immigrants it became apparent that the trae racial statn of many of them was imperfectly understood even in communities properly clascifying the many ethnieal names that were employed to

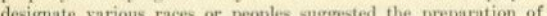
olume that would promote a better knowledme of the numerons European countries resident in the United States, 


\section{B. Entry for: Hebrew, Jewish, or Israelite (Note the brief entry for "Hawaiian or Sandwich Islander" as opposed to the complex history of the "Hebrews," which although not displayed in its entirety here, continues for three pages.}

\begin{tabular}{|c|c|}
\hline Dictionary of $\mathrm{R}$ & aces or Peoples. \\
\hline 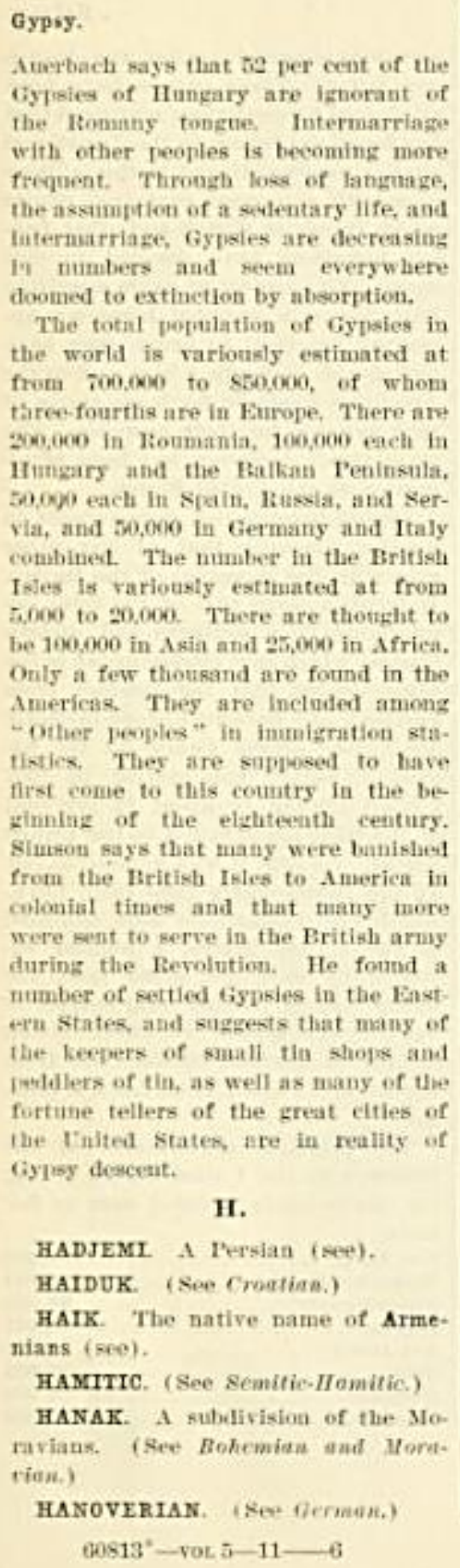 & 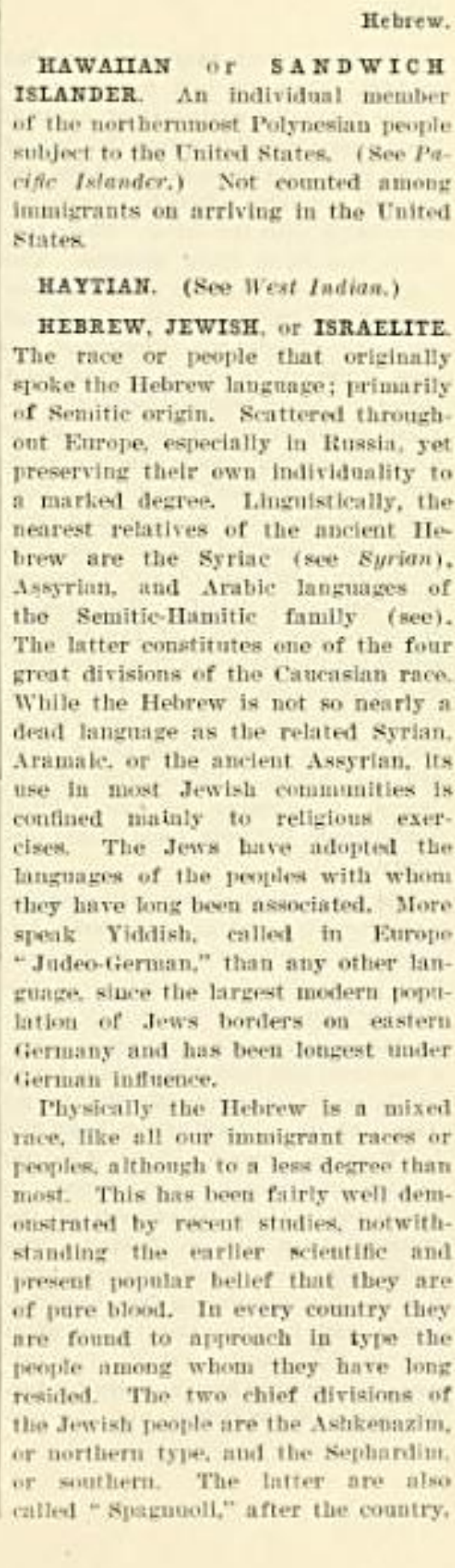 \\
\hline
\end{tabular}


THE NEBRASKA EDUCATOR, VOLUME 6

Table 2: Schraub (2019) Footnotes regarding Intersectionality of Whiteness and Jewishness

\begin{tabular}{|c|c|}
\hline \multicolumn{2}{|c|}{ Intersectionality of Whiteness and Jewishness } \\
\hline $\begin{array}{l}\text { a. Intersectionality of } \\
\text { Jews and } \\
\text { Whiteness }\end{array}$ & $\begin{array}{l}\text { Schraub's Footnotes reference the marginalization of Jews } \\
\text { throughout history and incongruencies of self and outward } \\
\text { identification: } \\
\text { The concept of the Jew as even being potentially White is of } \\
\text { relatively recent vintage. As racial discourse began to emerge } \\
\text { in Europe in the seventeenth century, the general (though not } \\
\text { universal) view was that Jews were at the very least racially } \\
\text { Other and perhaps even "Black." This went hand in hand with } \\
\text { Jewish subordination - Jewishness and Blackness reciprocated } \\
\text { and reinforced one another, as both served as markers of } \\
\text { disease, ugliness, and inferiority of all sorts. } \\
\text { (Schraub, 2019, p. 379-380) }\end{array}$ \\
\hline $\begin{array}{l}\text { b. } \begin{array}{l}\text { Exclusion in } \\
\text { multicultural } \\
\text { discourse }\end{array} \\
\end{array}$ & $\begin{array}{l}\text { Schraub's Footnotes reference the following articles that reflect } \\
\text { discourse about Jews included/excluded in multicultural trends } \\
\text { See, e.g., Michael Galchinsky, "Glimpsing Golus in the Golden } \\
\text { Land: Jews and Multiculturalism in America," Judaism 43, no. } \\
4 \text { (1994): 360-68; Peter F. Langman, "Including Jews in } \\
\text { Multiculturalism," Journal of Multicultural Counseling \& } \\
\text { Development 23, no. } 4 \text { (1995): 226-36; Dan Ian Rubin, "Still } \\
\text { Wandering: The Exclusion of Jews from Issues of Social } \\
\text { Justice and Multicultural Thought," Multicultural Perspective } \\
\text { 15, no. } 4 \text { (2013): 213-19; Rubin, "Whiter Shade of Pale: } \\
\text { Making the Case for Jewish Presence in the Multicultural } \\
\text { Classroom," International Journal of Multicultural Education } \\
\text { 19, no. } 2 \text { (2017): 131-45. } \\
\text { (Schraub, 2019, p. 395) }\end{array}$ \\
\hline $\begin{array}{l}\text { c. Implication of } \\
\text { Jewish hegemonic } \\
\text { white privilege } \\
\text { and complicity }\end{array}$ & $\begin{array}{l}\text { Schraub's Footnotes reference explicit dismissal of aligning } \\
\text { Jewishness with "Otherness" } \\
\text { Rosa Pegueros recounts an experience where two mentions } \\
\text { of Jewishness on a listserv for contributors to Gloria E. } \\
\text { Anzaldúa and AnaLouise Keating's This Bridge We Call } \\
\text { Home: Visions for Radical Transformation (New York: } \\
\text { Routledge, 2002) sufficed to elicit complaints about Jewish } \\
\text { take-over of the space. Rosa Maria Pegueros, "Radical } \\
\text { Feminists-No Jews Need Apply,"Nashim } 8 \text { (2004): 174- } \\
\text { 80. Her experience coheres with my own. } \\
\text { (Schraub, 2019, p. 396) }\end{array}$ \\
\hline
\end{tabular}




\title{
Multiracial Individuals and Educational Testing
}

\author{
Karen Alexander \\ Department of Educational Psychology \\ University of Nebraska-Lincoln
}

\begin{abstract}
A literature review focused on quantitative measures and methods regarding multiracial individuals and educational testing revealed that multiracial individuals are uniquely different than monoracial individuals in terms of their racial identity and these unique identities interact with test scores. Until recently, this uniqueness has been ignored by institutions and within the field of educational testing. The uniqueness of multiracial identity should be taken into consideration when using test measures to make decisions for selection and when comparing group outcomes. The review provides a brief picture regarding the history of categorization of multiracial individuals and current research which connects the multiracial experience to test score performance, followed by information on data collection, data coding, data analysis, implications, and recommendations. Suggested methods to address the methodological and analytical challenges of how to categorize multiracial individuals for purposes of group comparisons are challenging and frankly, unsatisfying. Yet, there are some clear recommendations such as allowing individuals to check as many racial/ethnic categories that apply to their identity versus forcing a choice of one race or using "Other" as an option. The limited research regarding multiracial individuals and educational tests supports the need for further research in this field.
\end{abstract}

Keywords: multiracial identity, educational tests, racial identity, standardized tests, psychometrics 
THE NEBRASKA EDUCATOR, VOLUME 6

In 1997 Tiger Woods, who is one-fourth Black, one-fourth Thai, one-fourth Chinese, one-eighth White and one-eighth American Indian, identified himself as "Cablinasian" (AP News, 1997). Tiger's statement made national news due to his unique descriptor of how he identifies racially/ethnically, and because it brought to light the challenge that many, if not all, multiracial people in the United States have in terms of racial/ethnic identity. Multiracial individuals do not fit neatly into the demographic boxes that have been used in the past by the U.S. Census Bureau (USCB) (Jones \& Smith, 2001), in surveys, and on standardized testing materials, etc. The complexity of racial/ethnic identity for people like Tiger Woods has ramifications on the interpretations and use of test scores categorized by race/ethnicity in terms of validity and reliability. The purpose of this review is to summarize the literature regarding the educational testing of multiracial individuals in terms of measurement practices, and implications for research as well as policy, and recommendations, particularly in terms of categorization of race/ethnicity. Because educational test scores are used for many decisions such as college admittance, scholarship offers, course options for students, etc., it is important to understand the effects of test scores on multiracial individuals. The main body of this manuscript is preceded by a framework that includes some historical background, definitions of terms and a review of research demonstrating that identifying multiracially is quantitively different than identifying as a monoracial individual and these differences are meaningful within the context of educational testing.

\section{Framework}

\section{Definitions and Historical Background}

According to the U.S. Census Bureau (2017), race is a person's social group(s) selfidentification, while ethnicity refers to whether someone's origin is Hispanic or Latino. Based 


\section{THE NEBRASKA EDUCATOR, VOLUME 6}

upon these definitions, a multiracial person would be someone who would identify with at least two racial social groups. These definitions indicate that the USCB has chosen to use social construction to define race. Others have proposed using biology to define race, but genetics does not support this definition (Sternberg et al., 2005). The social construction definition of race is what is used within this manuscript. It is important to note that race and ethnicity are not mutually exclusive, which makes research involving race somewhat challenging and it means that at times race and ethnicity may be used interchangeably within this manuscript.

It was not until 1997 that the USCB gave the option to individuals to mark more than one race, so the first U.S. census that included this option was conducted in the year 2000. Options for racial social groups on the 2000 U.S. Census were: "white", "black or African American", “American Indian and Alaska Native", "Asian”, and "Native Hawaiian and Other Pacific Islander". Prior to 2000 multiracial people had the option of checking a box labeled "Other" and writing in their racial identity. For statistical purposes, the USCB used whichever racial category was listed first in the "Other" category, assigning multiracial individuals to one race.

In 2010 the USCB had the following options for racial groups and allowed people to mark more than one box: "white", "black, African American, or Negro", "American Indian or Alaskan Native”, “Asian Indian”, “Japanese”, “Native Hawaiian”, “Chinese”, “Korean”, “Guamanian or Chamorro", "Filipino”, "Vietnamese”, “Samoan”, “Other Asian”, “Other Pacific Islander", and "Some other race". The increase in options did not lead to less people identifying as Multiracial. In fact, the estimated multiracial population in the United States grew from 6.8 million to 9.0 million between the 2000 and 2010 U.S. Census (Jones \& Bullock, 2012).

Similarly, students have had to self-identify according to racial groups for the purposes of educational testing. Educational testing within this review is defined as any kind of standardized 
THE NEBRASKA EDUCATOR, VOLUME 6

measurement of student behavior, knowledge, or ability (American Educational Research Association (AERA) et al., 2014), that is used within the field of education. Examples of educational tests are state accountability tests, nationally administered tests such as The Iowa Assessments (Riverside Insights, 2021), and college admissions exams such as The SAT (College Board, 2021) and the GRE (Graduate Record Examinations) (ETS, 2021). Assessments that are not standardized, such as classroom tests, are excluded from this definition of educational testing.

While the US Census is not a "test", often whatever racial/ethnic categories are used by the USCB are frequently used by researchers, testing companies, government agencies, etc. Initially USCB data, and the lack of allowance for multiple races on USCB data, may seem to have no connection to the use of racial/ethnic identity on tests. However, due to the historical background of race and slavery in America, there are significant connections. One of the first connections can be made with the outcome of Plessy vs. Ferguson (1896), which essentially stated that racial segregation was constitutional if services provided were "equal". Plessy, the plaintiff in the case, was Multiracial and was seven-eighths Caucasian and one-eighth Black. Based upon the court's decision, someone who was Multiracial was in the end, assigned the minority race. While Plessy's case had to do with which rail car he could sit in, based upon race, the outcome of this case led to continued segregation throughout the United States in many institutions, including education, which led to comparison of educational outcomes by race/ethnicity to demonstrate that the services offered were "equal". Even after desegregation, educational outcomes continue to be assessed along racial/ethnic categories to assess concerns with fairness and equity. 
THE NEBRASKA EDUCATOR, VOLUME 6

Prior to allowing students to choose multiple racial/ethnic options or to selecting an option such as Two or More Races, students were forced to select one option. The practice of forcing multiracial students to choose one racial/ethnic category puts into question the validity of results that compare outcomes by race/ethnicity used in evaluating racial/ethnic group differences. Test scores are considered valid when there is sufficient evidence and theory to support the interpretation of scores for the intended purposes (AERA et al., 2014). Valid test scores are measuring what they are intended to measure, not other factors. Additionally, the practice of forcing multiracial students to choose one race raises questions about the reliability of test scores, in terms of consistent results across multiple test administrations (AERA et al., 2014), when interpreting racial/ethnic group mean scores. By forcing multiracial students to choose one race their test scores were included in race/ethnic group means that do not necessarily represent how they identify racially/ethnically. The guideline given in the Standards for Educational and Psychological Testing (AERA et al., 2014) states that when reporting scores for subgroups, such as by racial/ethnic categories, the subgroups are to be clearly defined and the construct measured needs to be comparable across groups. The practice of forced choice option for racial/ethnic identification seems to be in direct contradiction to the guideline.

\section{Multiracial Identification}

Research on the theory of racial identity first posited that multiracial individuals developed their identity through a "marginal man" model (Shih \& Sanchez, 2005). The "marginal man" model states that those who are biracial exist on the margins of society as they live within two different worlds (Park, 1928). However, with time the "marginal man" model was seen as a negative approach to racial identity and new theories were posited in which multiracial identity was the same, or "equivalent" to monoracial identity development (Shih \& 


\section{THE NEBRASKA EDUCATOR, VOLUME 6}

Sanchez, 2005). Following the "marginal man" model was the variant model which established that racial identification for multiracial individuals is uniquely different than that of monoracial individuals (Poston, 1990). In the variant approach multiracial individuals are thought to arrive at an integrated multiracial identity. Further research has countered the variant approach and has led to an ecological model (Rockquemore et al., 2009). The major assumptions of the ecological model are: 1) multiracial individuals are fluid in their racial identity based upon contextual factors, 2) the process of racial identity for multiracial individuals is not linear and is a lifelong process, 3) forcing multiracial individuals to identify as Multiracial or Monoracial perpetuates the same issues in terms of analysis of outcomes by racial/ethnic categories (Rockquemore et al., 2009).

The fluidity of racial identification among multiracial individuals based upon social context is supported by a review of multiracial identity literature conducted by Shih \& Sanchez (2005). Factors such as the parental identification of race/ethnicity for their multiracial children (Campbell \& Eggerling-Boeck, 2006), geographic location (Brunsma, 2006), changes in social groups over a lifespan (Hitlin et al., 2006), and peers (Renn, 2003), all affect how multiracial individuals identify racially/ethnically at any one time.

The complexity of the socialization of multiracial individuals can be seen by the mixed and somewhat contradictory results of a study conducted by Pearce-Morris and King (2012) that analyzed the well-being of multiethnic children (multiethnic was used within this study for people who identify as two or more races or ethnicities) compared to monoethnic children (referred to as same-ethnic in the study). When controlling for background and family characteristics, relationship stressors, and quality of parenting, multiethnic children were found to have a statistically significant negative affect compared to their monoethnic peers, yet there 


\section{THE NEBRASKA EDUCATOR, VOLUME 6}

were no differences found between the two groups in overall well-being, positive affect, or behavior problems. These results are particularly important as monoethnic children were used as a control group, which means that the higher negative affect for multiethnic children is significant beyond what is expected in the population. The authors were not able to explain these contradictory findings but noted that these results could be due to sample characteristics.

When analyzing young adults who identified as Asian/White in America and Canada it was found that those with an integrated view of their racial identity (equally positive feelings towards being Asian and White) had lower distress levels than those who identified primarily as Asian or White (Chong, 2012). Villegas-Gold and Tran (2018) also found significant positive relationships between an integrated view of racial identity, well-being, and self-esteem. Multiracial individuals who lived in families in which socialization celebrated the different racial/ethnic identities within the family demonstrated greater well-being than those whose families were less egalitarian in their socialization. But the relationship between an integrated racial identity and self-esteem was moderated by the physical appearance of multiracial individuals. Specifically multiracial individuals with more phenotypic racial ambiguity (physical features that make it harder for others to racially categorize someone) were found to have lower levels of self-esteem.

Differences between multiracial students and monoracial students in terms of academic achievement have seen mixed results in the research. Research by Herman (2009) found no difference in academic achievement between multiracial and monoracial students when accounting for the type of educational program within the school (college preparatory versus general education, vocational, English as a second language or business track) but Herman (2009) found that a student's multiracial racial identity has a statistically significant effect on 


\section{THE NEBRASKA EDUCATOR, VOLUME 6}

student's academic performance. Students who are Black/White or Hispanic/White and identify themselves as White had statistically significantly higher grades then those who identified themselves as Black or Hispanic. There was no statistically significant difference in achievement for Asian/White students who identified as Asian. These results were found while controlling for demographic, contextual, and prior achievement factors. The results indicate that there is an interaction between racial identity for multiracial youth who identify with the minority portion of their race and that their achievement is different from their peers. Phinney and Alipuria (1996) found no difference between multiracial youth and their monoracial peers in academic performance while in high school based on GPA. Harris and Thomas (2001) found similar results with the exception that Asian/White students had statistically significantly worse GPAs than White or Asian students, when controlling for school racial composition.

While research involving multiracial individuals is complex and there exists some contradictory findings, based upon the above research it is argued that multiracial individuals are different enough in their socialization compared to their monoracial peers that they should be treated differently when looking at group differences. Both increased distress levels and negative affect have been shown to decrease student scores on tests (Jones, 1994; Pretz, Totz, \& Kaufman, 2010; Shang et al., 2013) and there are clearly contextual factors involving racial/ethnic identity that influence achievement of multiracial individuals. Additionally, multiracial youth who self-identify with a minority race may be impacted by stereotype threat (Herman, 2009). Stereotype threat occurs when a person of minority status feels anxious about confirming a negative stereotype and this feeling causes the test-taker to score lower than predicted (Steele \& Aronson, 1995; Wicherts et al., 2005). The student is aware of the negative 
THE NEBRASKA EDUCATOR, VOLUME 6

stereotype which exists for her/his racial identity and the fear of reinforcing this stereotype by scoring low on the test leads to a lower test score then would be expected for that student.

\section{Search Method}

For this literature review an initial web search of the APAPsycInfo database was conducted using the following phrases "educational testing biracial and multiracial", "testing multicultural students", "student self-report of race ethnicity", "educational testing ethnic minorities", and "analysis by student race ethnicity". Articles were then chosen to provide a general picture of what quantitative research has shown regarding multiracial individuals and educational testing. The focus of this article was on quantitative methods of measurement and therefore qualitative and mixed methods studies were not included in the review.

Based upon feedback provided by peer review further systematic searches were done of the literature. A search of the terms "achievement test*" OR "standardized test*" OR "educational test*" AND "biracial" OR "multiracial” OR "two or more races" resulted in 11 articles between 1968 - 2020 in the APA PsycInfo database and in six articles between 1975 2020 in the ERIC ProQuest database. None of these were relevant to this review. A further search of the terms "ACT" OR "SAT" OR "PSAT*" OR "PreACT" OR "Stanford Achievement" OR "Stanford 10" OR "Iowa Assessment*" OR "Iowa Test of Basic Skills" OR "GRE" OR "TOEFL" OR "Educational Records Bureau" OR "ERB" OR "CTP" OR "Terra Nova" OR "Comprehensive Testing Program" OR "California Assessment" OR "AP" AND "biracial" OR "multiracial" OR "two or more races" OR "multiple races" in ERIC ProQuest resulted in 19 articles and in APAPsycInfo in 39 articles. From the above only five articles were applicable to this review. Secondary searches through the websites of educational testing companies were then used to find specifics to individual tests. With the notable exceptions of the College Board, ACT 
THE NEBRASKA EDUCATOR, VOLUME 6

and ETS, most educational testing companies do not share any information regarding their tests. One can clearly see between the literature review and educational testing websites that there is limited research regarding educational testing and multiracial individuals.

While a few articles that individually address data collection, data coding, and/or data analysis of multiracial individuals could be found, none were found that address these topics collectively within educational testing. This review fills that gap in the literature. Often race and ethnicity are used interchangeably, which can lead to confusion. For brevity in writing, this review focuses on multiracial individuals versus multiethnic individuals. But, as noted above, the lines between the two are not clear. At times it may seem that the language used within the manuscript is contradictory in terms of race versus ethnicity and some of the terms used are offensive by today's standards. An effort was made to remain true to the content of the summarized research by using the language used within the cited research. When quoting racial/ethnic categories from an instrument, such as the U.S. Census, the terms are written within this manuscript as they are on the instrument. Otherwise, all race/ethnicity categories that are used as noun within the manuscript are capitalized, including Multiracial, to be uniform.

\section{Review Results}

This section is divided into five categories: data collection, data coding, data analysis,, implications, and recommendations. The discussion section includes potential impacts on policies, limitations of the review, as well as suggestions for further research.

\section{Data Collection}

Educational testing manuals reveal the lack of accounting for multiracial students when asking students to self-report their racial/ethnic identity. Only recently, in 2015-2016, did the SAT Suite of Assessments (the SAT, PSAT/NMSQT, PSAT 10, and PSAT 8/9 tests) add two 
THE NEBRASKA EDUCATOR, VOLUME 6

new options for Race/Ethnicity categories: Native Hawaiian or Pacific Islander and Two or More Races (Marini et al., 2019). A review of the ACT® Technical Manual (2020a) does not include multiracial individuals when reporting the demographics of test-takers until 2015-2016. The SAT Suite of Assessments Technical Manual (2017) does not include students of Two or More Races as the data came from the 2011 - 2014 cohort, which was prior to the inclusion of Two or More Races as an option. The Iowa Assessments (Riverside, 2012), a K-12 standardized achievement test, uses the 2010 U.S. Census ethnic and racial groupings by first having students indicate ethnicity as Hispanic or Non-Hispanic and then by selecting among racial categories which includes the option of Two or More Races. A test administration manual from 2010 for the Stanford Achievement Tests Series, Tenth Edition (a set of standardized, nationally normed achievement tests for students in grades $\mathrm{K}-12$ ) for the state of Arkansas gives directions for students to choose all racial/ethnic categories that apply (Arkansas Department of Education \& NCS Pearson, 2010). It could not be determined when tests such as the Iowa Assessments and the Stanford achievement Tests started to have these kinds of options for students to select more than one racial/ethnic identity. As of the 2018 administration of the GRE, a standardized test used by many colleges as part of graduate admissions, there was not an option for GRE test takes to identify as two or more races/ethnicities (ETS, 2019). It is important to note that it could not be determined from the literature if GRE test takers are able to select more than one race/ethnicity.

\section{Data Coding}

Allowing test takers to select multiple racial/ethnic categories or to select an option which indicates they identify as multiple races raises several challenges for researchers if the goal is to compare outcomes across racial/ethnic categories. The practical issue in coding the 


\section{THE NEBRASKA EDUCATOR, VOLUME 6}

data of multiracial individuals is simply that individuals can only be counted once in the same study. This is one of the reasons why the USCB and previous studies assigned people one race. There is no easy solution to this dilemma. Options are to treat all multiracial individuals as their own group, or to further break the multiracial group down into respective parts so that someone who identifies as Black/White is in a different category than someone who identifies as Asian/Hispanic. A question this author has had is whether it is possible to use fractions to represent people, such as someone who identifies as Asian/White coded as .5 Asian and .5 White.

Support for having multiracial individuals be their own racial category is the commonality that they share, the factor of belonging to more than one racial social category and most likely being influenced by multiple cultural values. Research has shown that multiracial youth are more aware of the concept of race at an earlier age than monoracial youth, including monoracial youth of minority status (Kich, 1992, Root, 1992). Additionally, the fluidity of racial/ethnic identity among multiracial individuals (Doyle \& Kao, 2007; Harris \& Sim, 2001) lends itself to multiracial individuals being their own category. How a multiracial student identifies racially/ethnically depends upon a variety of factors such as the options available on the demographic question (Harris \& Sim, 2001), the racial/ethnic background of the multiracial student (students who are partially Black tend to identify as Black) (Doyle \& Kao, 2007; Phinney \& Alipuria, 1996), and social context (Phinney \& Alipuria, 1996). Multiracial students attending a predominately white college campus were found to identify as White more often than multiracial students attending a minority white college campus. This fluidity does not exist for monoracial students (Phinney \& Alipuria, 1996). 


\section{THE NEBRASKA EDUCATOR, VOLUME 6}

The argument for breaking multiracial group data down into more granular data is based on the idea that there are still differences within multiracial people that are important. Research has shown there are different outcomes for members of different multiracial groups (Campbell, 2009; Charmaraman, Woo, Quach, \& Erkut, 2014). Because race is a social construct the racial identity of multiracial students is influenced by their socialization experiences, which are affected by geography. For example, a multiracial student in Hawaii is going to have a different socialization experience than a multiracial student in Nebraska and those differences need to be taken into consideration (Herman, 2009). These differences exist for many reasons, one of which is simply that $24.0 \%$ of people in Hawaii identify as Multiracial while $2.3 \%$ of people in Nebraska identify as Multiracial (Jones \& Smith, 2001). Lumping all multiracial individuals into one category does not account for these differences. These differences speak to the greater variability that exists within racial/ethnic groups than between them (Suzuki \& Valencia, 1997). Due to the large variability within multiracial individuals and since they are a minority, studies that include multiracial identity as its own racial category need to be very careful in thinking through the approach to sampling (Root, 1992). Small subgroup population numbers tend to not properly measure group characteristics which means the results are not generalizable to the larger multicultural population (Goldstein \& Morning, 2000; Herman, 2009).

The use of fractions to code for racial/ethnic categories will lead to needing to use more careful contrasts in coding to look at differences and this solution suffers from the same issue as all studies that compare differences by race, it assumes that race/ethnicity are mutually exclusive. Literature analyzing this approach was not found except for one study that looked at fractional assignment to analyze trends in race across the United States from 1990 to 2000 (Allen \& Turner, 2001). Prior to 2000 it is impossible to know the number of people who identified as 


\section{THE NEBRASKA EDUCATOR, VOLUME 6}

Multiracial when using data from the USCB. Allen and Turner (2001) did find fractional assignments that could be used for some biracial individuals. But there are many limitations to their study. For example, they did not include Hispanics in the study, which constituted approximately $8 \%$ of the U.S. population at the time. Due to the struggle for many to distinguish between race and ethnicity, they could not find fractional assignments for biracial individuals who are part American Indian or Alaska Natives, and the study only applied to those who identify as Biracial. Another option is to use imputation methods that make use of a "primary race" assignment and covariates (Schenker \& Parker, 2003). But this option is only possible if past research has some form of multiple race measurement, which most educational tests lack.

\section{Data Analysis}

In testing, between-group variability (differences in two or more groups) is compared to within-group variability (differences among members of the same group) to determine if the differences between two groups is significant. Concerns of fairness or equity arise if patterns of differences exist between test scores and variables for different groups (Camilli, 2006). No analyses of racial/ethnic comparisons could be found pertaining to K-12 achievement tests such as the Iowa Assessments or the Stanford Achievement Tests. The review revealed that often even if data on multiracial students was available, that data was not necessarily used in analyses of outcomes. When using data from 2015-2016 to compare student performance on the ACT by race/ethnicity the multiracial group is not included (as well as other racial groups such as American Indian/Native Alaskan, Native Hawaiian/Other Pacific Islander, etc.) (ACT, 2020a), yet these groups were included in the collection of demographic information within the same manual. The ACT® Technical Manual (2020a) does not state why these groups were not included in the analysis. ETS has a collection of studies which analyze GRE performance by 
THE NEBRASKA EDUCATOR, VOLUME 6

ethnic groups, not by racial groups (Wendler \& Bridgeman, 2014). A search of the term ethnic throughout the collection reveals that none of the included studies had a category for multiple ethnicities.

More students identified as Two or More Races $(\mathrm{N}=464)$ from a pilot test of the PreACT in May 2016 than as Asian $(\mathrm{N}=364)$ and yet, students identifying as Two or More Races were not included in the racial/ethnic subgroup analyses of PreACT scores, while the smaller sample of students who identify as Asian was included. Obviously students who identify as Asian should be included in racial/ethnic subgroup analyses of tests scores. But it seems that it is also obvious that the data exists with a large enough sample size for multiracial students to be included in the subgroup analysis and yet, they were not.

Psychometrically a test is considered "fair" when individuals from different groups, of the same ability, have similar average item scores (Camilli et al., 2013). Psychometrics is the study of tests used to measure psychological constructs such as intelligence or achievement (Price, 2017). Tests would be considered "fair" if multiracial individuals of certain abilities had comparable scores to equal ability members from other racial groups. But to whom should we compare multiracial individuals? To the majority racial group, as we do minority groups? Or, should we compare them to the multiple racial groups to which they self-identify? And, what are the consequences of choosing one comparison over the other?

One can measure this concept of "fairness" by measuring what is known as differential item functioning (DIF). There are two kinds of DIF, content relevant DIF and content irrelevant DIF. Content relevant DIF occurs when the items on the test accurately distinguish between test takers on the construct of measure, such as differentiating between those with low and high math achievement. Content irrelevant DIF occurs when items on the test inappropriately distinguish 


\section{THE NEBRASKA EDUCATOR, VOLUME 6}

between test takers based on something other than the construct of measure, such as students of different race/ethnicities of similar ability having statistically different scores on an item (AERA et al., 2014). Presence of content relevant DIF and lack of content irrelevant DIF provide evidence towards test score validity. It is standard procedure for test makers of standardized tests to assess DIF across racial/ethnic categories in test preparation so that items that demonstrate content irrelevant DIF can be eliminated from the test. When measuring DIF the practice has been to use the majority group, White, as the reference group (Camilli, 2006) and to compare the minority group(s), the focal group(s), to the reference group. The Fairness Report for the ACT Tests 2015-2016 (2017) did not include multiracial individuals as a category when measuring DIF.

Tests such as the ACT and the SAT are often analyzed for predictive validity of college success as they may be used in determining college admittance or scholarships. The ideal would be that scores on these tests predict college success equally for members of all racial/ethnic groups. In the recent manuscript in which ACT evaluates the validity of ACT scores in predicting college first-term grades multiracial individuals are included in a category labeled “multiple/unknown" (Radunzel \& Mattern, 2020). A study on the predictive validity of the SAT found that students who identify as Multiracial perform better on the SAT (along with students who identify as White and Asian), than students from other racial/ethnic categories (Marini et al., 2019). SAT scores of students who identified as Two or More Races on the SAT in 2017 was found to "overpredict" those students first year college grade point averages (Marini et al., 2019), meaning that these students had slightly lower first year college grade point averages than expected given their scores on the SAT. An analysis of the effects of superscoring (students reporting the highest ACT subscores on college applications versus reporting scores from their 
THE NEBRASKA EDUCATOR, VOLUME 6

most recent ACT test) on subgroup differences in 2018 ACT scores included multiracial students as their own group (Mattern \& Radunzel, 2019). The study found that use of superscores versus reporting the most recent ACT scores did not affect subgroup differences.

Helms (2008) analyzed the effects of a variety of different cut scores on eligibility, such as might be used for college acceptance, between Black and White test takers when taking within-group variability into account. Data from 31 different studies in which cognitive ability test scores were grouped by race were analyzed. It was found that the use of the same cut scores across race led to statistically significantly harder standards for Black than White test takers, when within-group variability was not taken into consideration. The results varied depending upon the cut scores used, but regardless of which cut scores were used, the results indicate that the use of cut scores, which do not take into consideration within-group variability, favors White test takers. While this study only looks at Black and White test takers, it speaks to the need to include within-group variability when categorizing by race. The inclusion of within-group variability is even more important for those who are Multiracial as their within-group variability is even larger (Suzuki \& Valencia, 1997).

\section{Implications}

To have valid test interpretations, educational tests are given using standardized methods and procedures. When taking standardized educational tests students are asked at the beginning stages of the test to answer demographic questions such as birth date, gender, and race/ethnicity. While the demographic questions are standardized and test administrators may use the same phrases to guide students in answering the demographic questions, the actual act of having to answer questions about race/ethnicity may impact a multiracial test taker's score on the test due to anxiety about having to choose one race (Chong, 2012; Shih \& Sanchez, 2005). The actual 


\section{THE NEBRASKA EDUCATOR, VOLUME 6}

wording of the race/ethnicity identification question may impact the score on the test for a multiracial individual as research has shown that multiracial individuals take issue with having to identify as “other" (Johnson et al., 1997; Panter et al., 2009). In other words, multiracial students may feel as if they are being treated differently than monoracial students solely due to the demographic questions. Townsend et al. (2009) found that multiracial students forced to select one race had statistically significantly lower scores on performance self-esteem, feelings of agency, feelings of self-efficacy and motivation than those who could check all possible racial categorizations that applied. Aside from the negative psychological impact of having to select one race, lower values for agency, self-efficacy, and motivation have been shown to be related to lower achievement test scores (Bruning et al., 2011).

The most important implication is simply that any comparison along racial/ethnic categories should be questioned. When conducting research, one assumes that the groups being compared are mutually exclusive. Race and ethnicity are not mutually exclusive. And yet, it should also be noted that research which makes comparisons between racial/ethnic categories is valuable to assess important concerns such as fairness and equity (AERA et al., 2014).

Marini et al., 2019 states that due to the inclusion of Two or More Races on the suite of SAT assessments in 2016, the composition of all racial groups has changed which makes any comparisons to earlier SAT research inaccurate. The concern raised by Marini applies to all educational research that includes data in which multiracial students were forced to choose one racial/ethnic category including longitudinal comparisons by race/ethnicity that include data from earlier dates. The sheer number of educational studies for which this applies is simply astounding. The sample sizes for each racial/ethnic category are not accurate as they do not 
THE NEBRASKA EDUCATOR, VOLUME 6

reflect students who would have selected more than one category or the option of Two or More Races, had those options been available.

Some may argue that the number of multiracial students is so small that the changes in sample sizes are negligible. That may have been true at one time point, however recent figures indicate that the argument of being a negligible amount is no longer warranted. The PreACT, a nationally standardized test that is intended for students in the $10^{\text {th }}$ grade to predict how students would perform on the ACT exam, does not include multiracial individuals in its listing of fall demographics (ACT, 2020b). But 5.6\% of the Fall testing sample are listed as Other and 9.3\% are listed as Missing. Surely, these two categories contain a portion of multiracial individuals. PreACT 2018-2019 Operational Test Data reveal that more students identified as Two or More Races $(\mathrm{N}=36,466)$ than Asian $(\mathrm{N}=26,417)$ (ACT, 2020b). Approximately 4.4\% of all ACT test-takers in 2018 identified as Multiracial (Mattern \& Radunzel, 2019). A study of test validity for the SAT that was conducted in 2017 lists $4 \%$ of the sample identifying as Two or More Races and lists 3\% of SAT test-takers who were graduating seniors as Two or More Races (Marini et al., 2019). One cannot pick a date to determine when the number of multiracial individuals was large enough to make a difference in sample sizes. In addition, the effects of changes in subgroup sample sizes on study outcomes depends upon the overall studies initial sample size as well as subgroup sample sizes and the portions of each subsample to the overall sample size.

\section{Recommendations}

A study that compared the responses of multiracial people to different types of questions regarding their racial makeup found that multiracial people identified differently depending upon the type of question used, even when all question types allowed for the possibility of sharing that they were multiracial (Johnson et al., 1997). Multiracial individuals preferred questions about 


\section{THE NEBRASKA EDUCATOR, VOLUME 6}

race/ethnicity in this order: questions that allowed them to state that they are Multiracial, a forced-choice option in which they could choose "not classifiable", followed by a forced-choice option with "other" as an option. Respondents noted that the term "other" implies that you do not belong to a group.

More recently, a study conducted with the purpose of informing changes to the demographic questions on the GRE found that multiracial respondents most desired the opportunity to select more than one race (Klieger et al., 2013). Somewhat similarly to the finding by Johnson et al., (1997), some respondents in the more recent study expressed discomfort with an option of "Some Other Race" as "Some" was seen as pejorative. Respondents indicated that alphabetizing the racial/ethnic categories was seen as more neutral compared to what has primarily done in practice, which is to list White as the first option. The Urban Institute recently put out some guidelines for collecting racial/ethnic data (Schwabish \& Feng, 2021) that advise in place of the word "Other" one could use "Another Race", which is more inclusive language In terms of data coding, literature regarding other coding alternatives to distinguish between racial/ethnic groups could not be found. But some have suggested using additional measures to inform how to categorize students. Helms (2006) proposes the use of psychological constructs that deal with race/ethnicity in place of current racial grouping practices to account for the interaction between racial identity and test scores. If this approach is used then fairness is not test dependent, but rather is sample dependent. According to the joint American Educational Research Association (AERA), American Psychological Association (APA) and National Council on Measurement in Education (NCME) 2014 Standards, fairness is interpreted as "responsiveness to individual characteristics and testing contexts so that test scores will yield valid interpretations for intended uses." (p. 50). Helms (2006) defines test fairness as "the 


\section{THE NEBRASKA EDUCATOR, VOLUME 6}

removal from test scores of systematic variance, attributable to the test takers' psychological characteristics, developed in response to socialization practices or environmental conditions, that are "irrelevant to measurement of the construct of interest to the test user or assessor"" (p. 847). The use of racial/ethnic psychological constructs has merit and should be further explored. However, it also means that test takers would have to take more than one assessment as they would need to be tested on achievement and on the psychological constructs of race/ethnicity. Somewhat similarly, Sternberg, Grigorenko, and Kidd (2005) propose using multiple measures or factors that account for culture, in addition to test scores.

Of course, the challenge then becomes how to measure the experiences of multiracial individuals on a psychological measure. Salahuddin and O’Brien (2011) created the Multiracial Challenge and Resilience Scale (MCRS). The scale was developed using a sample of 317 selfidentified multiracial individuals ranging in age from $18-53$ years who lived in large metropolitan areas. Individuals in the sample were given accepted validated scales that measure self-esteem, depression, social connectedness, ethnic identity, and racial encounters in addition to the developed MCRS. The initial MCRS scale showed convergent validity with these validated measures. This first study resulted in a factor structure comprised of 1) Others' Surprise and Disbelief Regarding Racial Heritage, 2) Lack of Family Acceptance, 3) Multiracial Discrimination, 4) Challenges with Racial Identity, 5) Appreciation of Human Differences, and 6) Multiracial Pride. A measure of test-retest reliability found all measures reliable over time except Lack of Family Acceptance scores. Researchers could not account for the lack of reliability over time for Lack of Family Acceptance but thought that it might be due to participants feelings changing over time based upon recency, or lack of recency, of family interactions. 
THE NEBRASKA EDUCATOR, VOLUME 6

A second study conducted to assess the internal validity and reliability of the MCRS scale and the stability of the factor structure found that the MCRS demonstrated good internal consistency reliability for all factors except for Challenges with Racial Identity (Salahuddin \& O'Brien, 2011). Further study of this scale is warranted as the researchers note that the majority of those who participated in both studies were women who had higher education levels and income than the general population. But the MCRS is certainly a step in the right direction in terms of being able to measure the socialization experience of multiracial individuals.

There really are few analyses that include multiracial individuals, and it seems that the biggest recommendation is for more research involving multiracial individuals. Because of the large within-group variability that exists within the multiracial group one of the recommendations made is to use other methods such as qualitative. When measuring test fairness Camilli (2006) states the value in using qualitative data through processes such as sensitivity reviews to assess cultural impact as well as DIF analysis. Sensitivity reviews are procedures involved in test development that ensure that test materials reflect the diversity within society and that the wording of test items do not offend different subgroups within society. The author recommends using mixed methods research, which integrates quantitative and qualitative data (Plano Clark \& Ivankova, 2016), as it seems it would be a particularly useful way to include test performance information of racial/ethnic groups that may be too small in sample size to include within the larger analyses of group results.

Okazaki and Sue (1995) created a list of recommendations for any analysis that includes minorities, including Multiracial individuals. They recommend researchers 1) make explicit the definitions of ethnicity and race being used within the study, 2) provide more detailed descriptions of the sampling method and sample obtained, 3) include enough sample 


\section{THE NEBRASKA EDUCATOR, VOLUME 6}

information, such as comparisons of ethnic differences on measured items, so that comparisons can be made between studies, 4) use multiple measures and multiple methods, 5) use expert cultural or ethnic consultants both prior to conducting the study and to assist in interpretation of the study, and 6) use caution in assuming the findings are valid, but instead have the findings lead to more hypotheses for testing. Charmaraman et al. (2014) make similar suggestions and include the guideline of breaking the multiracial group into more granular data if sufficient sample size is available and if it serves the purpose of the study.

In 2003 the American Psychological Association (APA) came out with guidelines pertaining to the research of multiracial people and implications for the field of psychology. The first guideline is that psychologists need to be aware of their own biases. This guideline applies to all research and should be taken into consideration when testing multiracial individuals. Secondly, psychologists are encouraged to be aware of the importance of recognizing multicultural differences. Ignoring the uniqueness of multiracial individuals when testing and when assessing the validity of test scores does not recognize this uniqueness. The APA also recommends that psychological research should recognize the importance of research being culture-centered.

DIF analysis has tended to use dummy codes (0s and 1s) to indicate membership in the reference group or the focal group. Mayhew and Simonoff (2015) recommend using effect code (group average responses) as opposed to dummy codes to address issues of test fairness regarding interpretation of test scores. The language used when interpreting results from a study that uses dummy coding for racial categorization tends to have the dominate, White, race as the norm. Effect coding would remove the language of a "normed" race and instead replace the interpretation with language that would speak to the expected outcome of each racial group 


\section{THE NEBRASKA EDUCATOR, VOLUME 6}

compared to an "overall level". This has the added benefit of being able to include the expected outcome of the dominant race compared to an overall level, something that is missing when researchers use dummy codes. Another option, particularly when evaluating multiracial youth, is to use monoracial minority youth as the control group (Cauce et al., 1992), as opposed to monoracial white youth. Meaning, a student who is Black and White would be compared to Blacks as the control group, not White. The question this leads to is what to do with students who identify with more than one racial/ethnic minority category?

\section{Discussion}

Based upon the review of literature it seems that while race is hard to define, using a social construct approach makes the most sense. After all, it is in the socialization process that children learn about the construct of race. In the U.S., multiracial individuals face unique socialization practices compared to their monoracial peers. In particular, the act of having to

select one race prior to the 2000 census, instead of being able to select all races that apply, is just one example of an institutional practice that affects the socialization of multiracial individuals. Research is clear that formation of identity is different for multiracial individuals than monoracial individuals and these differences have to do with socialization practices.

The use of contextual information when interpreting standardized test scores by subgroups is recommended (AERA et al., 2014). Interactions between a test taker's internalized racial or cultural experience, their environmental experience, and the test or test taking process (Herman, 2009; Sternberg et al., 2005) affect test scores. Racial identification for multiracial children leads to a unique interaction between their racial identity and scores on tests as they most likely have more than one set of cultural values influencing them (Herman, 2009; PearceMorris \& King, 2012). Rockquemore et al., (2009) provides a very thoughtful review of the 


\section{THE NEBRASKA EDUCATOR, VOLUME 6}

challenges in creating a multiracial identity theory due to the multiplicity of cultural influences on racial identification for multiracial individuals.

For purposes that many would deem good or bad, group differences continue to be analyzed in educational testing. Some would deem analysis of group differences good as they aid in ensuring that groups are being treated fairly during test administration and in assessing fair impact in use of test scores. Comparing group differences helps in assessing the validity and reliability of results. However, the consequences of comparing group differences can also be interpreted as bad when group membership is somewhat vague in its construct and when individuals do not neatly fit into the provided categories. The latter examples apply to the testing of multiracial individuals and comparing people based upon racial/ethnic categories.

One option is to simply do away with racial categorization (Mays et al., 2003). However, to do this ignores that there are racial group differences in scores which impact opportunities differently for members of different races. Therefore, this option does not currently seem tenable. It seems the best option is to continue to use racial grouping when appropriate in comparing group scores. But changes should be made that more accurately reflect the uniqueness of multiracial individuals, including, but not limited to: allowing individuals to check more than one race when applicable on all demographic information, provide as much clarity as possible regarding how the construct of race and ethnicity is defined and used within a study, analyze the data using effect coding with multiracial people as their own group, if possible break the multiracial group into more granular data, and use measures of the psychological construct of racial identity, such as the MCRS, along with other measures in order to capture the interaction between racial identity and the measures. Guidelines for related topics such as language when writing analysis results and data visualization exist (Schwabish \& Feng, 2021). 


\section{THE NEBRASKA EDUCATOR, VOLUME 6}

While the use of standardized test scores such as the ACT and SAT for purposes of college enrollment are currently declining, they are still used by many colleges and if not used for college admittance they are often used for scholarships. Because of the educational benefits a diverse student population provides, race may be taken into consideration by colleges when making admittance decisions (Grutter vs Bollinger, 2003). There are no guidelines on how multiracial students should be operationalized within this context (Sanchez et al., 2020). Should they be identified as a minority? Should multiracial students who are part White be categorized with monoracial students of minority status in scholarship opportunities? Would this be seen as an act of taking away a scholarship from someone who is a monoracial minority? Sanchez et al., (2020) argues for established policies in this area. However, the researchers also express concern based upon how multiracial individuals are categorized within the legal system (they tend to be categorized according to their minority status, regardless of how they identify).

The varied results of the included research can be attributed to many things.

Charmaraman et al. (2014) analyzed the research methods used in 133 studies of multiracial individuals from 1990 - 2009. They found that multiracial study samples were more likely to contain people from the West, those who identify as Black/White, individuals from collegeeducated households, women, and young adults or adolescents. Additionally, it was found that most studies forced multiracial participants into one racial category. All of which may lead to misleading conclusions.

There is still quite a bit of research that can and should be done regarding testing and multiracial individuals. We are just beginning to have access to data in which we can measure trends that include multiracial identity. It is understandable that the major testing organizations such as the ACT and the College Board, need to wait for enough data which accurately measured 


\section{THE NEBRASKA EDUCATOR, VOLUME 6}

multiracial individuals before multiracial individuals could be included in their analyses. It is hoped and expected that since both the ACT and the SAT started collecting data on multiracial individuals in 2015-2016 more recent research will be forthcoming. Research regarding how to statistically account for multiracial individuals is needed. There are many studies that compare monoracial individuals to one another that should now be replicated with multiracial individuals. Lastly, measuring the impacts of certain statistical practices on the use of test scores for multiracial individual is lacking.

One of the limitations of this review is that it does not address both qualitative and mixed methods analyses that may be important in measuring multiracial individuals. The limitation was one that the author deliberately chose as analyses which involve group comparisons are quantitative. Therefore, the focus was on quantitative research. While there were recommendations to include more qualitative data when interpreting test scores of multiracial individuals, it was surprising to see that there were no recommendations to use more mixed methods within the literature as the earlier recommendation came from the author. Mixed methods has the distinct advantage of integrating both quantitative and qualitative data, which allows for greater representation of members from both large and small subgroups within the testing population.

This review was written from a primarily psychometric view and therefore focuses on measurement. However, the real importance and value of a review on educational testing and multiracial individuals is only realized when one connects the measures to actual people and understands that how one measures psychological constructs and how one uses those measures affect people. Multiracial individuals should not have to identify as other, or lesser, or fractional. 


\section{THE NEBRASKA EDUCATOR, VOLUME 6}

They are whole people, and measurement practices need to better reflect their lived and experienced reality as measurement practices affect those lived experiences. 
THE NEBRASKA EDUCATOR, VOLUME 6

\section{References}

ACT. (2017). Fairness Report for the ACT Tests.

https://www.act.org/content/dam/act/unsecured/documents/2015-

2016_Fairness_Report_for_the_ACT_Tests_WebSecured.pdf

ACT. (2020a). ACT® Technical Manual.

https://www.act.org/content/dam/act/unsecured/documents/ACT_Technical_Manual.pdf

ACT. (2020b.) PreACT® Technical Manual.

https://www.act.org/content/dam/act/unsecured/documents/PreACT_Technical_Manual_ 2020.pdf

Allen, J. P., \& Turner, E. (2001). Bridging 1990 and 2000 census race data: Fractional assignment of multiracial populations. Population Research and Policy Review, 20, 513533. https://link-springercom.libproxy.unl.edu/article/10.1023\%2FA\%3A1015666321798

American Educational Research Association (AERA), American Psychological Association (APA), \& National Council on Measurement in Education (NCME). (2014). Joint Committee on Standards for Educational and Psychological Testing. Standards for Educational and Psychological Testing. Washington, D. C.: AERA

American Psychological Association (APA). (2003). Guidelines on multicultural education, training, research, practice, and organizational change for Psychologists. http://doi.apa.org/getdoi.cfm?doi=10.1037/0003-066X.58.5.377

AP News (1997, April 22). Tiger Woods describes himself as 'Cablinasian'. AP News. https://www.apnews.com/458b7710858579281e0f1b73be0da618 


\section{THE NEBRASKA EDUCATOR, VOLUME 6}

Arkansas Department of Education, NCS Pearson. (2010). Test Administration Manual. Stanford Achievement Test Series, Tenth Edition. https://pdf4pro.com/view/test-administrationmanual-state-board-of-education-34b652.html

Berry, C. M., Clark, M. A., \& McClure, T. K. (2011). Racial/ethnic differences in the criterionrelated validity of cognitive ability tests: A qualitative and quantitative review. Journal of Applied Psychology, 96(5), 881-906. https://doi.org.10.1037/a0023222

Bruning, R. H., Schraw, G. J., \& Norby, M. M. (2011). Cognitive psychology and instruction. Boston, MA: Allyn \& Bacon.

Brunsma, D. L. (2006). Public categories, private identities: Exploring regional differences in the biracial experience. Social Science Research, 35(3), 555-576. https://doi.org/10.1016/j.ssresearch.2004.10.002

Camilli, G. (2006). Test fairness. In R. Brennan (Ed.), Educational measurement (4 ${ }^{\text {th }}$ ed., pp. 221-256). Westport, CT: American Council on Education and Praeger.

Camilli, G., Briggs, D. C., Sloane, F. C., Chiu, T. (2013). Psychometric perspectives on test fairness: Shrinkage estimation. In K. F. Geisinger (Ed.-in-Chief), B. A. Bracken, J. F. Carlson, J. C. Hansen, N. R. Kuncel, S. P. Reise, \& M. C. Rodriguez (Assoc. Eds.), APA handbooks in psychology: APA handbook of testing and assessment in psychology: Volume 3. Testing and Assessment in school psychology and education. Washington, D.C.: American Psychological Association

Campbell, M. E. (2009). Multiracial groups and educational inequality: A rainbow or a divide? Social Problems, 56(3), 425-446. https://doi.org/10.1525/sp.2009.56.3.425 
THE NEBRASKA EDUCATOR, VOLUME 6

Campbell, M. E., \& Eggerling-Boeck, J. (2006). "What about the children?" The psychological and social well-being of multiracial adolescents. The Sociological Quarterly, 47(1), 147173. https://doi.org/10.1111/j.1533-8525.2006.00041.x

Cauce, A. M., Yumi, H., Mason, C., Aquilar, T., Ordonez, N., \& Gonzales, N. (1992). Between a rock and a hard place: Social adjustment of biracial youth. In M. P. P. Root (Ed.), Racially mixed people in America (pp. 207-222). Newbury Park, CA: SAGE Publications, Inc.

Charmaraman, L., Woo, M., Quach, A., \& Erkut, S. (2014). How have researchers studied multiracial populations? A content and methodological review of 20 years of research. Cultural Diversity and Ethnic Minority Psychology, 20(3), 336-352. https://doi.org/10.1037/a0035437

Chong, V. (2012). Racial identity, family, and psychological adjustment in Asian-White biracial young adults [Doctoral dissertation, University of Windsor]. Electronic Theses and Dissertations, 4797. https://scholar.uwindsor.ca/etd/4797

College Board. (2021). The SAT. https://collegereadiness.collegeboard.org/sat

Doyle, J. M., \& Kao, G. (2007). Are racial identities of multiracials stable? Changing selfidentification among single and multiple race individuals. Social Psychology Quarterly, 70(4), 405-423. https://www.jstor.org/stable/20141804

ETS. (2019). A snapshot of the individuals who took the GRE® general test. https://www.ets.org/s/gre/pdf/snapshot_test_taker_data_2019.pdf

ETS. (2021). GRE® Guide to the Use of Scores. https://www.ets.org/s/gre/pdf/gre_guide.pdf 


\section{THE NEBRASKA EDUCATOR, VOLUME 6}

Goldstein, J.R. \& Morning, A. J. (2000). The multiple-race population of the United States: Issues and estimates. Proceedings of the National Academy of Sciences, 97(11), 62306235. https://doi.org/10.1073/pnas.100086897

Grutter v. Bollinger. (2003). Oyez. https://www.oyez.org/cases/2002/02-241

Harris, D. R., \& Sim, J. J. (2001). An empirical look at the social construction of race: The case of multiracial adolescents. [Research Report 39]. Retrieved from http://citeseerx.ist.psu.edu/viewdoc/download?doi=10.1.1.22.6942\&rep=rep1\&type=pdf

Harris, D. R. \& Thomas, J. L. (2001, March). The educational costs of being multiracial: Evidence from a national survey of adolescents. [Presentation] Population Association of America, Washington, D.C.

Helms, J. E. (2006). Fairness is not validity or cultural bias in racial-group assessment: A quantitative perspective. American Psychologist, 61(8), 845-859. https://doi.org. 10.1037/0003-066X.61.8.845

Helms, J. E. (2008). Implications for social policy of variability in racial groups' test scores: How cut scores on tests of cognitive abilities, knowledge, or skills matter. American Psychologist, 63(8), 721-739. http://web.b.ebscohost.com.libproxy.unl.edu/ehost/pdfviewer/pdfviewer?vid=1\&sid=3f9 8e657-2a95-44ce-9568-3974023d7155\%40pdc-v-sessmgr01

Herman, M. R. (2009). The Black-White-other achievement gap: Testing theories of academic performance. Sociology of Education, 82(1), 20-46. https://www.jstor.org/stable/40376036 


\section{THE NEBRASKA EDUCATOR, VOLUME 6}

Hitlin, S., Scott Brown, J., \& Elder, G. H. (2006). Racial self-categorization in adolescence: Multiracial development and social pathways. Child Development, 77(5), 1298-1308. https://doi.org/10.1111/j.1467-8624.2006.00935.x

Jones, M. C. (1994). Life stress and reading comprehension test scores in the middle school student. [Master's Thesis]. Kean College. https://files.eric.ed.gov/fulltext/ED369057.pdf

Jones, N. A., \& Smith, A. S. (2001). The two or more races population: 2000. U.S. Census Bureau. https://www.census.gov/prod/2001pubs/c2kbr01-6.pdf

Jones, N. A., \& Bullock, J. (2012). The two or more races population: 2010. U.S. Census Bureau. https://www.census.gov/prod/cen2010/briefs/c2010br-13.pdf

Kich, G. K. (1992). The developmental process of asserting a biracial, bicultural identity. In M. P. P. Root (Ed.) Racially mixed people in America (pp. 304-317). Newbury Park, CA: SAGE Publications, Inc.

Mattern, K., \& Radunzel, J. (2019). Does superscoring increase subgroup differences. https://www.act.org/content/dam/act/unsecured/documents/R1774-superscoringsubgroup-2019-07.pdf

Mayhew, M. J., \& Simonoff, J. S. (2015). Non-White, no more: Effect coding as an alternative to dummy coding with implications for higher education researchers. Journal of College Student Development, 56(2), 170-175. https://doi.org/10.1353/csd.2015.0019

Mays, V. M., Ponce, N. A., Washington, D. L., \& Cochran, S. D. (2003). Classification of race and ethnicity: Implications for public health. Annual Review of Public Health, 24(1), 83110. https://doi.org/10.1146/annurev.publhealth.24.100901.140927 
THE NEBRASKA EDUCATOR, VOLUME 6

Okazaki, S., \& Sue, S. (1995). Methodological issues in assessment research with ethnic minorities. Psychological Assessment, 7(3), 367-375.

http://citeseerx.ist.psu.edu/viewdoc/download?doi=10.1.1.905.4003\&rep=rep1\&type=pdf

Panter, A. T., Daye, C. E., Allen, W. R., Wightman, L. F., \& Deo, M. E. (2009). It matters how and when you ask: Self-reported race/ethnicity of incoming law students. Cultural Diversity and Ethnic Minority Psychology, 15(1), 51-66. https://doi/org/10.1037/a0013377

Park, R. E. (1928). Human migration and the marginal man. American Journal of Sociology, 33(6), 881-893. https://www.jstor.org/stable/2765982

Pearce-Morris, J. \& King, V. (2012). The well-Being of children living with interethnic parents: Are they at a disadvantage? Journal of Family Issues, 33(7), 898-919. https://doi/org.10.1177/0192513X11420938

Phinney, J. S. \& Alipuria, L. L. (1996). At the interface of cultures: Multiethnic/multiracial high school and college students. The Journal of Social Psychology, 136(2), 139-158. http://web.a.ebscohost.com.libproxy.unl.edu/ehost/pdfviewer/pdfviewer?vid=1\&sid=484 2795e-deca-4cec-895f-0ff3ec19232b\%40sdc-v-sessmgr01

Plano Clark, V., \& Ivankova, N. V. (2016). Mixed methods research: A guide to the field. SAGE Publications, Inc.

Plessy vs. Ferguson, Judgement, Decided May 18, 1896; Records of the Supreme Court of the United States; Record Group 267; Plessy v. Ferguson, 163, \#15248, National Archives. https://www.ourdocuments.gov/doc.php?flash=false \&doc=52

Poston, W. S. C. (1990). The biracial identity development model: A needed addition. Journal of Counseling \& Development, 69, 152-155. 
THE NEBRASKA EDUCATOR, VOLUME 6

http://web.a.ebscohost.com.libproxy.unl.edu/ehost/pdfviewer/pdfviewer?vid=1\&sid=4b4 29052-7a54-44ce-aba7-c8c2cbf17cba\%40sessionmgr4007

Pretz, J. E., Totz, K. S., \& Kaufman, S. B. (2009). The effects of mood, cognitive style, and cognitive ability on implicit learning. Learning and Individual Differences, 20, 215-219. https://www-sciencedirectcom.libproxy.unl.edu/science/article/pii/S1041608009001095?via\%3Dihub

Price, L. R. (2017). Psychometric methods: Theory into practice. The Guilford Press.

Radunzel, J., \& Mattern, K. (2020). A case study: ACT section retest scores and superscores are predictive of first-term grades. ACT. https://www.act.org/content/dam/act/unsecured/documents/R1817-he-section-retest2020-05.pdf

Riverside Insights. (2021). Iowa assessments. https://info.riversideinsights.com/iowaassessments

Riverside. (2012). Iowa assessments Form E technical summary. https://central-riversjuiceboxinteract.netdna-ssl.com/wp-content/uploads/2017/03/H5_Iowa-AssessmentsForm-E-Technical-Summary.pdf

Root, M. P. P. (Ed.) (1992). Racially mixed people in America. Newbury Park, CA: SAGE Publications.

Johnson, T. P., Jobe, J. B., O’Rourke, D., Sudman, S., Warnecke, R. B., Chávez, N., ChapaResendez, G., \& Golden, P. (1997). Dimensions of self-Identification among multiracial and multiethnic respondents in survey interviews. Evaluation Review, 21(6), 671-687. https://doi.org/10.1177/0193841X9702100602 


\section{THE NEBRASKA EDUCATOR, VOLUME 6}

Klieger, D. M., Adler, R., \& Ezzo, C. (2013). Asking differently About race and ethnicity: New needs for a changing population. ETS Research Report Series, 2013(2), i-59. https://doi.org/10.1002/j.2333-8504.2013.tb02344.x

Marini, J., Westrick, P. A., Young, L., Ng, H., Shmueli, D., \& Shaw, E. J. (2019). Differential validity and prediction of the SAT®. https://files.eric.ed.gov/fulltext/ED597325.pdf

Renn, K. A. (2003). Understanding the identities of mixed-race college students through a developmental ecology lens. Journal of College Student Development, 44(3), 383-403. https://doi.org/10.1353/csd.2003.0032

Rockquemore, K. A., Brunsma, D. L., \& Delgado, D. J. (2009). Racing to theory or retheorizing race? Understanding the struggle to build a multiracial identity theory. Journal of Social Issues, 65(1), 13-34. https://doi.org/10.1111/j.1540-4560.2008.01585.x

Salahuddin, N. M., \& O’Brien, K. M. (2011). Challenges and resilience in the lives of urban, multiracial adults: An instrument development study. Journal of Counseling Psychology, 58(4), 494-507. https://doi.org/10.1037/a0024633

Sanchez, D. T., Gaither, S. E., Albuja, A. F., \& Eddy, Z. (2020). How policies can address multiracial stigma. Policy Insights from the Behavioral and Brain Sciences, 7(2), 115122. https://doi.org/10.1177/2372732220943906

Schenker, N., \& Parker, J. D. (2003). From single-race reporting to multiple-race reporting: Using imputation methods to bridge the transition. Statistics in Medicine, 22(9), 15711587. https://doi.org/10.1002/sim.1512

Shang, J., Fu, Q., Dienes, Z., Shao, C., \& Fu, X. (2013). Negative affect reduces performance in implicit sequence learning. PLoS ONE, 8(1), e54693. https://doi.org/10.1371/journal.pone.0054693 


\section{THE NEBRASKA EDUCATOR, VOLUME 6}

Shih, M., \& Sanchez, D. T. (2005). Perspectives and research on the positive and negative implications of having multiple racial identities. Psychological Bulletin, 131(4), 569-591. https://doi.org/10.1037/0033-2909.131.4.569

Steele, C. M., \& Aronson, J. (1995). Stereotype threat and the intellectual test performance of African Americans. Journal of Personality and Social Psychology, 69(5), 797-811. https://doi.org/10.1037//0022-3514.69.5.797

Sternberg, R. J., Grigorenko, E. L., \& Kidd, K. K. (2005). Intelligence, race, and genetics. American Psychologist, 60(1), 46-59. https://doi.org/10.1037/0003-066X.60.1.46

Suzuki, L. A., \& Valencia, R. R. (1997). Race-ethnicity and measured intelligence. American Psychologist, 52(10), 1103-1114. http://web.a.ebscohost.com.libproxy.unl.edu/ehost/pdfviewer/pdfviewer?vid=1\&sid=6f84 5a07-bfb7-48a7-aec0-08fa3702f130\%40sessionmgr4008

Townsend, S. S. M., Markus, H. R., \& Bergsieker, H. B. (2009). My choice, your categories: The Denial of multiracial identities. Journal of Social Issues, 65(1), 185-204. Rhttps://doi.org/10.1111/j.1540-4560.2008.01594.x

U.S. Census Bureau. (2017). Race \& ethnicity. https://www.census.gov/mso/www/training/pdf/race-ethnicity-onepager.pdf

Villegas-Gold, R., Tran, A. G. T. T. (2018). Socialization and well-being in multiracial individuals: A moderated mediation model of racial ambiguity and identity. Journal of Counseling Psychology, 65(4), 413-422. https://doi.org/10.1037/cou0000277

Wendler, C., \& Bridgeman, B. (2021). The research foundation for the GRE® revised general test: A compendium of studies. ETS. https://www.ets.org/s/research/pdf/gre_compendium.pdf 


\section{THE NEBRASKA EDUCATOR, VOLUME 6}

Wicherts, J. M., Dolan, C. V., \& Hessen, D. J. (2005). Stereotype threat and group differences in test performance: A question of measurement invariance. Journal of Personality and Social Psychology, 89(5), 696-716.

http://web.b.ebscohost.com.libproxy.unl.edu/ehost/pdfviewer/pdfviewer?vid=1\&sid=74d 9f7fd-f339-4b74-ba0c-312164224560\%40pdc-v-sessmgr03 


\title{
Diversifying the Classroom: Masculinity and Intersectionality in (Teacher) Education A Review of Literature
}

\author{
Scott Gealy \\ Department of Teaching, Learning, and Teacher Education \\ University of Nebraska-Lincoln
}

\begin{abstract}
While much has been written about the gender and demographic divide in the U.S. between the population of students and their teachers, complex gendered, cultural, and socioeconomic forces appear to be widening it. In an effort to reveal the many ways that teacher education programs can attract and retain a more diverse body of candidates, this literature review lays out a general overview of masculinity's work as it pertains to the socialization of boys and young men in K-12 schools; it examines the influence of gendered, racial, and socio-economic assumptions on both teachers and learners; it looks at the experience of men from a variety of backgrounds in teacher education programs and the obstacles to their attraction and retention; and it looks at what the research says about how teacher education programs can be adapted to better account for the intersection of racial, gendered, and socioeconomic identities. Ultimately, the literature suggests work to be done to disrupt gendered, racial, and cultural assumptions about teacher identity that lead to blind spots in teacher education in hopes of better understanding the sources of and finally bridging the gender and demographic divide.
\end{abstract}

Keywords: Masculinity, intersectionality, teaching, teacher education, demographic imperative, gender divide 
THE NEBRASKA EDUCATOR, VOLUME 6

\section{The Gender and Demographic Divides in K-12 Education}

As it has for decades, the population of K-12 teachers in the United States consists primarily of White, middle-class women (Snyder, 1993; Villegas \& Irvine, 2010), a limited demographic that does not align with the population of public-school students, the majority of whom come from diverse racial, cultural, and socioeconomic backgrounds (Snyder, 1993; U.S. Department of Education, 2021). This divide contributes to the disenfranchisement of a large portion of the student population who may not experience teachers who "look like them" (Stillman, et al., 2019) and to boys and young men who may come to equate education with femininity (Connell, 2005; Pascoe, 2007; Young, 2007; Kimmel, 2008; Kivel, 2009). Despite years of measures taken to address them, these gender and cultural divides between the student and teaching populations remain glaring (Ingersoll et al., pp. 12, 15).

The implications of the gender divide in education are significant. Such divisions, argue Johnson, Porter, and Nelsen (2008), "go against the democratic and egalitarian values schools are expected to promote" (p. 3). So long as these divisions persist and students grow up believing they are natural, they will "continue to feed a preponderance of women into teaching and men into administrative or managerial positions, reinforcing the powerfully corrupt idea that men rule women and women rule children" (p. 3). The perpetuation of this binary is a core obstacle to complicating American culture's historically reductive understanding of gender identity.

R.W. Connell, a formative figure in masculinity studies, notes that society communicates and perpetuates an "essentialist" view of gender. This view, as Connell (2005) explains, communicates that "boys and girls are naturally different, in character as well as in body" (2005, pp. 11-12). These differences are used to justify what Connell calls hegemonic masculinities: "the configuration of gender practice which embodies the [...] legitimacy of patriarchy, [and] 


\section{THE NEBRASKA EDUCATOR, VOLUME 6}

guarantees $[\ldots]$ the dominant position of men and the subordination of women" $(2005, \mathrm{p} .77)$.

Schools, explain Eckert and McConnell-Ginet (2013), are "prime sites for socialization," and as such, are "key institutions for the construction of gender" (p. 31).

Indeed, compulsory education is a crucible for identity construction. Pascoe (2007), too, makes clear that "schools are a primary institution for identity formation, development, and solidification for contemporary American youth," (p. 18) and the social construction of gendered behavior is central to this. Quoting Griffin and Lees (1997), Heinrich (2012) describes how “different forms of masculinity are 'performed, contested, negotiated, and resisted in a variety of educational contexts by boys, girls, teachers, and parents"' (p. 105). Pascoe (2007) illustrates these high stakes: "men or boys who do not conform to normative understandings of masculinity and sexuality [are] mocked, humiliated and possibly feared" (p. 90). As in Pascoe's (2007) study, the young men in Heinrich's study (2012) spoke continuously of fear that if they did not prove themselves as sufficiently masculine, they would face persistent and cutting ridicule. Both Pascoe's (2007) and Heinrich's (2012) participants repeatedly called one another 'gay,' an epithet used to imply that one does not measure up or is showing weakness, and therefore not appropriately masculine. Even among boys in school who find themselves well within the margins of mainstream masculinity, there exists a pervasive climate of fear.

The performance — and policing — of gender follows us well into adulthood, and the way teachers unconsciously interact with students is impacted significantly by their gender identity, since "we perform gender in the minutest acts" say Penelope Eckert and Sally McConnell-Ginet (2013, p. 44), "from gait to body language to vocal cadence" (Eckert \& McConnell-Ginet, 2013, p. 44). Teachers contribute to this socialization through gender-based signals of what is appropriate communication for boys and what is appropriate for girls. Though "it is by virtue of 


\section{THE NEBRASKA EDUCATOR, VOLUME 6}

the accumulation of these performances that the gender order is maintained, it is by the virtue of small changes in these performances that the gender order can be restructured" (Eckert and McConnell-Ginet, 2013, p. 44). The messages sent as a result are internalized and reproduced by students, so it is important for teachers to be cognizant of the messages they send. As Connell (2005) explains, "address[ing] the diversity of masculinities, and the intersection of gender with race, class and nationality," will enable society to end the "sterile choice between celebration and negation of masculinity in general" (p. 238). Beyond simply hiring more men to teach, educators must consider the ways in which teachers model gendered behavior in the classroom.

Of course, teachers' and students' identities are shaped by myriad factors beyond gender. It is crucial to consider the role of intersectionality, a term Kimberlé Crenshaw (1991) coined to help account for the ways in which race and gender overlap to represent the multiple forms of identity construction (p. 1245). Following Crenshaw's intersectional examination of the ways in which both race and gender contribute to the oppression of African American women, Patricia Hill Collins (2015) argues that multiple factors contribute to cultural power structures, a matrix made up of "race, class, gender, sexuality, ethnicity, nation, ability, and age [that] operate not as unitary, mutually exclusive entities, but as reciprocally constructing phenomena that in turn shape complex social inequities." (p. 2) These hierarchies of power are both established and fortified in our schools at the expense of the most vulnerable communities.

Shifting the teaching population to match that of students can play a significant role in addressing long-standing structural inequalities that continue to threaten our democracy (Philip, et al., 2019). When students of color do not encounter teachers who look like them, they “implicitly learn that White people are better suited than people of color to hold positions of authority in society" (Philip et al., 2019, p. 285). This logic persists beyond race, however, to 


\section{THE NEBRASKA EDUCATOR, VOLUME 6}

gender, gender identity, ethnicity, socio-economic class, religion, and ability. When students repeatedly encounter teachers who don't look like them, think like them, or interact like they do, the implicit message is that only other people are supposed to teach.

\section{Masculinity in Teaching and Learning}

A man who teaches and is aware of the conventional ways in which our society acculturates gender could help to liberate boys from the oppression of what Kivel (2009) calls the "man box." Men as teachers presenting a more complex and nuanced gender identity in a classroom space where alternate gender expressions are welcomed could be a powerful force for disrupting hegemonic masculinity. Indeed, students' default view of gender as a monolithic category could be disrupted by teaching, both explicitly and implicitly, the myth of the gender binary, and when young people begin to recognize their own place "within dominant discourses of masculinity or femininity, they can begin to understand how this positioning has restricted their own gendered identity" (Heinrich, 2013, p. 105). Abelson (2019) suggests such "changes in style" (gendered behavior in the classroom, for example) could foment real change, but "it takes much deeper collective work of structural relations to make changes in social relations a reality" (p. 205). Since classrooms are among the "specific spaces and places where power relations are created and recreated" (Abelson, 2019, p. 206), perhaps a broad enough shift in the diversity of teachers' identities could lead them to become important social spaces for expanding students' acceptance of the spectrum of gender identity.

Many scholars argue that the presence of a man at the head of the classroom serves as a valuable role model for boys and young men who may rarely see their gender represented by their teachers, but arguments vary on the direct impact of gender on instructional outcomes. Hammerness and Reininger (2008) point to research indicating that same-gendered teachers 


\section{THE NEBRASKA EDUCATOR, VOLUME 6}

“comprise a notable 'environmental influence' on student performance” (p. 3). Dee's (2005, 2007) work notes that "gender interactions" between teacher and student "constitute [a] qualitatively important environmental determinant of the comparative outcomes of both girls and boys" (p. 551), but Johnson, Porter, and Nelson (2008) disagree, asserting that "adequate empirical evidence does not exist that supports matching students and teachers by gender [...] has any effect on a variety of student achievement and satisfaction measures" (p. 3). It is reasonable to assume, therefore, that this single factor cannot reliably account for the complex connection between a teacher's identity and a student's performance.

In fact, on its own, the view that a man who teaches is by nature a role model for boys and young men is regularly seen as overly simplistic. Davison and Nelson (2011) point to the "messiness" of identities in the classroom, "not as something that needs to be sorted, solved, or fixed in a prescriptive way, but as a complex concern for educators and the children and families they teach" (p. 95). Much of this "messiness" results from tension surrounding descriptions of what it means to be a man, an educator, and role model, particularly in the face of "conflict and tension regarding popular understanding of masculinity and a reliance on narrow gender expectations for boys and young men" (Davison and Nelson, 2011, p. 93). The reality is that being a boy or a man should not be easily described; so to assume that the latter will be a role model for the former strictly because of this single factor is misguided.

Gosse (2011) follows Davison and Nelson (2011) to weigh in on the debate over the value of men who teach in the primary grades. Gosse's research shows the issue falling into two camps: those who believe that any child can succeed in a classroom lead by any teacher, regardless of gender, race, or ethnicity, and the one to which Gosse subscribes, where men contribute as role models, an important factor for establishing "a gender balance, along with 


\section{THE NEBRASKA EDUCATOR, VOLUME 6}

other identity markers, in order to better represent and reflect diversity in education" (p. 119). Here we see the "messiness" described by Davison and Nelson (2011). One can reasonably see the value of a variety of identity markers in the conglomeration of leaders experienced by students in a classroom.

Regardless of the correlation between teachers' gender and student performance, there is little doubt that a teacher's performance of gender contributes to students' understanding of appropriately gendered behavior. Johnson, Porter, and Nelson (2008) argue that there needs to be an increase in men who teach, but not simply as role models to improve student outcomes or the disruption of conventional gender roles (pp. 2-3). Instead, they argue that "an overwhelming majority of women $[\ldots]$ in an entire social institution violates fundamental democratic principles of equal opportunity, access, and self-determination based on gender in a free and open society" (p. 3). "It is possible," they argue, "that restrictive gender roles limit equal opportunity by discouraging men from teaching who might otherwise be predisposed" (p. 3), while tacitly communicating that girls and young women are best suited to teach.

A number of studies push for but question the motivation to increase the number of men in the classroom. Skelton (2007) argues that government programs meant to increase the number of men who teach in public schools are problematic without a more robust focus on gender issues in teacher education programs. Francis (2008), too, challenges the motives. The push for male teachers as role models, often for disaffected boys, is grounded in the assumption that men teach students differently than women, since "arguments for the desirability of male [...] teachers of boys rests on stereotypes of male teachers as disciplinarian and 'robust"' (Francis, 2008, p. 109). These notions assume that gender identity is "foundational and fixed," built on the assumed binary of gendered behavior (Francis, 2008, p. 119). In reality, the role of men who teach is 
THE NEBRASKA EDUCATOR, VOLUME 6

described by Francis (2008) as a form of heteroglossia, "whereby 'competing dialects of masculinity and sexuality engage each other in a single text," which cannot be easily discerned by gender alone (p. 120). The three cases in Francis's study illustrate "the complex, shifting and nebulous nature of gendered subjectivity," identities "riven with contradictions and fluidity," and that "masculinity and femininity are not the exclusive provinces of 'appropriately' sexed bodies" (2008, p. 120). Mills (2004) argues that initiatives aimed at diversifying the teaching profession by attracting and retaining more men "only recognizes diversity between males and females and does not give any indication that it recognizes diversity among males and females" (p. 31). According to these scholars, increasing the number of male teachers does not provide real diversity. Rather, it reinforces gender binaries as the status quo, marginalizing, particularly, LGBTQ+ students who continue to face an environment in schools where the "heterosexual-us" and the "homosexual-them" paradigm continues to thrive (p. 34).

This gender duality is apparent in Haase's (2008) study, which demonstrates that many male teachers see it as their duty to socialize boys to a single standard that proves their strengths and viabilities as young men. Moreover, these men appear to compensate for their role in a largely "feminized" teaching environment by using their masculinity to serve a need for boys that only they can, according to common sentiment, thus reinforcing gender normativity (Haase, 2008, p. 115). This aligns with Britzman's (2003) assertion that "male teachers are expected to assert a machismo identity in their classrooms, and depending upon their proximity to this image, become characterized either as wimps or tough guys" (p. 29). Fischman (2000) asserts that without significant efforts to redefine gender regimes in schools, future teachers will have "few opportunities of transforming resistance into agency and break [...] with the essentialist view of caring as a feminine activity and 'discipline' as the exclusive realm of men” (p. 164). Haase 


\section{THE NEBRASKA EDUCATOR, VOLUME 6}

(2008) synthesizes these points by arguing that expanding not only the number of male educators, but the variety of individuals asserting identities of 'manhood' becomes crucial for disrupting hegemonic gender binaries. "Unless [...] strategies designed to attract more male teachers by sophisticated understandings of gender and social power [are put in place], masculine stereotypes will simply be passed down" (Hasse, 2008, p. 115). Thus, it is not just the number of men attracted to the profession, but the type of men that may disrupt norms of gender identity construction in the classroom.

Martino and Rezai-Rashti (2010) draw on feminist, queer, and postcolonial theoretical frameworks to examine the complexity of gender dynamics in teachers' lives as they intersect with race, social class, and sexuality. Their work follows other studies that problematize the reductionist notion of teachers as "idealized role models," which fails to acknowledge "the damaging effects of reducing the formation of gender identity to the category of sex-role stereotyping" (p. 250). The authors take an intersectional approach to "move beyond singularity" of the heteronormative binary, "taking into account the reality that each of us embodies a wide range of categorical commitments such as race, sexuality, generation, [and] class" to more accurately capture the ways in which "the shifting meanings of these social markers arrange the experience of gender" (Rezai-Rashti, 2010, p. 251). Ultimately, these arguments further complicate the assumption that simply increasing the number of men who teach will disrupt conventional gender norms.

Embedded in the discussion but less often raised in the research is the way a teacher's gender is read by their students. “A teaching body,” argues Waite (2017), “will always be waited for, looked at, put on its front-of-the room stage as the first kind of student knowledge, the first body of knowledge" (p. 23). The gendered traits of what we look like and how we communicate 


\section{THE NEBRASKA EDUCATOR, VOLUME 6}

are fundamental markers of our gendered teacher identity, though many White, cisgender teachers likely do not pause to consider the implications.

Braun's (2011) work explores the physical and psychic embodiment of pre-service teachers as they make the transition into a full-time teaching role. The study consists of a series of qualitatively analyzed interviews with post-graduate teachers in training. The emphasis in the findings is very much on the physical embodiment of the teaching persona - the way in which student teachers feel as if they need to inhabit a certain kind of physical body in order to generate authority in the classroom. Braun examines findings under two categories: "the appropriately gendered body, signified by heteronormative readings of gender and sexuality; and the gendered authoritative body, conceptualized as male" (2011, p. 127). Ultimately, Braun (2011) argues for embodied considerations as part of teacher training programs, since such notions are the reality of teachers' lived experience in the classroom.

Sarah Bortolome's (2016) narrative study sought "to explore the experiences of a [maleto-female] transgender music educator as she navigated her teacher preparation program and entered the field" while in the process of deciding how to present, as Matthew, Mel, or Melanie. How does one embody the teacher when one's body itself has the potential to disrupt the classroom? In addition to the commonplace preservice teacher's insecurities, Melanie was forced to ask herself, "Are the kids going to realize that I am a 'gender imposter'?” (p. 36) Ultimately, according to Bortolome, the students appeared to take little notice. Melanie's narrative provides evidence that relatively seamless dismantling of the reductionistic gender binary of the classroom teacher is possible, at least in certain contexts. Nevertheless, addressing in teacher education the effects of a teacher's gender identity performance on the subtle messages sent to students should be an important component of teacher education. 
THE NEBRASKA EDUCATOR, VOLUME 6

\section{Consequences in the Classroom}

Increasing the number and diversity of men who teach could complicate the too often rigid definition, both in schools and in broader society, of what it means to 'act like a man' (Kivel, 2009). As Johnson and Weber (2011) argue, "a man who is passionate about teaching often belies the gender codes that constitute mainstream masculinity" (p. 154). As the scholarship makes clear, however, increasing the number of male teachers is not enough. Traditional socialization of gender norms in public schools appears to leave little room for boys and young men to deviate from acceptably masculine behavior. Hiding emotions, being aggressive, not backing down, and toughening up all become the enforced norm (Kivel, 2009). An increase in the number and variety of men who teach, particularly in the humanities, could help to establish new norms for appropriately masculine behavior.

Being a good student is one of the behaviors that is often strictly policed among boys and young men. As Dowd (2010) argues, "to be viewed as sufficiently masculine, boys must not be seen as working too hard at schoolwork, so boys are not 'free' simply to achieve at school without great social cost" (p. 79). The internalization of this message has long term consequences for achievement among untold many young men. This is particularly true in an English context. Heinrich's (2012) study “revealed the English classroom as a politicized and gendered arena" (p. 112) where being productively engaged was, for boys, to be stepping out of acceptable behavior. To stand out for being studious conveys the appearance of being 'weak' or 'feminine,' and thus is both implicitly and explicitly discouraged.

Research conducted by Martino (2001) in the 1990s demonstrated that English as a subject is seen as more feminine than other subjects. The result was that "boys were caught up in a gender bind in which they perceived [...] English as a feminized learning practice that 


\section{THE NEBRASKA EDUCATOR, VOLUME 6}

conflicted with their tenuous masculinity" (p. 193). The boys in Martino's (2001) study found reading "boring," so they chose not to engage with learning that they felt did not "validate a form of masculinity that they find desirable" (p. 193). A significant body of scholarship confirms Martino's (2001) observations. Smith and Wilhelm (2002) argue that literature and language tend to focus on "narrative, emotional response, expressivity, and creativity," instead of more hands-on learning or action-oriented texts, but, perhaps most importantly, "[English classes] are most often taught by females, [which] deprives boys of male models who embrace the life of the mind, the emotions, and the various forms of literate creativity" (p. 16). Again, though, these assumptions appear reductionistic.

Dowd (2010) refers to a "boy crisis," resulting from a sort of zero-sum-game where boys are falling further behind because the system is somehow failing them, and that this failure is a price being paid for girls' and women's progress in schools (p. 76). This argument, advanced by Farrell and Gray (2018), was predated by nearly 50 years by Patricia Cayo Sexton in The Feminized Male (1969). But this view, like many, is generalized and reductive. As Kimmel (1998) argues, "it is not the school experience that 'feminizes' boys, but rather the ideology of traditional masculinity that keeps boys from wanting to succeed. Boys see academic success itself as a disconfirmation of their masculinity" (p. 294). Heinrich's (2012) study exemplifies Kimmel's contention, illustrating that it is the fear of ridicule, "not apathy or stupidity as teachers sometimes assume," that suppresses boys' willing participation in class, "for the process of finding voice was a high-stakes one, laden with considerable risk and consequence" (pp. 110111). Men who appear to students as 'sufficiently masculine,' yet model passion for literature and creative expression could resonate with boys in ways that give them the comfort and confidence to risk being socially vulnerable in the classroom. 


\section{THE NEBRASKA EDUCATOR, VOLUME 6}

The feeling of disconnection from school appears to correlate with concerning patterns in motivation and achievement as students transition from high school to college. For boys and young men, performance of masculinity often erodes membership in the academic community. In order to re-establish academic success among boys, Mintz (2019) argues, there are a number of issues that need to be addressed, both cognitive and behavioral. Boys and young men tend to be academically underprepared for a variety of reasons, many of them related to behavioral tendencies, learning style, and cognitive function; in the last twenty years, boys have undergone consistent decline in academic aspirations, and schools have become increasingly unresponsive to the differing needs of students. As Kahn, Brett, and Holmes (2011) discovered in their study of the connection between masculine norms and achievement in higher education, women entering college are better motivated and better achieving than their male counterparts, which has consequences throughout their ensuing education (p. 66).

Views regarding boys' under-achievement, too, are often generalized, however. Girls tend to do better in language and literacy (the effect of factors listed above), while boys tend to do better in math, and the genders are roughly equal in science, and much of the disadvantage demonstrated by men is linked to class and race, not just gender (Dowd, 2010, p. 77). Thus, looking at equity as a matter of gender alone is problematic, since class and race are far more significant in the differentiation of outcomes in school. Focusing on gender alone can unintentionally distract from other issues that may have a more significant impact (Dowd, 2010, pp. 80-81).

Far more impactful than gender for student performance is social class, a factor typically determined by a combination of family income, occupation(s), and level of education (American Psychological Association, 2015). Lareau's (2011) extensive ethnographic work demonstrates 


\section{THE NEBRASKA EDUCATOR, VOLUME 6}

how social class provides parents a "set of cultural repertoires for managing the experiences of their children as they interact with institutions such as schools" (p. 265). In fact, Lareau's work demonstrated that much of the experience children have in schools is closely tied to their social class. "Middle-class kids tend to go to different, and more academically, socially, and physically desirable schools than do working-class and poor kids" (Lareau, 2011, p. 265), and high schools typically expect parent involvement in bringing about a child's successful navigation of the complicated process of applying to college (Lareau, 2011, p. 265). Parents without the understanding of school's institutional structure and culture or the time to help their students navigate this sophisticated system often leave their children at an insurmountable disadvantage.

Key among the discoveries of Lareau's (2011) work is a classed approach to child rearing. The study identifies two distinct ways in which parents raise children: "concerted cultivation" and "natural growth" (pp. 2-3). The former, deeply associated with middle-class parents, is an approach to parenting emphasizing the development of children to "cultivate [their] talents in a concerted fashion," which typically means that "organized activities, established and controlled by mothers and fathers, dominate the lives of middle-class children" (Lareau, 2011, pp. 1-2). The result is parents providing for their children advantages that will contribute to their educational and professional advancement. Lareau (2011) distinguishes this approach from "natural growth," most frequently practiced by poor and working-class parents, who, in the study, did not consider the manipulation of their children's development through organized activities an important element of good parenting (p. 2). Children of poor and working-class families are often marginalized, since institutions such as schools typically assume that parents are taking an approach of deliberate cultivation. The result, Lareau explains, is that "for workingclass and poor families, the cultural logic of child rearing at home is out of sync with the 


\section{THE NEBRASKA EDUCATOR, VOLUME 6}

standards of institutions" (p. 3). Moreover, Benton (2007) describes how schools in working class neighborhoods sort kids mostly into subservient roles, allowing for a handful to make it out by defying their peers and learning to play by the rules established by the "weeding process and the tracking system" (p. 70). The others, the vast majority in poor and working-class communities, "know that trying too hard at school will cost them friends and make them targets for violence" (p. 70), making academic achievement and social status a seemingly either-or proposition. Thus, children in middle- and upper-middle class families enjoy tremendous longterm educational and professional advantages. Teachers and administrators, often raised in middle-class backgrounds themselves, must understand the cultural advantages and disadvantages children may bring with them to the classroom and adjust their support accordingly.

Dykins Callahan’s (2008) autoethnographic article, “Academic Outings,” chronicles her experiences of learning to hide her family's poverty, doing everything in her power to "pass" as middle class from the tumultuous years of middle school, through high school, into college, graduate school, and an academic career. "Derogatory representations of poor Whites," she argues, "combined with physical, emotional, and educational 'flaws' that individuals acquire because of their class status clearly position members of the lower classes as highly stigmatized" in the academic community (p. 365). The concept of "class passing," Dykins Callahan (2008) explains, means that students have to work harder to reconcile conflicts between their "inherited" identity and their "chosen" identity at school (p. 364). Her life at home would never let her outrun the feeling of being an imposter at school, of not being good enough to truly belong. Even in a university setting, she worked exhaustively to remove traces of her private life from her social and academic persona. "The academy is often considered a classless arena whose 


\section{THE NEBRASKA EDUCATOR, VOLUME 6}

participants exist outside the confines of economic categories," but this "myth of classlessness only perpetuates the invisibility of the working poor who limp through the hallowed halls" (Dykins Callahan, 2008, p. 369). Her paralyzing fear of being recognized as inferior haunted her from her earliest years in school through a career in academia. Benton (2007) elaborates on issues underlying class discrimination and prejudice on college campuses based on his experiences both as a student and a faculty member, arguing that, "academe's admissions, hiring, and the promotion practices seem to favor people who look different but mostly think alike, largely because they belong to similar class strata," which leads to "making privileged people feel like they care about inequality without having to really change anything” (p. 70). Social class, "nearly a caste system" (Benton, 2007, p. 70), must be included in any consideration of diversity, though he laments the fact that it does not. The world of the academe must acknowledge the complexities of the impact social class has on the experience of the students (Dykins Callahan, 2008, p. 371). Understanding this impact on students adds a crucial layer to the effect of gender, sexuality, race, and culture on power dynamics in the classroom. "Focus[ing] on the axes of these [intersectional] positionalities, their co-constitution [and] permeability, as well as how they are negotiated in specific contexts" (Dykins Callahan, 2008, p. 371) is crucial for providing a safe space for students from diverse poor and working-class backgrounds.

The interplay between poverty, race, and education is particularly complex. Increasing the number of teachers of color, as Villegas, Strom, and Lucas (2012) argue, "decreases the sense of alienation that students of color — from both poor and affluent backgrounds — often experience in schools" (p. 285). Young (2007) digs deeply into the complicated intersection of race, poverty, gender, and education that exists in much of the African American community. 


\section{THE NEBRASKA EDUCATOR, VOLUME 6}

Success in school, Young points out, is often equated with "acting White," a behavior that many African American boys and men are particularly resistant to, since to act White means not only selling out your Black identity, but adopting what are typically seen as feminine traits. As a Black academic whose roots are in urban poverty, Young is caught between cultures; he is "required to perform [his] academic (read white) and ghetto (read black) languages in order to quell and fulfill the racial, class, and gender fantasies that others have of [him]" (2007, p. 3). African American men who succeed in academic environments "must often contend with being perceived as unmanly [...] [and] being deemed inadequately masculine is tantamount to being judged homosexual" (2007, p. 65). For Young, the culture of the Black man and the culture of school existed almost in binary opposition and, as a career academic, he felt accepted by neither his home community nor the academy.

The complexity of the human experience one encounters in the classroom is best served by a varied and reflective teaching body. While academic success is in many ways impacted by gender, unraveling that component from the intersectional experience of students who struggle to find their place extends far beyond that single factor. According to Mintz (2019), "the challenge for teachers is to develop the abilities of all students as fully as possible. This requires attentiveness to classroom dynamics, including gender dynamics, responsiveness to students' needs, and the ability to differentiate instruction" (para. 18). In order to address the gender divide and the demographic imperative to make inroads with students the system has traditionally left behind, educators must consider the totality of human experience in our understanding of who becomes a teacher, how, and to what end. 
THE NEBRASKA EDUCATOR, VOLUME 6

\section{Multiplying Identities in Teacher Education}

As Britzman (2003) explains, too often images of teachers have little to do with individual behavior, but instead are grounded in an "adherence to patriarchal conventions, notions of a unitary non-contradictory identity, and images of professionalism that preclude the struggles of gender class, race, and generation.” Instead, as human beings, teachers' identities are "multiple... both given and possible," but too often become lost in a cycle of "cultural determinism" (Britzman, 2003, p. 29) where images of the teacher are one-dimensional. This contributes to Stillman et al.’s (2019) findings, that “teacher education programs have been shown to privilege the experience of White preservice teachers [and] undervalue the knowledges and experiences of minoritized communities" (2019, p. 266). Zeichner (2020) makes the more definitive claim that "most teacher education programs, including those that have claimed to be about social justice," too often contribute to the disenfranchisement of poor communities and communities of color by training teachers "who have not benefited from the knowledge and expertise that exists within their students' families and communities" (p. 42).

To overcome this, teacher education programs must work toward what Stillman et al. (2019) call asset-oriented teacher education, "committed to the preparation of asset-oriented teachers, who recognize, leverage, and sustain the knowledge, values, and voices of minoritized students" (p. 266). While care must be taken to avoid what Lowenstein (2009) calls the “homogenization lens," through which the often complex backgrounds within a seemingly unidimensional demographic (White and largely female, in this case) can be overlooked (p. 168), further diversifying the preservice teaching population is the surest way to provide depth to the classroom experience, both in teacher education programs and K-12 schools. 


\section{THE NEBRASKA EDUCATOR, VOLUME 6}

In addition to gender-based stereotypes, superficial understanding of teachers' identities and backgrounds have led to African American men frequently being valued in K-12 classrooms for their ability to "save" troubled African American boys (Strachan and Davis, 2020, p. 69). This reductive understanding makes urgent the need for the stories of African American male educators in order to better understand why they chose the field and the experiences that got them there. Such stories would serve as an effective vehicle "to examine how the pathway to K12 classrooms [for men of color] can be improved" (p. 69) and help to transcend superficial understandings of who teaches and why. Much blame for this simplistic understanding, however, lies at the feet of traditionally culturally homogeneous teacher education programs (Lowenstein, 2009; Villegas, 2008).

Tucker (2015) looks at the experiences of men in teacher education programs through the lens of "hybridity," citing Moss (2003) who defines the term as the "the joining of two entities to create a third $[\ldots]$ produced by the interaction of cultures, communities, or individuals"' (p. 6). The study investigates "how male preservice elementary school teachers negotiate different aspects of their identities as they navigate their educational experiences" (Tucker, 2015, pp. 6-7). Their findings suggest that preservice male teachers' identities are more complex than gender alone, that "being in multiple minority groups may compound challenges for preservice male teachers, and that teacher training alone may not sufficiently address issues of identity" (Tucker, 2015, p. 3).

Research by Bower-Phipps et al. (2013) indicates that minority teacher candidates often feel disconnected from teacher education, since "the voices of underrepresented teacher candidates are missing from the curricula, the classroom, and the literature" (p. 32). Overall, students who identified as "other" felt they faced different expectations from those set for White, 


\section{THE NEBRASKA EDUCATOR, VOLUME 6}

women teacher candidates," which "generated feelings of insecurity" (p. 32). Overall, the participants "faced the challenges of isolation; lack of background knowledge; different, often lower, expectations from cooperating teachers" (Bower-Phipps, 2013, p. 38). The prevalence of such experiences can do nothing but further widen the demographic and gender divide among teachers in this country.

The experience of being "othered" is common among Black men in teacher education programs. Warren's (2013) autoethnography describes his experience as a Black man in one such program. In his predominantly White elementary education cohort, he quickly found himself in the position of other. Warren began his program as the single Black man "among what seemed to be a sea of White female preservice teachers" (p. 170). Most of his classmates were from suburban and rural areas, and "most flaunted [their] privileged upbringings" (Warren, 2013, p. 170). He felt the strong presence of intimidation in his peers, many of whom had never interacted with a person of color, "let alone a Black man" (p. 171). He felt alone and misunderstood, and often felt the need to challenge the assertions made by peers he saw as naïve or misguided when it came to understanding people who were different from them. Sadly, Warren's story "is one of many that exist among an isolated cohort of Black males persisting in an increasingly White and female-dominated profession" (2013, p. 169). Jones (2011), however, concludes through his study of three African American men in a graduate teacher education program that the idea that all experiences of African American students in teacher education programs are the same is misguided (p. 115). There were a number of common experiences, however, including the persistence of microaggressions and the ways in which students of color are perceived, manners in which the participants avoided race and racism "as a permeating force" in their graduate teacher education program, and the burden of having to "live up to" the role of racial 


\section{THE NEBRASKA EDUCATOR, VOLUME 6}

"spokesperson" in a predominantly White cohort with predominantly White professors or to "live down to" societal expectations (Jones, 2011, p. 114).

While efforts to recruit and retain more male teachers is extremely valuable, it is crucial that such teachers embody a wide range of gender and cultural identities in order to match the broad spectrum of socio-cultural experiences of the students they will teach. The more we diversify the teaching force and narrow the gap between students' and teachers' lived experience, the more likely we will be to disrupt culturally homogeneous and binarily-gendered notions of what teacher education programs feel like and what good teaching looks like.

\section{The Challenge of Attracting and Retaining a Diverse Teaching Force}

Teacher education programs that often struggle to attract and retain men and students from culturally diverse backgrounds are tasked with addressing both the gender divide and the "demographic imperative" (Villegas, 2009) to better align the multiple identities of teachers with those of their students. This has proven to be a tremendous challenge, however, since as recently as 2017, women earned more than 80 percent of degrees in education (Perry, 2019, online chart), and students of color have far lower college attendance rates, tend to enroll in teacher education programs in relatively small numbers, and score far lower on licensure exams than their White counterparts (Ahmad and Boser, 2014, pp. 11-13). As a result, teacher preparation programs continue to struggle to provide an intersectionally diverse pool of applicants to K-12 schools (Hammerness and Reininger, 2008).

The research makes clear several factors that contribute to the limited enrollment of men and those of diverse cultural backgrounds in teacher education programs, including those grounded in socioeconomic, racial, and cultural biases in education. One factor that seems to cut across the cultural spectrum is the role of hegemonic masculinities (Connell, 2005, p. 77), which 


\section{THE NEBRASKA EDUCATOR, VOLUME 6}

tend to pressure men into the need to avoid "anything feminine in pursuit of achievement of status, independence and self-confidence (p. 4). Such socialization, the preponderance of research shows, has led men away from teaching, which enjoys relatively low professional status (Dolton et al., 2018, p. 18) and is often associated with femininity (Monticenos and Nielsen, 2004). This characterization has faced much criticism, however, for its reductionistic perpetuation of masculinity as a "unitary concept," instead of one that is constantly evolving (Monticenos and Nielsen, 2004, p. 4).

Much of the literature citing obstacles to the attraction and retention of men focuses on elementary education, since the gulf between men and women teachers is less severe in secondary education (64\% to $36 \%$ ) than elementary (89\% to $11 \%$ ) (National Center for Education Statistics, 2021, Figure 1). It must be noted, however, that in secondary education, these percentages are deceiving, since they can be further disaggregated by subject. For example, according to the Brown Center Report on American Education (2018), 54 percent of secondary social studies teachers were male, compared to only 20 percent of English/language arts teachers (Hansen et al., 2018, Figure 1), further indicating the need for more men from diverse backgrounds in arts and humanities classrooms, which continue to be stigmatized as feminine (Martino, 2001; Smith and Wilhelm, 2002; Martino, 2010; Heinrich, 2020).

Shortages of men who teach, particularly in elementary education, can be traced to common stereotypes about teacher education programs. Weaver-Hightower's (2011) work pointed to the perceived ease of teacher education courses. One participant lamented the fact that he couldn't just learn the material and be tested over it, instead having to "“draw little balloons around all my [...] projects" (p. 105). Project-based learning is something commonly associated with femininity, and many students feel such an approach doesn't provide the "rigor" of other 


\section{THE NEBRASKA EDUCATOR, VOLUME 6}

programs (Weaver-Hightower, 2011, p. 105). The implicit message is that smart and talented men can do something more important.

The messages received by the young men in Weaver-Hightower's (2011) study came primarily from male peers and elders. Many of their fathers tried to dissuade them from teaching, instead encouraging them to pursue work with higher pay and higher status. This supports Kimmel's (2008) findings that "guys hear the voices of the men in their lives-fathers, coaches, brothers, grandfathers, uncles, priests - to inform their ideas of masculinity" (p. 55). The message to many young men was that "only the unsuccessful [...] should teach." (WeaverHightower, 2011, p. 107), a message heavily laden with the link between financial and professional success, since "an intelligent, capable male maximizes his earning and status potential" (p. 108). Many of the participants in Monticenos and Nielsen's (2004) study acknowledged the evolution of gender roles, noting that women are "becoming stronger" while "men are being portrayed now as the sensitive man" (p. 6), which allowed them to feel more at home in elementary education than they may have in the past. As encouraging as this shift seems, "adopting this new cultural image of manhood came with warnings and resistance from family members" (Monticenos and Nielsen, 2004, p. 6). While young men's perception may be that the culture is shifting, pressure remains to adhere to traditional and confining roles of masculinity.

Another pervasive fear of men in education is that their actions will be "misperceived as sexual, whether homosexual or pedophilic" (Weaver-Hightower, 2011, pp. 108-109). Men in the classroom often worry that they are assumed to be "sexual initiators, or worse, [even] aggressors" (Weaver-Hightower, 2011, p. 109). In this vein, Everitt (2018) describes the ways such programs reinforce gender conformity by articulating a clear dress code, particularly for 


\section{THE NEBRASKA EDUCATOR, VOLUME 6}

women. Appropriate women's dress relies on the assumption that "boys will be boys" and that if female teachers dress provocatively_-"exposed cleavage, bra straps, thongs, midriff, or legs" (p. 64) — they are inviting inappropriate attention and behavior from (male) students. There is a clear gender distinction that reinforces men as subjects and females as objects - men are inherently predatory, and women are inherently vulnerable — which has implications for men who teach.

While teacher professionalism standards for women relied heavily on dress, professional standards for men had much to do with behavior, particularly toward young women. Just as men in elementary education often fight negative stereotypes and suspicions regarding their sexuality and their motives for working with young children, men in secondary education are stigmatized as sexually targeting female students. Many men feel they are "perpetually under scrutiny—if not suspicion—for pursuing sexual relations with minors" (p. 68). Men often possess a fear "rooted in the knowledge that people assume men to be initiators of amorous relationships with women based on rationalized meanings of masculinity" (Kimmel, 1998, p. 69). The result is that men preparing for careers in teaching come to learn that they must subdue such behaviors, but "even abstaining from [them] is often not enough to avoid this kind of scrutiny" so that, "men who work as teachers face constant suspicion" (Kimmel, 1998, p. 69). Thus, both men and women face ambivalence about their gender conformity in the classroom. "While women must $[\ldots]$ cope with the possibility of being sexually objectified [...] men must cope with the possibility of being viewed as sexual predators despite their best efforts to avoid it" (Kimmel, 1998, p. 69). Of course, gender embodiment inherently includes "sexualized meanings," and the construction of a teacher identity assumes the removal of such meanings; "teacher candidates face complex contradictions" (Kimmel, 1998, p. 69) when envisioning who they are and how they behave in the classroom. 


\section{THE NEBRASKA EDUCATOR, VOLUME 6}

The men in Jones' (2008) study were very aware of this culture of suspicion, in which male elementary teachers are viewed as potential pedophiles or sexual predators (p. 127). Johnson, Porter, and Nelson (2008) note that "men experience undue pressure to avoid physical contact $[\ldots]$ for fear of perceived impropriety" (p. 5). The literature suggests that this at least perceived scrutiny causes stress for men who enjoy working with children (p. 5). Montecinos and Nielsen's (2004) work demonstrates that men tend to be leery of the ways in which their actions around young children could be interpreted. Many men noted that "districts' policies and guidelines regarding physical contact between children and adults were enforced differently for men than women" (Montecinos and Nielsen, 2004, p. 6), which led male preservice teachers to be aware that they would have to exercise greater restraint in their emotional expression and demonstration of affection than other educators. This is consistent with the findings of WeaverHightower (2011), who notes that teachers often modify their behavior, becoming less warm or affectionate, to decrease the likelihood of being perceived as sexually deviant (2011, p. 109). Haase (2008) suggests that such modification of behavior "serve[s] to propagate widespread perceptions of male teacher role models as non-nurturing, or less nurturing than female colleagues, and thus less equipped to work with children" (p. 128). This leads to a "heterosexist and rigidly gendered educational system that helps keep [women] in majority status" (Haase, 2008, p. 128) and supports Johnson, Porter, and Nelson's (2008) assertion that “male teachers reinforce rather than challenge the same restrictive gender roles that turn men away from teaching in the first place" (p. 3), since to do otherwise could give rise to suspicion. Interestingly, these constraints tended not to trouble the participants in Montecinos and Nielson's study, however, with many citing "their own proclivities for traditional male 'distance"” (2004, p. 6) a nod, no doubt, to Haase's (2008) and Kimmel's (1998; 2008) notions of gendered socialization. 


\section{THE NEBRASKA EDUCATOR, VOLUME 6}

Sandles (2020) points out that the dearth of Black men who teach contributes to a broader cultural message that African Americans are not as well-suited for positions of authority as Whites. Thus, "it is crucial for all students to observe and interact with capable, qualified Black male teachers in order to deconstruct deficit-oriented paradigms regarding Black men" (p. 71). Among the primary contributors to the shortage is "the centrality of race and racism in society" (Sandles, 2020, p. 71), the product of which continues to be racial segregation and decreased access to quality education and economic opportunities. This leads to fewer men of color with interest in becoming or the skills to become teachers and the tendency for men of color who do teach, "voluntarily or involuntarily [...] to work in environments with concentrations of [B]lack students," which often land them in the most difficult schools (Sandles, 2020, p. 72). Black men who teach in predominantly White schools often become marginalized within largely White communities of educators, particularly if they deviate from conventional forms of instruction that perpetuate the racial status quo (Sandles, 2020, p. 73). Institutional forms of racism such as color-blindness and meritocracy serve to assuage the guilt of Whites while perpetuating racist practices, and thus the quantity of Black men in the classroom (pp. $73-74)$.

Based on their institutions' difficulties attracting and retaining students of color, Miller and Hidehiro (2005) set out to learn about the experiences of education students of color to better understand why they hoped to become teachers. Their work found that the primary factors leading students of color to teaching were having educators in the family, having parental support for teaching as a career, having previous teachers as significant role models, and close bonds with influential teachers (Miller \& Hidehiro, 2005, pp. 6-7). While many of these bonds were with White teachers, participants noted that they need teachers with whom they can “identify culturally, racially, ethnically, and perhaps linguistically" (p. 7). Any number of factors 
THE NEBRASKA EDUCATOR, VOLUME 6

may lead men and traditionally marginalized students to teacher education, but it is clear that increasing teacher diversity will add important role models to students' lives, perhaps leading to a proportionate increase of their representation in the classroom.

As teacher education considers its path forward, it is important to take a critical approach to issues of intersectional diversity, following Creswell and Poth's (2018) assertion that critical theory is grounded in "empowering human beings to transcend the constraints placed on them by race, class, and gender" (p. 29). There is tremendous value for adolescents in escaping typically well-policed behavioral expectations in order to inhabit more liberating social contexts. Teachers have the unusual opportunity to support such empowerment, but just as much ability to stifle it. Teacher education programs must work, not only to attract and retain future educators from a variety of backgrounds, but to instill in them an understanding of the impact a teacher's identity has on their students.

\section{Interventions in Teacher Education Programs}

Beyond working to attract and retain a more diverse preservice force, it is crucial that the process of teacher education be framed by an understanding of gender theory and their implications for social justice. This may be the best way to combat the default to what Mills calls "common sense" approaches to gender (2004, p. 34). Such approaches "are often shaped by conservative reading of contemporary politics and do little to change equity within education" (Mills, 2004, p. 34). Instead of bringing more diverse voices into education, the introduction of more men without the interrogation of gendered behavior and consequences can further entrench misogynistic and homophobic views. Ultimately, "exploring the ways in which homophobia and misogyny construct gendered relations within schools $[\ldots]$ affects all teachers and students" 


\section{THE NEBRASKA EDUCATOR, VOLUME 6}

(Mills, 2004, p. 35) and schools of education should make gender and other forms of social justice core components of their programs.

While Sanders' (2002) article and the statistics she cites are nearly twenty years old, her argument for the examination of both teacher education programs and the construction of new teaching identities seems to be increasing in urgency, since anecdotal observation and a baseline review of the literature indicate that little has changed in teacher education's examination of the impact of gender on the social construct of learning. Sanders' (2002) work comes on the heels of Sommers' The War Against Boys and at roughly the same time as Newkirk's Misreading Masculinities: Boys, Literacy, and Popular Culture (2002) and Smith and Wilhelm's Reading Don't Fix No Chevys (2004), which examine the differences between the ways in which boys interact and perform in the classroom. Sanders cites several studies in the 1990s showing that "gender equity [was] in its infancy in teacher education" (Sanders, 2002, p. 242) and that any focus on gender was sporadic and often tied to "a few committed faculty members" (p. 243). Sanders (2002) argues that attention to gender equity must be systemic, not approached like so many multicultural education courses — a "balkanized [...] sidebar to the 'real' work of education" (2002, p. 243). Despite many attempts at progress, the tokenistic or altogether absent examination of issues related to gender in programs of teacher education continues.

Johnson and Weber (2011) focus on the typical omission of the study of gender, and masculinities in particular. For preservice teachers, they found, complex discussion of nuanced masculinity and gender are often scarce. To Johnson and Weber (2011), "gender, along with other intersectional identities, should always be considered as one of the central lenses through which education research and practice are viewed" (pp. 141-142). Minus the opportunity to 


\section{THE NEBRASKA EDUCATOR, VOLUME 6}

reflect on our own gender construction and its impact on our practice, most preservice and inservice teachers will likely do little to understand or question the implications of the status quo.

Engebretson (2016) sought to better understand how preservice teachers conceptualize gender and gender discourses by following 25 students for a year through their secondary social studies teacher education program. Her findings indicate that it is "imperative that our teachers analyze and deconstruct their complex, personal, and often unshared ideas around gender," (p. 51). Preservice teachers' ability "to make connections between their lives, the lives of their students, and the larger gendered discourses" could open spaces in their current and future classrooms to better understand the larger gendered institutions in which we all participate (2016, p. 52). Weaver-Hightower (2011) points out places where intervention may disrupt both stereotypes about and biases against teachers; among them, the metacognitive awareness of "gendered stylizations" that may provide opportunities for preservice teachers to more deeply consider alternatives to the "explicit performance" of gender in front of the class (pp. 112-113). Helping students in teacher education programs to recognize their own biases is imperative for developing a teaching force equipped to continue this work with their students" (Engebretson, 2016, p. 52).

Problems of the masculine/feminine subject-object socialization that steer men away and lead those who teach to feel increased suspicion (outlined above in Everitt, 2018) may need to be addressed by larger cultural forces. Cushman's (2012) study is grounded in the movement to attract and retain more male teachers in elementary schools in Sweden, the U.K., and New Zealand. It explores the extent to which men in these countries "considered their teacher education had enhanced their understanding of gender and prepared them to teach in ways that counteracted traditional gender patterns" (p. 776). Similar to the U.S., because of the disparity 


\section{THE NEBRASKA EDUCATOR, VOLUME 6}

between men and women in teacher education programs in the U.K. and New Zealand, "the journey through teacher education can be a lonely and challenging experience" for men (Cushman, 2012, p. 787). In Sweden, however, the experience was very different. Cushman argues that this is a product of cultural distinctions resulting from more than 50 years of political emphasis on gender equality where challenging gender stereotypes has become pervasive. Teacher education courses there tend to complement this agenda, and their immersion in a culture prioritizing gender equality means, perhaps, that less emphasis is necessary (Cushman, 2012, p. 787). Cushman's findings indicate that, minus such a nationwide phenomenon, increasing the emphasis on gender equality in teacher education programs may not be enough without a broader cultural push (Cushman, 2012, p. 788).

Vavrus (2008) argues for "queering" the teacher education curriculum, deconstructing and interrogating "normative dichotomous sexualities" (p. 384) as a way for prospective teachers to examine the formative experiences that give voice to their own gender and sexual identities. Such queering helps education students, the vast majority of whom are cisgender and heterosexual, "to examine how their own sense of sexuality and gender identification is imbued with various degrees of compulsory heterosexuality and the resulting problematic effects this can have for all young people at various stages of identity development” (Vavrus, 2008, p. 384). Vavrus (2008) argues for the use of critical texts with an emphasis on student autoethnographic writing to emphasize reflection on issues related to sex, sexuality, and gender "intended to propel the teacher education student into critical insights as to how their own subjective meanings connect to wider social phenomena and how emancipatory action is possible" (p. 386).

Like Vavrus (2008), Warren (2013), emphasizes reflection in his recommendations for questioning cultural and institutional assumptions. Writing of his experience as a man of color in 


\section{THE NEBRASKA EDUCATOR, VOLUME 6}

a teacher education program, he discusses the misalignment of many programs with the realities of dealing with the intersectional marginalization faced in poor classrooms. Teaching demands awareness and innate in that is reflection, an understanding of "how to critique his or her own practice in such a way that children stay central to the work" (Warren, 2013, p. 173), even as the administrative culture of school reform tries to put instruction at the center. "Technical skills such as how to write a lesson plan mean very little to a child labeled by the institution as 'at-risk' and uneducable. My training didn't account for the uniqueness of Black, poor, or urban youth” (Warren, 2013, p. 173). Preservice teachers must have the awareness and the tools to educate, a process that extends far beyond methods and instructional strategies.

Additionally, consistent multicultural and multilayered coursework must be woven into the discussion of gender norms in teaching programs. Jones' (2011) study found that both overt and institutional racism "wreak havoc on the success of the preservice African American male social studies teacher" (p. 116). He recommended implementing a number of steps to mitigate this oppression, including requiring all faculty in teacher education programs "to be well-versed in and teach from culturally relevant pedagogies and practices that best support students of color" to be sure that all teacher education students, regardless of race, but particularly students of color, "feel empowered to respond to racist presentations without fear of repercussions" (p. 117). To claim this agency, this "voice," as Jones calls it, could help the African American preservice teacher "fight racism whenever and wherever it happens" (p. 117), and to be able to take that attitude into a classroom of their own.

Powers and Duffy (2016) built on the premise that "teacher education requires that preservice teachers do more than just read about anti-oppressive education, [they must] engage in ways that situate them within the shifting dynamic of teaching and learning." (p. 63) In this case, 


\section{THE NEBRASKA EDUCATOR, VOLUME 6}

the physical interaction of theatre became a vehicle for pursuing empathy. Powers and Duffy's (2016) study examines whether Augusto Boal's theatre of the oppressed could create openings for preservice teachers "to... recognize subordinated positionalities in themselves and 'the other'... to interrupt the cycle of socialization" (p. 63). Participants (pre-service teachers) walked away with a sometimes profound and deepened sense of the complex web of possible identities and how various intersectional factors contribute to inequalities. While there were limits to the extent to which this sample of largely White, middle-class women could internalize an understanding of intersectional contributions to oppression through a few performance activities, the data indicate that in subsequent classroom interactions there was better empathetic connection to lived experience.

Beyond activities, classes, or general recommendations, there have been systematic changes made to address these issues. Kearns, Mitten-Kukner, and Tompkins (2017) explain the “Positive Space Program” at Queen's University in Canada providing LGBTQ+ education for preservice teachers. The results of their study show the promise of the program for helping to develop educators "who can interrupt the gender binary [and] allow spaces for diversity of genders to be seen" (2017, p. 22). Developing such awareness in teachers and the willingness to act on that awareness, according to Kearns, Mitten-Kukner, and Tompkins (2017) can help to foster "the highly nuanced and complicated school, gender, and social justice advocacy discussions that embody social change" (p. 22). Rosiek, Schmitke, and Herffernan (2017) have worked to implement such change at the University of Oregon. They spent years shifting the focus of teacher education programs to emphasize issues of LGBTQ+ and gender justice, despite the silence that so often permeates such programs driven by "patriarchal and heteronormative ideologies [that] operate to minimize recognition of the seriousness of these issues" (p. 14). As 
THE NEBRASKA EDUCATOR, VOLUME 6

faculty members, they reinvented their teacher education program to deeply and consistently examine issues of gender justice, illustrating "the vital importance of breaking such silences in professional and educational settings" (2017, p. 14). Rosiek, Schmitke, and Herffernan's (2017) description of the process that led to that change offers much to faculty and administrators who are working to reimagine their own programs.

Consistent among these arguments for change is ongoing engagement with notions of "difference" in order to shift a largely White, female, cisgender paradigm to one that includes regular inclusion of multiple students' and teachers' voices. Such programs clearly have advantages for disrupting gender binaries and broadening the cultural and institutional understanding of what it looks like to teach, but while curriculum and reflection are essential elements for teacher preparation, they are just one step toward cultivating a vibrant and diverse cohort of students and faculty.

\section{Summary and Conclusions}

Despite years of steps taken to address the gender and cultural divides between students and their teachers, the gulf remains glaring and the consequences severe. The result has been the continued perpetuation of gender, class, and racial stereotypes in classrooms, which only further marginalizes those who have traditionally felt unwelcome or uncomfortable. When students spend their educational lifetimes being instructed by teachers who don't look like them, think like them, or interact like they do, the implicit message is that only others are supposed to thrive in the classroom, and only others are destined to teach. Creating a more welcoming environment for traditionally marginalized students by increasing the diversity of embodiment and lived experience among teachers with whom they interact every day would play a crucial role in addressing long-standing structural inequalities that continue to threaten our society. 


\section{THE NEBRASKA EDUCATOR, VOLUME 6}

While much work has been done to investigate gender and race in K-12 schools and teacher education programs in hopes of addressing these divides, there is room for deeper, more sustained looks at intersectional groups of preservice teachers. As Weaver-Hightower (2011) wrote, "if teacher educators and policymakers are truly interested in an increased — and hopefully increasing racially, socioeconomically, and sexually diverse-pool of male teachers, the voices of those training to be teachers must be considered" (pp. 98-99). In the spirit of narrative work done by Jones (2011), Miller and Hidehiro (2005), Sharp-Hoskins and Robillard (2012), Heinrich (2012), and Bortolome (2016), a more sustained longitudinal look at men from a variety of backgrounds in a teacher education program could capture, in Frie, Berweger, and Buschor's (2017) words, a "better understand[ing] of the process leading to the decision for or against teaching” (p. 546). Longitudinal narrative work would provide a more intimate and sustained understanding of the social and cultural positioning that leads young men to the decision to teach and their experiences in a teacher education program. Observing and interacting in depth with these men for a period of several semesters could yield important insights into intersectionality in schools and teacher education that could help open the doors for more students to follow. The more teacher preparation programs understand about the experiences of those who come from communities that typically do not produce teachers, the better positioned they will be to invite students from diverse backgrounds into their programs and effectively prepare them to be conscientious teachers once they get there.

An increase in the number and variety of men who teach, particularly in the humanities, could help to establish new norms for appropriately masculine behavior. Kimmel's (2008) findings that "guys hear the voices of the men in their lives - fathers, coaches, brothers, grandfathers, uncles, priests - to inform their ideas of masculinity" (p. 55) could in fact become 


\section{THE NEBRASKA EDUCATOR, VOLUME 6}

the conduit that leads young men from diverse backgrounds into classrooms of their own. Teachers have the rare opportunity to support the empowerment of all of their students, but even by inadvertently perpetuating cultural prejudices, they have just as much power to stifle it. All teacher education programs must strive, not only to attract and retain future educators from a variety of backgrounds, but to better understand them when they get there and make sure they understand how powerful their presence can be for shaping the lives of their students. 
THE NEBRASKA EDUCATOR, VOLUME 6

\section{References}

Abelson, M. (2019). Men in Place: Trans Masculiniy, Race, and Sexuality in America. Minneapolis, Mn.: University of Minnesota Press.

Ahmad, F.Z., and Boser, U. (2014). “America’s Leaky Pipeline for Teachers of Color: Getting More Teachers of Color into the Classroom." Center for American Progress. Retrieved at Americanprogress.org

American Psychological Association (2015). "Measuring Socioeconomic Status and Subjective Social Status.” Retrieved from https://www.apa.org/pi/ses/resources/class/measuringstatus.

Bartolome, S. J. (2016). “Melanie's Story: A Narrative Account of a Transgender Music Educator's Journey.” Bulletin of the Council for Research in Music Education. No. 207207 (Winter/Spring 2016), p. 25-47.

Benton, T. (2007). “A Class Traitor in Academe." Chronicle of Higher Education. 54(11), p 7071.

Bower-Phipps, L., Homa, T.D., Albaladejo, C., Mello Johnson, A., Cruz, M.C. (2013).

“Connecting with the 'Other' Side of Us: A Cooperative Inquiry by Self-Identified Minorities in a Teacher Preparation Program. Teacher Education Quarterly (Spring 2013), p. 29-51

Connell, R.W. (2005). Masculinities. (2 ${ }^{\text {nd }}$ Edition). Berkeley, CA: University of California Press.

Crenshaw, K. (1991). "Mapping the Margins: Intersectionality, Identity Politics, and Violence against Women of Color.” The Stanford Law Review. 43(6), p. 1241-1299.

Davison, K.G. and Nelson, B.G. (2011) "Men and Teaching: Good Intentions and Productive Tensions." The Journal of Men's Studies. 19(2), 91-96. 
THE NEBRASKA EDUCATOR, VOLUME 6

Dee, T. (2005). “A Teacher Like Me: Does Race, Ethnicity, or Gender Matter?” American Economic Review. 95(2), p. 158-165.

Dee, T. (2007). "Teachers and the Gender Gaps in Student Achievement." The Journal of Human Resources. 42(3), p. 528-554.

Dowd, N. (2010) The Man Question: Male Subordination and Privilege. New York: NYU Press.

Dolton, P., Marcenaro, O., De Vries, R., \& She, P.W. (2018) “Global Teacher Status Index 2018." Varkey Foundation. Retrieved at https://www.varkeyfoundation.org/media/4867/gts-index-13-11-2018.pdf

Dykins Callahan, S. (2008). “Academic Outings.” Symbolic Interaction. 31(4), p. 351-375.

Ferrell, W. and Gray, J. (2018). The Boy Crisis: Why Our Boys are Struggling and What We Can Do About It. Dallas, TX: Benbella Books.

Fischman, G. (2000). Imagining Teachers: Rethinking Gender Dynamics in Teacher Education. New York: Rowman and Littlefield Publishers.

Francis, B. (2008). “Teaching Manfully? Exploring Gendered Subjectivities and Power Via Analysis of Men Teachers' Gender Performance." Gender and Education. 20(2), p. 109122.

Frie, A.K., Berweger, S., and Buschor, C.B. (2017). "Men Considering (and choosing) teaching as a career: what accounts for their decision to become a teacher?" European Journal of Teacher Education. Vol 40, No. 4, p. 535-549

Gosse, D. (2011). "Race, Sexual Orientation, Culture, and Male Teachers as Role Models: 'Will Any Teacher Do as Long as They Are Good?"” The Journal of Men's Studies. 19(2), p. 116-137. 
THE NEBRASKA EDUCATOR, VOLUME 6

Haase, M. (2008). "'I don't do the mothering role that lots of female teachers do:' male teachers, gender, power, and social organization.” In Coffee, A. and James, D. (Eds) (2014) Masculinity and Education. London: Routledge.

Hammerness, K., \& Reininger, M. (2008). Who goes into early-entry programs? In P. Grossman \& S. Loeb (Eds.), Alternative Routes to Teaching: Mapping the New Landscape of teacher education (pp. 31-64). Cambridge, MA: Harvard Education Press.

Hansen, M., Lovesque, E.M.,Valant, J. \& Quintero, D. (2018). The 2018 Brown Center Report on American Education. "Understanding the Social Studies Teacher Workforce." Retrieved October $12^{\text {th }}, 2020$. https://www.brookings.edu/research/2018-brown-centerreport-on-american-education-understanding-the-social-studies-teacher-workforce/

Heinrich, J. (2012). "The Making of Masculinities: Fighting the Forces of Hierarchy and Hegemony in the High School Setting.” The High School Journal. 96(2) p. 101-115.

Ingersoll, R.M., Merrill, E., Stuckey, D., \& Collins, G. (2018). “Seven Trends: The Transformation of the Teaching Force - October 2018." CPRE Research Reports. Retrieved from https://repository.upenn.edu/cpre_researchreports/108

Johnson, S. P., Porter, G., \& Nelson, B. G. (2008, Winter). The status of male teachers in public education today (Education Policy Brief Vol. 6, No. 4, pp. 1-12). Bloomington: Center for Evaluation \& Education Policy, Indiana University.

Jones, S. (2011). “A Long Road to Travel: Narratives of African American Male Preservice Educators' Journeys Through a Graduate Teacher Education Program.” (Unpublished doctoral dissertation). Georgia State University, Atlanta, Ga. 
THE NEBRASKA EDUCATOR, VOLUME 6

Kahn, Jack S., Brett, Benjamin, L., and Holmes, Jessica R. “Concerns with Academic Motivation in Men's Higher Education: An Exploratory Investigation of the Role of Masculinity. The Journal of Men's Studies. Vol. 19. No. 1, Winter 2011, p 65 - 82.

Kearns, L., Mitton-Kukner, J., and Tompkins, J. (2017). “Transphbia and Cisgender Privilege: Pre-Service Teachers Recognizing and Challenging Gender Rigidity in Schools.” Canadian Journal of Education. 40(1), p. 1-27

Kimmel, M. (1998, 2018). Manhood in America: A Cultural History. New York, NY.: Oxford University Press.

Kimmel, M. (2008, 2018). Guyland: The Perilous World Where Boys Become Men. Understanding the Perilous Years Between 16 and 26. New York, NY.: Harper Collins. Kivel, P. (2009) “The Act-Like-A-Man Box.” Kimmel, M. S. and Messner, M. A. (Ed). Men's Lives (10 ${ }^{\text {th }}$ Edition). (2019). New York, NY: Oxford University Press

Lareau, A. (2011). Unequal Childhoods: Class, Race, and Family Life. Berkeley, Ca: University of California Press.

Lewis, C.W. (2009). "Black Male Teachers' Path to U.S. K-12 Classrooms: Framing the National Discussion." Diversity and Education: Teachers, Teaching, and Teacher Education. (Richard H. Milner, Ed). Springfield, Il: Charles C. Thomas.

Lowenstein, K.L. (2009). “The Work of Multicultural Teacher Education: Reconceptualizing White Teacher Candidates as Learners." Review of Educational Research. 79(1) p. 163196.

Martino, W. (2001). "Dickheads, Wuses, and Faggots: Addressing issues of masculinity and homophobia in the critical literacy classroom.” In B. Comber \& A. Simpson (Eds.), 
THE NEBRASKA EDUCATOR, VOLUME 6

Negotiating critical literacies in classrooms (pp. 191-210). Mahwah, NJ: Lawrence Ehrlbaum Associates.

Martino, W. and Rezai-Rashti, G.M. (2010). “Male Teacher Shortage: Black Teachers’ Perspectives." Gender and Education. 22(3), p 247-262.

Miller, R. (2005). Teaching at the End of the World. Pittsburgh, Pa: University of Pittsburgh Press.

Miller, P. C. and Hidehiro, E. (2005). "Journey to Becoming a Teacher: The Experience of Students of Color.” Multicultural Education. 3(1) Oct - Dec 2005, p. 2 - 9.

Mills, M. (2004). “Male Teachers, Homophobia, Misogyny and Teacher Education.” Teaching Education. 15(1), 27-39.

Mintz, S. (2019). “The Other Gender Gap.” Inside Higher Ed. Blog: Higher Ed Gamma, August $4^{\text {th }}, 2019$. Accessed August 31, 2020. https://www.insidehighered.com/blogs/higher-edgamma/other-gender-gap.

Pascoe, C. J. (2011). “Guys Are Just Homophobic: Rethinking Adolescent Homophobia and Heterosexuality.” Kimmel, M. S. and Messner, M. A. (Eds). Men's Lives (10 ${ }^{\text {th }}$ Edition). (2019). New York, NY: Oxford University Press.

Pascoe, C.J. (2007). Dude, You're A Fag: Masculinities and Sexuality in High School. Berkeley, CA: University of California Press.

Perry, Mark J. (2019). “Chart of the Day: Female Shares of BA Degrees by Major, 1971 2017." American Enterprise Institute. Accessed July 27 $7^{\text {th }}, 2021$. https://www.aei.org/carpe-diem/chart-of-the-day-female-shares-of-ba-degrees-by-major1971-to-2017/ 
THE NEBRASKA EDUCATOR, VOLUME 6

Powers, B. and Duffy, P.B. (2016). “Making Invisible Intersectionality Visible through Theatre of the Oppressed in Education." The Journal of Teacher Education. 67(1), p. 61-73.

Sanders, J. (2002). "Something is Missing from Teacher Education: Attention to Two Genders." Phi Delta Kappan, 84(3), p 241-244.

Sandles, D. (2020). "Using Critical Race Theory to Explore the Black Men Teacher Shortage." The Journey of Negro Education. 89(1), p. 67-81.

Sexton, P.C. (1969). The Feminzed Male: Classrooms, White Collars and the Decline of Manliness. New York, NY: Vintage Books.

Sharp-Hoskins, K. and Robillard, A. (2012). "Narrating the 'Good Teacher' in Rhetoric and Composition: Ideology, Affect, Complicity.” JAC. 32(1/2), pp. 305-336.

Skelton, C. (2007). “Gender, Policy, and Initial Education.” Gender in Education. 19(6), p. 677690.

Snyder, T.D. (Ed). (1993). 120 Years of American Education: A Statistical Portrait. Published by the Center for Educational Statistics. Accessed at https://nces.ed.gov/pubs93/93442.pdf

Stillman, J., Struthers Ahmed, K., Luciano Beltramo, J., Catañeda-Flores, E., Garza, V.G., \& Pyo, M. (2019) "From the ground up: cultivating teacher educator knowledge from the situated knowledges of emerging, asset-oriented teacher educators." Asia-Pacific Journal of Teacher Education. 47(3), 265-285.

Tucker, Stephen. (2015). “Three Men and a Maybe: Identity and Privilege in Preservice Elementary School Teachers.” Journal of Men's Studies. 23(1), p. 3-20.

U.S. Department of Education (2021). Report on the Condition of Education 2021. Accessed at https://nces.ed.gov/pubs2021/2021144.pdf 
THE NEBRASKA EDUCATOR, VOLUME 6

Villegas, A.M. (2008). “Diversity and Teacher Education.” M. Cochran-Smith, S. Freiman Nemser, \& D.J. McIntyre (eds.). Handbook on Research in Teacher Eduduation: Enduring Questions in Changing Contexts ( $3^{\text {rd }}$ Edition). Philadelphia, PA: Routledge.

Villegas, A.M., \& Irvine, J.J. (2010). "Diversifying the Teaching Force: An Examination of Major Arguments." The Urban Review. 42, 175-192

Waite, S. (2017). Teaching Queer: radical possibilities for writing and knowing. Pittsburg, Pa: University of Pittsburg Press.

Warren, C. A. (2013). Being black, being male, and choosing to teach in the 21 st century: Understanding my role, embracing my call. In C. W. Lewis \& I. A. Toldson (Eds.), Black male teachers: Diversifying the United States' teacher workforce (pp. 167-182). Bingley: Emerald Group Publishing Limited.

Weaver-Hightower, M. (2011). "Male Preservice Teachers and Discouragement from Teaching." The Journal of Men's Studies. 19(2) pp. 97-115.

Young, V. A., (2007). Just Your Average Nigga Performing Race and Masculinity. Detroit, Mi: Wayne State University Press.

Zeichner, K. (2020). "Preparing Teachers as Democratic Professionals.” Action in Teacher Education. 42(1). 38-48. DOI: 10.1080/01626620.2019.1700847 